\title{
Concentrations and Reactions of Iron in Crystalline Silicon after Aluminum Gettering
}

\author{
Dissertation \\ zur Erlangung des Mathematisch-Naturwissenschaftlichen Doktorgrades \\ „Doctor rerum naturalium“ \\ der Georg-August-Universität Göttingen
}

vorgelegt von

Doaa Mohamed Othman Abdel Barey

aus

Menufia/ Ägypten

Göttingen 2011 
D 7

Referent: Herr Prof. Dr. M. Seibt

Korreferent: Herr Prof. Dr. H. Hofsäß

Tag der mündlichen Prüfung: 29.11.2011 


\section{Contents}

Chapter 1: Introduction......................................................................

Chapter 2: Literature review ..................................................................

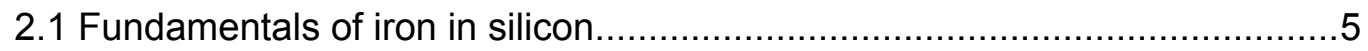

2.1.1 Solubility and diffusivity of iron in silicon ...................................... 5

2.2 Point defect reactions of iron in silicon ..................................................

2.2.1 Interaction of iron with shallow acceptors ................................... 8

2.2.2 Interaction of iron with hydrogen ...............................................

2.2.3 Interaction of iron with intrinsic point defects ................................ 10

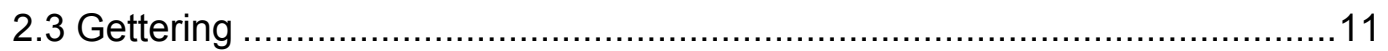

2.3.1 Concept of impurity gettering process.......................................... 11

2.3.2 Aluminum alloying-induced impurity gettering.................................13

2.3.3 Impact of aluminum gettering on solar cell performance..................... 14

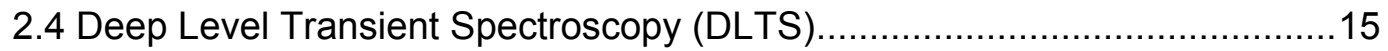

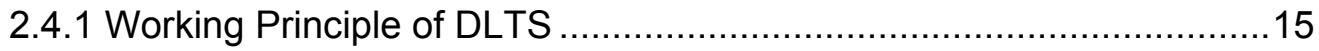

2.4.2 Analysis of DLTS parameters ................................................. 16

Chapter 3: Experimental Procedures ..................................................21

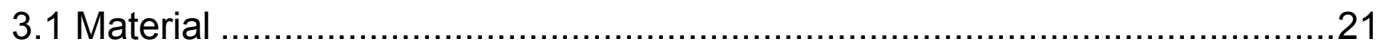

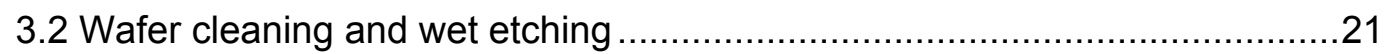

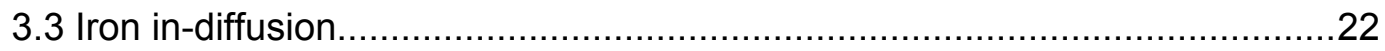

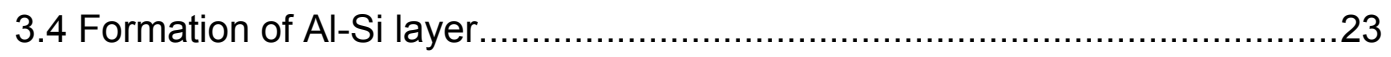

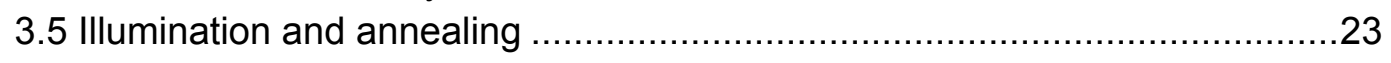

3.6 Au and Pt diffusion used to monitor the vacancy concentration ...................24

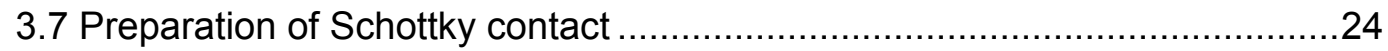

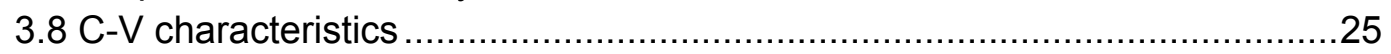

3.9 Deep Level Transient Spectroscopy measurements .................................26

Chapter 4: Results and Discussion ........................................................29

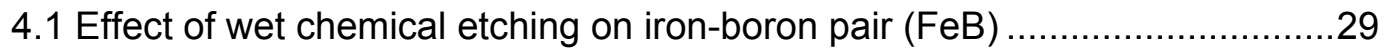

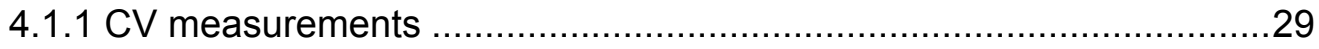

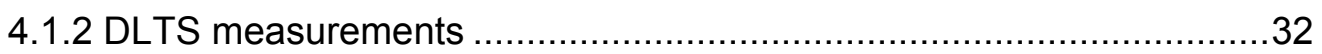

4.2 Aluminum gettering of iron in p-type silicon ..........................................39

4.3 Aluminum gettering injects vacancies ................................................49

4.3.1 Platinum diffusion to monitor vacancy .........................................50

4.3.2 Gold diffusion to monitor vacancy ..............................................5

4.4 Light-induced formation of metastable defect after AIG ...........................63

4.4.1 Light-induced transformation of FeB into new trap...........................65

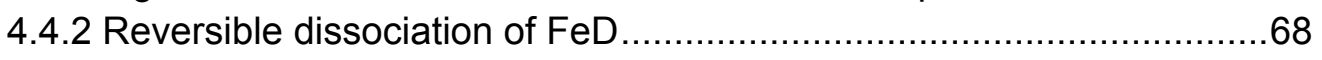

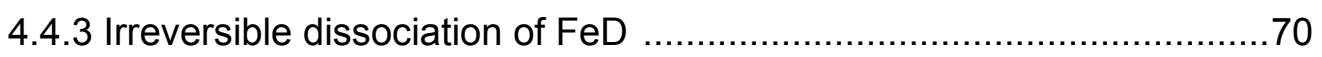

4.4.4 Characteristics of FeD ............................................................ 71

4.4.5 Possible candidates of FeD …....................................................... 71 


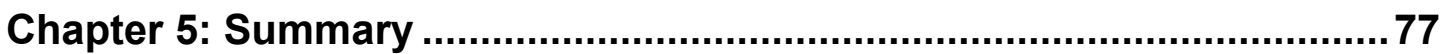

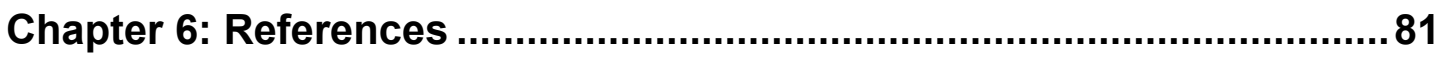

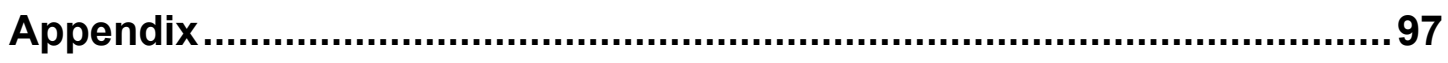

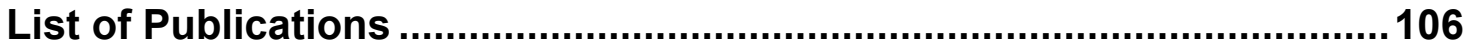

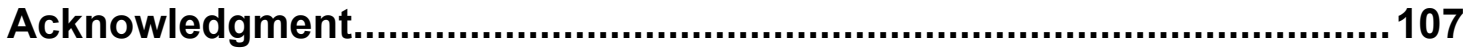




\section{Introduction}

The demand for energy is growing rapidly due to the explosion of the world population and the higher quality of living. The majority of the energy demand has been supplied by natural fuels that are depleted through heavily use. At present, renewable energy sources are becoming very essential. Thus solar cell production, as a source for solar energy, is increasing worldwide and subsequently photovoltaic (PV) materials such as pure silicon are getting to be expensive.

Industrially, high quality wafers, the material used to produce solar cell with higher efficiencies are highly expensive due to less abundant low cost silicon feedstock as well as dramatic increases in the solar cell production (Dubois et al., 2007). Silicon as a raw material in the wafers manufacturing process represents more than $80 \%$ of the PV production line, therefore has a big influence on the final cost (Kazmerski, 2006; Sopori, 2002). The increased demand and the availability of silicon can partially deplete the raw material for solar cell. To maintain cost effectiveness, use of reusable feedstock or dirty silicon containing higher concentrations of metal impurities has been proposed because silicon accounts for more than $50 \%$ of the cost of processed solar cell (Istratov et al., 2006). In addition to optimizing the solar cell production processes, work is also being done to increase the level of efficiency by controlling metal contamination. In particular, as typically being one of the processing steps during solar cell manufacturing, gettering becomes the beneficial part of this control. This leads to a calculated (28\%) and measured (25\%) maximum level of efficiency for crystal silicon (Swanson, 2004; Green et al., 2011). Thus, several studies have been proposed various kinds of gettering methods to obtain better performance for semiconductor devices (Myers et al., 2000). For example, phosphorus diffusion and aluminum alloying already play an important role in silicon solar cell processing through the formation of the P-doped $\mathrm{n}^{+}$emitter and Al-doped back surface field.

Iron is the most common transition metal impurities in semiconductor industry and PV silicon. Thus, it seems unlikely to avoid contamination with iron that has been considered to have the highest concentration in silicon wafers (Jastrzebski, et al., 1995). Unfortunately, less than $1 \mathrm{ppb}$ of iron was found to degrade the performance of p-type silicon device through the massive reduction of the minority carrier diffusion length (Buonassisi et al., 
2005). Better understanding of characteristics of iron related defects and their reactions, formation as well as transformation can help in improving device fabrication and effecicency. Consequently, in this study we have contaminated silicon samples with defined iron concentration in a clean environment to minimize the other impurities and to prevent complicating defect reactions especially by using float zone silicon.

As devices become smaller, they become more sensitive to the trace concentrations of transition metals like Fe that can operate as lifetime killers. Accordingly, one should use the better understanding of iron defect reactions in solar silicon as well as its effect on electrical material properties to improve the efficiency of solar cell. One of the most important techniques used to determine the electrical properties of a defect is known as Deep Level Transient Spectroscopy (DLTS). DLTS is therefore extensively used to study the electrical properties, depth profiles, metastability and annealing of ironrelated defects and mechanisms for their formation in this study.

One of the most efficient processes to reduce the concentrations of the impurities is aluminum gettering (AIG). From a survey of the available data, it emerges that investigation of the aluminum gettering of iron and its related vacancy complexes are either scarce or lacking in the literature. Therefore, the present study was undertaken to throw light on the optimal conditions for aluminum gettering of iron in float zone p-type silicon as well as measuring its segregation coefficient. During this work, the effects of wet chemical etching on concentration of Iron boron pair and its boron passivation in iron contaminated p-type silicon have been studied. Vacancy injections monitored by platinum and gold diffusion before and after aluminum gettering have formed another focus of our study. In addition to the ability of aluminum gettering to induce vacancies, new iron-related deep level has also been shown by our study. The new level (FeD), in addition to the well known ironrelated donor level has been found during the investigations on iron-doped $p$ type silicon after aluminum gettering. Cold light illumination, before and after aluminum gettering provides interesting insights on interactions between iron and AIG-induced vacancies, and on the nature of the FeD defect.

This thesis consists of five chapters including this introduction. A detailed review of the available information on iron in silicon, gettering of iron and iron related defects is presented in chapter 2. In addition, the general theory of defects and deep-level transient spectroscopy is discussed. In Chapter 3, general sample preparations, experimental procedures and techniques used for investigation of defects in p-type silicon are presented. The detection and characterization of the defects by DLTS system is also 


\section{Chapter 1. Introduction}

described. Results and discussion are included in chapter 4. This chapter is divided into four parts; the influence of wet chemical etching on the iron concentration in silicon as well as the correspondence between time of etching, different etchants and boron passivation profile are studied in the first part. The second part deals with the aluminum gettering of iron in silicon and the physical mechanisms relevant for such temperature-dependent segregation coefficient in order to increase the understanding of the abilities and limitations of aluminum gettering in silicon solar cell processing, while the third part treats various aspects of aluminum gettering induced vacancies and using several ways to monitor vacancy concentration such as platinum and gold diffusion. Based on these finding, the last part in this thesis investigates the interaction between iron and induced vacancies from aluminum gettering under light illumination. Particular attention is devoted to gettering of iron and the interplay with vacancy, as well as to the influence of light on the formation of iron vacancy complexes (FeD). Finally, the main ideas of the thesis are summarized along a short conclusion and outlook in chapter 5 . 
Introduction 


\section{Literature review}

Transition elements are prevalent contaminants in both integratedcircuit and solar cell materials. Some of them are highly detrimental like iron, nickel and copper and several process step including wafer handling, annealing, ingot growth, oxidation and wet chemical cleaning are usually helping in the introduction of these metals (Istratov et al., 2000a). These metals have been divided into two categories, the first group contains cobalt, nickel and copper which cannot stay in the interstitial site; the second group includes iron and other metals, are able to stay in the interstitial site even at room temperature (Weber, 1983). A deep concern has been devoted to the effect of these metals on the silicon device because small amounts of the transition metals having high diffusivities are enough to induce device impairments (Schröter et al., 2000) and electrical shorts as well as acting as carrier recombination/generation centers. Even very minute amounts of impurities, on the order of parts-per trillion (ppt), within the active device region can create these deleterious conditions.

\subsection{Fundamentals of iron in silicon}

First studies on the reactions of iron in silicon were carried out in the fifties and early sixties of the last century applying radiotracer techniques, resistivity measurements, and electron spin resonance (ESR) (Struthers, 1956; Collins and Carlson, 1957; Woodbury and Ludwig, 1960; Sheperd and Turner, 1962). Solubility, diffusivity and as a result the electrical activity and precipitation conditions of iron are the main properties that determine the reactions and behavior of iron in silicon. Because of its high solubility and fast diffusion at high temperature iron is easily introduced into silicon crystals. Hence, it has been detected even after probably clean annealing and quenching processes (Weber and Riotte, 1980; Gerson et al., 1977; Feichtinger et al., 1979). Interstitial iron $\left(\mathrm{Fe}_{\mathrm{i}}, 2 \cdot 10^{12} \mathrm{~cm}^{-3}\right)$ or iron boron pair $\left(\mathrm{Fe}_{\mathrm{i}} \mathrm{B}_{\mathrm{s}}, 2 \cdot 10^{13}\right)$ were found to induce dramatic reduction in the minority carrier diffusion length to $50 \mu \mathrm{m}$, a value far below to produce high efficiency of PV device (Istratov et al., 2000b). Unfortunately, less than $1 \mathrm{ppb}$ of iron was found to degrade the performance of $p$-type silicon device through the massive reduction of the minority carrier diffusion length (Buonassisi et al., 2005).

\subsubsection{Solubility and diffusivity of iron in silicon}

Due to extensive experimental and theoretical investigation, the nature, behavior and properties of solubility and diffusivity of iron in silicon are now 
well understood. In the following sections, we briefly summarize some of the keystone studies regarding iron solubility and diffusivity at high temperature.

\section{Solubility}

The solubility of iron increases with temperature below the eutectic temperature, passes through a maximum, and finally decreases above the eutectic temperature, which is $1207^{\circ} \mathrm{C}$ for the Si-rich $\mathrm{FeSi}_{2}$ phase (Westbrook, 1997; Massalski et al., 1990). Within the temperature range below the eutectic temperature, the solubility of iron in silicon follows the Arrhenius equation.

$$
C_{F e}=5 \cdot 10^{22} \exp \left(\frac{S_{M}}{K_{B}}\right) \exp \left(\frac{-Q_{M}}{K_{B} T}\right) c^{-3}
$$

Where $\mathrm{C}_{\mathrm{Fe}}$ is the solubility, $\mathrm{S}_{\mathrm{M}}(8.2 \mathrm{kB})$ and $\mathrm{Q}_{\mathrm{M}}(2.94 \mathrm{eV})$ are the solution entropy and enthalpy respectively in the range $900-1207^{\circ} \mathrm{C}$ (Weber, 1983). The same author measured the solubility as a function of temperature by neutron activation analysis (NAA) and electron paramagnetic resonance (EPR) at $900^{\circ} \mathrm{C}$ and $1200^{\circ} \mathrm{C}$ to be about $3 \cdot 10^{13} \mathrm{~cm}^{-3}$, and $1.5 \cdot 10^{16} \mathrm{~cm}^{-3}$, respectively (Weber and Riotte, 1980).

Previous EPR or DLTS studies found that iron concentrations measured by these instruments are two or three times less than that estimated by NAA at $950^{\circ} \mathrm{C}$ or above (Weber and Riotte, 1980). Exactly, the total iron concentration, a sum of iron boron pair and interstitial iron, in silicon was measured by DLTS also at $950^{\circ} \mathrm{C}$ to be $10^{14} \mathrm{~cm}^{-3}$ (Feklisova et al., 2000). At least four possible reasons for the disagreement between the electrically active (DLTS measured) and inactive (NAA measured) were discussed in the literature:

1. If the iron partially located in the substitutional site, it will be undetectable by techniques designed only for the interstitial iron (Feichtinger et al., 1979).

2. During annealing, either the concentration of iron on the surface of the sample is not enough or there is silicon dioxide barrier resulting in less iron dissolution, and as a consequence iron concentration may be below its solubility (Weber and Riotte, 1980; Weber, 1983).

3. The third reason for the disagreement between the experimental data is the purity of argon gas, used as ambient and usually contaminated with oxygen or nitrogen, during iron indiffusion (Istratov et al., 1999).

4. The quenching rate of iron after annealing should be considered as an important reason for disagreement. Insufficient quenching might not 
enough to keep iron in interstitial site or prevent iron precipitation (Graff, 1999).

On the other hand, iron solubility was found to be influenced by doping concentration. Increased iron solubilities were detected by NAA (McHugo et al., 1998) and these values have confirmed the previously reported data of Gilles et al., (1990) in heavily doped silicon. Accordingly, factors such as formation of silicide phase, time of annealing, argon gas and quenching rate should be considered to obtain reliable values for the iron solubility.

\section{Diffusivity}

It is well known that iron diffuses interstitially in silicon. In the literature, one could find a diffusion coefficient for iron at $1200^{\circ} \mathrm{C}$ to be about $7 \cdot 10^{-6}$ $\mathrm{cm}^{2} / \mathrm{s}$; and at $900^{\circ} \mathrm{C}$ it is still $10^{-6} \mathrm{~cm}^{2} / \mathrm{s}$ (Struthers, 1956). Owing to its higher diffusion coefficient, it is impossible to avoid iron contamination at high temperature (Weber and Riotte, 1978; Rijks et al., 1979). In his pioneer study about the first expression for iron diffusivity at different temperatures, Weber (1983) has derived the following diffusion coefficient by fitting data obtained from Struthers (1956); Kimerling et al., (1981); and Shepherd et al., (1962).

$$
D\left(F e_{i}\right)=1.3 \cdot 10^{-3} \exp (-0.68 \mathrm{eV} / \mathrm{kT}) \mathrm{cm}^{2} / \mathrm{s}
$$

Accordingly, diffusion coefficients at room temperature were obtained either by extrapolation from high temperature or detected by pair formation kinetics range from $2 \cdot 10^{-32} \mathrm{~cm}^{2} / \mathrm{s}$ for titanium, over $5 \cdot 10^{-15} \mathrm{~cm}^{2} / \mathrm{s}$ for iron, to $3 \cdot 10^{-11} \mathrm{~cm}^{2} / \mathrm{s}$ for nickel (Schröter et al., 2000).

\subsection{Point defect reactions of iron in silicon}

Complexes of iron in p-type silicon are of significant interest for semiconductor industry and technology. Iron-acceptor complexes such as Iron boron pair has been extensively studied in silicon. This defect is seen by DLTS, EPR, and/or electron-nuclear double orbital resonance (ENDOR). Normally, the formation of $\mathrm{FeB}$ complexes is occurred through the electrostatic attraction between the positively charged interstitial $\mathrm{Fe}$ atoms and the negatively charged boron atoms in $\mathrm{Si}$. In addition to complexes with shallow acceptors, interstitial iron is known to form electrically active complexes with phosphorus (Mchedlidze and Suezawa, 2004), gold (Brotherton et al., 1984; Utzig and Schröter, 1984; Ali et al., 2007), oxygen (Trushin et al., 2009), and platinum (Czaputa, 1989). Some of these 
complexes are proved to bind together with hydrogen by ESR measurements such as FePH (Mchedlidze, 2005). Furthermore, intrinsic defects such as vacancies, and self interstitial might be considered as another source for complex formation with iron.

\subsubsection{Interaction of iron with shallow acceptors}

There has been a significant amount of work devoted to characterizing iron complexes in silicon in order to better understand, and hopefully reduce, their impact on devices. Naturally, FeB pair is the prominent defect in iron doped p-type silicon. Data obtained from various studies using DLTS, EPR, and Hall effect demonstrated that FeB pair may form positive, negative or neutral charge state. The binding energy $\left(E_{b}\right)$ of the neutral form of FeB is estimated to be in the range of 0.58 to $0.65 e V ; \mathrm{Fe}_{i}{ }^{+}+\mathrm{B}^{-} \rightarrow[\mathrm{FeB}]^{0}+\mathrm{E}_{\mathrm{b}}$ (Kimerling and Benton, 1983; Walz et al., 1996; Sanati et al., 2007).

FeB pairs form a donor level at $E_{V}+0.1 e V$, an acceptor level at $E_{C^{-}}$ $0.27 \mathrm{eV}$ (Istratov et al., 1999) and a double acceptor level at $E_{V}+0.074 e V$ (Nakashima et al., 1994). The same acceptor at $E_{C}-0.23 e V$ has been identified as a dominant recombination center by lifetime spectroscopy (Macdonald et al., 2001). Energy supply like illumination (Graff and Pieper, 1981; Geerligs and Macdonald, 2004), current injection (Kimerling and Benton, 1983) and heating dissociate these pairs into negatively charged boron and positively charged interstitial iron. The dissociation of iron boron pair is strongly depending on the concentration of iron and boron in silicon (Hayamizu et al., 1991). On the other hand, the association time, sufficient for pair re-formation, was assumed being a function of temperature and boron concentration (Zoth and Bergholz, 1990). Equilibrium between association and dissociation of iron boron pairs is established in silicon due to Coulomb attraction forces between interstitial iron and substitutional boron.

In relation to the effect of illumination, maximum dissociation of $\mathrm{FeB}$ is not only depending on the illumination level but also on the iron and boron concentrations as well as other recombination centers (Geerligs and Macdonald, 2004). Keeping samples in the dark allows the pair to re-form and this re-association reaction is strongly influencing the solar cell performance due the release of interstitial iron. Faster re-association rate might be better because the liberated interstitial iron is three times affecting the solar cell efficiency than FeB. Therefore, it is crucial to determine the carrier lifetime for iron doped samples by $\mathrm{FeB}$ pair, concentration of $\mathrm{Fe}_{i}$ or both species (Zoth and Bergholz, 1990). 


\subsubsection{Interaction of iron with hydrogen}

It is well known that passivation of defect by hydrogen could change their electrical activity. Generally, silicon is contaminated by hydrogen during wet chemical etching before Schottky contact deposition or device production (Weber, 2008). Consequently, in iron contaminated samples there is great possibility for hydrogen to interact with iron related defects namely $\mathrm{Fe}_{\mathrm{i}}, \mathrm{Fe}_{\mathrm{s}}$ and $\mathrm{Fe}_{\mathrm{i}} \mathrm{B}_{\mathrm{s}}$ and this interaction has been extensively studied theoretically (Gonzalez Szwacki and Estreicher, 2007). Moreover, complexes of transition metals with hydrogen often introduce new levels in the bandgap (Weber, 2008). Indeed, hydrogen is introduced into the surface of silicon sample during wet chemical etching (Tavendale et al., 1988), leading to the passivation of dopant like boron in p-type silicon at room temperature and forming a resistive layer affecting the electrical properties of the material (Weber et al., 2003). Covalent binding of hydrogen to defects within silicon leads to passivation of the electrical activity of these defects (Estreicher, 1995) resulting in improvement of some kind of solar cells (Jiang et al., 2003). To follow up hydrogen motion is a difficult task, simply because hydrogen is mobile, reactive and readily trapped by defects and transition metal impurities forming defect complexes, and changing their electrical properties (Jost et al., 1996; Sachse et al., 1997; Shiraishi et al., 1999).

Although defect passivation is very important in silicon technology, there are only few studies about interaction between hydrogen and iron or iron-related defects. Dramatic reductions in the donor levels of $\mathrm{Fe}_{i}$ and $\mathrm{Fe}_{i} \mathrm{~B}_{\mathrm{s}}$ have been observed in hydrogenated samples following $\mathrm{H}$ implantation and simultaneously new hole traps are appeared at $\mathrm{E}_{\mathrm{v}}+0.23 \mathrm{eV}$ and $\mathrm{E}_{\mathrm{v}}+0.38 \mathrm{eV}$ (Kouketsu et al., 1995; Kouketsu and Isomae, 1996). Introduction of hydrogen during wet chemical etching induced $\mathrm{FeB}$ dissociation and release of interstitial iron (Yakimov and Parakhonsky, 1997). However, the mechanism of such a dissociation process remains unclear. Certainly, this interstitial iron is trapped again by boron at room temperature (Kimerling and Benton, 1983) and could be associated with the FeB pair re-formation (Feklisova et al., 2000).

Experimentally, $\mathrm{FeH}$ has been found for the first time in iron contaminated $\left(2 \mathrm{~h}\right.$ at $\left.930^{\circ} \mathrm{C}\right) \mathrm{P}$ - doped samples after introduction of hydrogen by wet chemical etching. Sadoh and his coworkers (1997) reported two donor levels, one at $\mathrm{E}_{\mathrm{V}}+0.41 \mathrm{eV}$ corresponding to $\mathrm{Fe}_{i}$ and the second at $\mathrm{E}_{\mathrm{V}}+0.31 \mathrm{eV}$ namely $\mathrm{Fe}_{\mathrm{i}} \mathrm{H}$. The latter annealed out at $175^{\circ} \mathrm{C}$ and the former associated with $\mathrm{Fe}_{i}$ does not disappear at the same temperature. Using the same material, distinct EPR spectra were observed in samples indiffused with ${ }^{57} \mathrm{Fe}$, annealed 
at $950-1250^{\circ} \mathrm{C}$ with or without hydrogen ambient. The authors proposed that these EPR spectra reflecting the existence of $\mathrm{FeH}$ which annealed out at $225^{\circ} \mathrm{C}$ (Takahashi and Suezawa, 1999). Furthermore, first-principles theory used mainly to study such defects theoretically, has demonstrated two FeH pairs, a donor at $E_{V}+0.36 \mathrm{eV}$ and an acceptor at $\mathrm{E}_{\mathrm{C}}-0.26 \mathrm{eV}$ levels in the band gap (Gonzalez Szwacki et al., 2008). A good agreement between the calculated donor level, $\mathrm{FeH}$ and the $\mathrm{Fe}_{\mathrm{i}} \mathrm{H}$ measured by thermally stimulated capacitance after hydrogen introduction by wet chemical etching was also reported for binding energy, gap level and defect components (Sadoh et al., 1997; Gonzalez Szwacki et al., 2008).

\subsubsection{Interaction of iron with intrinsic point defects}

Importantly, very little is known on the behavior of iron native defect complexes in silicon during heat treatment. These complexes can be formed after irradiation of iron-doped samples with electron or ions. Mchedlidze and Suezawa, (2002) proposed that mobile vacancies formed after silicon irradiation might be the main mechanism of pairing with interstitial iron. On the other hand, interaction of self interstitial, the second intrinsic defect in silicon and the interstitial iron is not well studied experimentally because the irradiated samples are vacancy-rich. First-principles theory was used to calculate the interactions between interstitial iron and self-interstitial forming a hypothetical $\mathrm{Fe}_{\mathrm{i}} \mathrm{Si}_{\mathrm{i}}$, a pair which has a donor level at $\mathrm{E}_{\mathrm{V}}+0.42 \mathrm{eV}$ and no corresponding acceptor suggesting that iron interstitial is trapped at self interstitial cluster (Estreicher et al., 2008).

The first study reported iron-vacancy pair was the one that performed EPR experiments and published by Muller et al., (1982). In this study, the float zone silicon samples, indiffused with iron for $16 \mathrm{~h}$ at $1200 \mathrm{C}$, and irradiated with electrons. Many EPR spectra (NL19-25) have been observed, and most of them having lower thermal stability annealed out at temperature less than $200^{\circ} \mathrm{C}$. Interestingly to our study, the iron-vacancy pair $\left(\mathrm{Fe}_{\mathrm{i}} \mathrm{V}, \mathrm{NL} 19\right)$ and the complex containing two iron atoms and vacancy (2FeV, NL20) were considered to be less important to the device fabrication due to their poor thermal stability. However, the same complexes were found to survive higher annealing at $400-500^{\circ} \mathrm{C}$ (Mchedlidze and Suezawa, 2001). In another ESR study, the same authors reported that $\mathrm{Fe}_{\mathrm{i}} \mathrm{V}$ is a hole trap at energy level $0.51 \mathrm{eV}$, more stable than $2 \mathrm{FeV}$ complex and survived annealing at $300-350^{\circ} \mathrm{C}$ (Mchedlidze and Suezawa, 2002). Transformation of the iron-vacancy complexes leads to the formation of new iron-related traps especially if the reaction of interstitial iron with native defects in involved (Kaminski et al., 2003). In fact, the thermal stability of iron-vacancy complexes has been 


\section{Chapter 2. Literature review}

discussed and reviewed (Watkins, 1999). Based on the data obtained from the previous studies, it could be concluded that the thermal stability of ironvacancy complexes could be higher than that of vacancy-oxygen complex and divacancies and their impact on device performance needs further investigation.

Instead of two iron atoms, it is also possible to find iron-vacancy complex with two vacancies. A donor and acceptor levels for $\mathrm{Fe}_{\mathrm{i}} \mathrm{V}_{2}$ were calculated to be at the positions $\mathrm{E}_{\mathrm{V}}+0.25 \mathrm{eV}$ and $\mathrm{E}_{\mathrm{C}}-0.75 \mathrm{eV}$ respectively (Estreicher et al., 2008). The calculated donor is in a good agreement with that observed by DLTS analysis and attributed to $\mathrm{Fe}_{\mathrm{i}} \mathrm{V}_{2}$ (Komarov, 2004). The formation of this defect was found to be highly correlated with disappearance of divacancies. According to our knowledge, there is no published information on DLTS measurement for complexes of iron with vacancy after aluminum gettering.

\subsection{Gettering}

The major problem that causes semiconductor device degradation and poor solar cell performance is the higher concentrations of dissolved or precipitated metallic impurities. Reductions in lifetime and diffusion length were usually taken as indicators for such degradation. The quality of the staring material as well as the thermal treatment is considered to be the most important parameters affecting the concentration of metallic impurities which included in the silicon feedstock or introduced during wafer processing. Hence, techniques by which you are able to diminish the concentration of metal impurities, preventing degradation of silicon device and improving solar cell performance are very useful for semiconductor technology. These techniques are referred as gettering and currently intensive gettering procedures are used in photovoltaic industry.

\subsubsection{Concept of impurity gettering process}

For more than fifty years, gettering was an essential step to remove impurities from integrated circuits, power devices and solar cells (see, for example, Goetzberger and Shockley, 1960). Historically, gettering is defined as a process to (i) remove the unwanted impurities from the active zone (Graff, 1989); (ii) reduce metal impurities by collecting them into a passive region of the silicon wafer (Kang and Schröder, 1989; Martinuzzi et al., 1995); (iii) minimize metallic impurities by transporting them to the gettering area (Meyers etal., 2000); (iv) to collect the unintentional contaminants at sites outside the device area (Weber, 2003). The common feature of these 
previous studies is that they have described the same gettering process using several words and phrases, however the physical meaning still the same i.e concentrating impurities in a specific region of a wafer. Cooling rate, thermal treatments, gettering layer and concentrations and distribution of metals in the wafers are the most important factors affecting the efficiency of gettering process (Istratov et al., 2003a).

Generally, gettering process encompasses three physical steps induced by heat treatments. Each step is considered to be a rate limiting step affecting the efficiency of gettering and all of them are also temperature dependent especially the temperature of release and diffusion of impurity. These physical steps are:

(1) Release of impurities from active region,

(2) Diffusion of impurities through the bulk, and

(3) Capture of impurities in the gettering site (Kang and Schröder, 1989).

For solar cell technology, the gettering layer containing higher concentrations of metal impurities should be removed at the end of gettering process.

Gettering is divided into two types according to the location of gettering site. In external gettering, impurities are transported on the external surface of the wafer. In internal gettering, the site of gettering should be inside the bulk such as oxide precipitate or extended defects serve as gettering region (Schröter et al., 1991). Taken into consideration that the first $10 \mu \mathrm{m}$ near the surface is the active region of integrated circuits, thus it seems likely that precipitation of the metal impurities in the bulk by internal gettering might improve device performance (Tice and Tan, 1981), however this is not the case for solar cell where you need to keep the whole bulk clean by external gettering.

It is necessary for solar cell to apply external gettering by which you will be able to clean the entire bulk and to collect all the metallic impurities in the gettering site on the surface, a sink for diffusing impurities. Several surface treatments such as phosphorus indiffusion (Ourmazd and Schröter, 1984; Seibt et al., 2000; Schröter et al., 2003), metal film deposition and subsequent annealing (Thompson and Tu, 1982; Martinuzzi et al., 1987; Apel et al., 1994; Joshi et al., 1995; Seibt et al., 2006), mechanically damaging the surface (Pomerantz, 1967; Nakamura et al., 1968; Ayad and Remram, 2006), growth of poly-Si films (Seibt et al., 1998) and ion implantation (Nassibian and Golja, 1982) have been shown to provide such sinks. A cumulative effect of two types of gettering was also found to provide greater segregation, noticeably, simultaneous application of phosphorus diffusion and aluminium gettering 
(Jooss et al., 1998; Schubert and Gee, 1996) results in better solar cell performance.

\subsubsection{Aluminum alloying-induced impurity gettering}

In laboratory, aluminium gettering is performed by evaporating or sputtering highly pure aluminium metal on the surface of the sample with specific thickness layer. On the industry scale, a full layer of aluminium is deposited by screen printing or pad printing on the rear backside. Historically, Thompson and Tu (1980) was the first to report the beneficial effect of aluminium gettering to dissolve a great amount of cupper diffused from the front side at $540^{\circ} \mathrm{C}$. According to the phase diagram, annealing of aluminium layer at higher temperature more than its eutectic temperature $\left(577^{\circ} \mathrm{C}\right)$ leads to the formation of liquid $\mathrm{Al}: \mathrm{Si}$ alloy. The content of silicon atoms in this liquid is proportional increased by increasing the temperature being 12 at.\% and 56 at\% respectively at 577 and $1000^{\circ} \mathrm{C}$ (Massalski et al., 1986). Direct contact between the molten layer and silicon lattice enables atoms of metallic impurities to migrate from silicon to the sink of Al:Si alloy due to their higher solubilities in the molten (Joshi et al., 1995). Segregation gettering like aluminium gettering can result from the difference (i) in phase between crystalline and liquid, (ii) in material like aluminium which has a greater solubility for metal impurities than silicon, (iii) in the concentration of doping forming impurity-acceptor complex (McHugo and Hieslmair, 1999).

Because the highest solubility of metals in silicon is below $10^{18} \mathrm{~cm}^{-3}$, a greater segregation coefficient is induced. Segregation induced gettering is established through transport of metals from the bulk to the liquid alloy by the driving force initiated from the segregation coefficient. Although silicon and aluminium phase diagram provide helpful information to calculate segregation coefficient, it is not useful due to its property related to ternary system (Myers et al., 2000). Segregation coefficient " $S$ " is described as a ratio between the solubility of metals in gettering region $(\mathrm{g})$ and their solubility in the wafer area (w) (Baldi et al., 1978). Because the solubility of metals is proportional to the concentration of impurities in the same region, the segregation coefficient " $\mathrm{S}$ " can also be defined as the ratio of the concentration $M$ in the AISi-melt and in silicon under thermodynamic equilibrium, i. e

$$
S_{M}^{(A l S i / S i)}=C_{M}^{(A l S i) e q} / C_{M}^{(S i) e q}
$$


Basically, the chemical potential in the gettering layer is lower than that of the wafer, $\mu_{\mathrm{M}}{ }^{(\mathrm{g})}<\mu_{\mathrm{M}}{ }^{(\mathrm{w})}$ (Schröter et al., 2003). Once the diffusion takes place, the difference in chemical potential initiates metal influx, diminishing this difference till zero, $\Delta \mu_{\mathrm{M}}{ }^{(\mathrm{w} / \mathrm{g})}=\mu_{\mathrm{M}}{ }^{(\mathrm{w})}-\mu_{\mathrm{M}}{ }^{(\mathrm{g})}$. Similarly, the difference in the standard chemical potential of metallic impurity $M$ in wafer and gettering produces the thermodynamic force which drives segregation, $\Delta \mu^{0}{ }_{\mathrm{M}}^{(\mathrm{w} / \mathrm{g})}$.

$$
\begin{gathered}
\mu_{M}^{(w)}=\mu_{M}^{0(w)}+K_{B} T \ln \left(C_{M}^{(w)} / N_{S i}\right) \\
\mu_{M}^{(g)}=\mu_{M}^{0(g)}+K_{B} T \ln \left(C_{M}^{(g)} / N_{g}\right)
\end{gathered}
$$

With $\mathrm{N}_{\mathrm{si}}$ and $\mathrm{N}_{\mathrm{g}}$ refer to the densities of the sites available for $\mathrm{M}$ in silicon and gettering layer respectively and $\mu_{\mathrm{M}}^{0}$ is the standard chemical potential of $\mathrm{M}$ in the wafer $(\mathrm{w})$ or gettering $(\mathrm{g})$ area. The maximum value of concentration ratio is obtained if the chemical potential of $M$ in wafer is becoming equal to that in gettering region i.e $\mu_{\mathrm{M}}{ }^{(\mathrm{W})}=\mu_{\mathrm{M}}{ }^{(\mathrm{g})}$.

$$
C_{M}^{(g)} / C_{M}^{(w)}=\frac{N_{g}}{N_{S i}} \exp \left[\Delta \mu_{M}^{0(w / g)} / K_{B} T\right]
$$

\subsubsection{Impact of aluminum gettering on solar cell performance}

Segregation of impurities by the aluminum gettering was observed for metallic atoms like copper, silver and gold (Thompson and Tu, 1982; Verhoef et al., 1990a; Martinuzzi et al., 1995), cobalt (Apel et al., 1994; Sattler, 2002; Seibt et al., 2006), iron (Hieslmair et al., 1996; Abdelbarey et al., 2009); nickel (Porre et al., 1996) and a very recent publication of Phang and Macdonald, (2011) has shown that aluminum alloying was extremely effective and removed more than $99 \%$ of the implanted iron from crystalline silicon.

In photovoltaic industry, aluminium gettering is used as a routine gettering procedure to improve the minority carrier diffusion length at temperatures above the $\mathrm{Al}: \mathrm{Si}$ eutectic temperature. Moreover, applying of multiple gettering processes were also found to induce better performance by using a thicker aluminium layer (Joshi et al., 1995). This result encouraged the same group to design a new experiment to find out the effect of an extended annealing for four hours at $1100^{\circ} \mathrm{C}$ of $1 \mu \mathrm{m}$ aluminium layer on the mc-Si material. Data obtained from their experiment revealed that aluminium 


\section{Chapter 2. Literature review}

gettering can homogenize the electrical properties of mc-Si and enhanced the minority carrier diffusion length (Joshi et al., 2001). Apel et al., (1994) have investigated the gettering effect of $\mathrm{Al}$ on float zone silicon and mc-Si doped with cobalt by Mössbauer spectroscopy. They provided evidence that aluminum gettering functions at high temperatures, drives diffusion of the cobalt atoms from the Si bulk to the liquid Al-Si phase, and has identical effect in different silicon materials. In multicrystaline silicon, the quality of the starting materials as well as thermal treatment influences the efficiency of aluminium gettering (Chen et al., 2004).

Furthermore, during the last few years, Martinuzzi and coworkers reported that diffusion length and lifetime are improved when a thick aluminum layer is deposited on the surface of silicon wafers (Dubois et al., 2009). Light beam induced current maps displayed that the recombination strength of dislocation arrays is lowered at room temperature after the sample have been subjected to Al-Si alloying at $900^{\circ} \mathrm{C}$ (Martinuzzi et al., 1997). Al-Si gettering after the deposition of a backside $1 \mathrm{~mm}$ thick Al layer seemed to be more efficient compared with helium implantation followed by the formation of nanocavities in FZ and mc-Si (Martinuzzi et al., 2000).

The synergistic effect of aluminium gettering together with different processes has been reported in several studies. Such effect was found to improve the electronic quality of $\mathrm{mc}-\mathrm{Si}$ together with porous silicon implementation (Vinod, 2007), and to increase the minority carrier diffusion length together with codiffusion of phosphorus only (Hartiti et al., 1993) or followed by firing (Laades et al., 2009). Certainly, it is believed that aluminum provides a gettering effect because of the higher solubility of metallic impurities in Al-Si alloy than in silicon.

\subsection{Deep Level Transient Spectroscopy (DLTS)}

DLTS technique is very unique in obtaining some important trap parameters including emission activation energy and trap concentration. However by using DLTS, it is impossible to gather direct information about the physical structure of a defect. Although it is a good advantage for DLTS to measure the electrically active defects, it cannot determine total number of impurity atoms located in the material. Thus, it is not plausible to compare DLTS concentrations to the impurity concentrations measured by neutron activation analysis.

\subsubsection{Working principle of DLTS}

Basically, the working principal of DLTS is mainly depending on the capacitance change related to space charge region of a Schottky diode or a 
p-n junction. The capacitance change is produced as a result of applying of an excitation pulse as a function of temperature to measure the electrically active deep levels (Miller et al., 1977; Blood and Orton, 1992). The temporal capacitance changes which increase exponentially in case of point defect, resulting from applying rapid bias change of a Schottky diode, are the basis for DLTS. The width of the space charge region is correlated with the change in the reverse bias and in the presence of deep level which redistribute the charges, capacitance transients are produced (Lang, 1974; Schubert, 1993). The deep levels will be completely occupied by charge carriers one the reverse of forward bias is applied. The values of these biases determine the depth for measuring. If reverse bias is applied on the diode, maximum width of the space charge region and depletion of majority carrier are achieved. By increasing the applied bias voltage, the majority carrier rapidly jump out of the space charge region. The capacitance of junction increases with emission of majority carrier from the trap to the conduction or valence band in $n$ - or $p$-type silicon respectively. This emission can be observed by monitoring the transient change in capacitance of the diode. It is possible to extract the electrical properties of the traps by repeating DLTS measurement against a wide range of temperature. A proportional relationship between the capacitance and time for majority carrier emission is expressed in the following equation:

$$
C(t)=C(0) \exp \left(-\frac{t}{\tau}\right)=C(0) \exp \left(-t . e_{p}\right)
$$

Where $\tau$ is the emission time constant and is equal to the inverse of the emission rate $e_{p}$, and $\mathrm{C}(0)$ is the capacitance at $\mathrm{t}=0$. Obtaining values and time constant of the capacitance transient in relation to the change in both temperature and rate window will be very helpful to deduce the trap parameters such as concentration, energy level and capture cross section. The latter two are considered to be the trap fingerprint in silicon ((Schröder, 2006) and changing the bias voltage, pulse duration, and amplitude of pulses were also necessary to estimate the depth profile of the trap as well as differentiating between donor and acceptor or point and extended defects (Schröter et al., 1995).

\subsubsection{Analysis of DLTS parameters}

To study deep levels, one has to use sensitive techniques that able to detect low concentration and to distinguish hole- and electron-carrier traps. These techniques are mostly based on the study of transient phenomena 


\section{Chapter 2. Literature review}

related to carrier capture and emission at the centers. DLTS is an example that able to gather information about the defect concentration $\left(\mathrm{N}_{\mathrm{T}}\right)$, activation energy level $\left(E_{T}\right)$ which is related to the position of the level in the band gap, and capture cross sections of electrons and holes $\left(\sigma_{n, p}\right)$ which provide a measure of the ability of the deep level to trap carriers (Lang, 1974). These parameters are also helpful to find out more characteristic properties of the traps such as its dependence on the physical structure or temperature, annealing behavior, transformation and depth profiles.

\section{Defect concentration}

To investigate materials for different potential use, we should estimate the concentration of defects and this might be the basic helpful information to decide. The simplest way to obtain the concentration of defects is to measure the capacitance change $(\Delta \mathrm{C} / \mathrm{C})$ where $(\Delta \mathrm{C}<<\mathrm{C})$, in case of all defect are filled in the space charge region. Assuming that the doping concentration $\left(N_{A}\right)$ is much greater than the concentration of the defect $\left(\mathrm{N}_{T}\right)$ and both are located in the p-type material; the $\mathrm{N}_{\mathrm{T}}$ is given by the following equation:

$$
N_{T}=2\left[\frac{\Delta C}{C}\right]\left(N_{D}-N_{A}\right)
$$

Where $\left(N_{D}-N_{A}\right)$ refers to the net donor concentration and $\Delta C$ is the capacitance change after removal of the pulse. This equation is obtained assuming that deep levels throughout the whole space charge region are recharged during the DLTS experiment which is a good approximation for large bias and pulse voltages.

To obtain the true defect concentration from the experimental data of DLTS, the lambda factor $\lambda$, is included for correction. In addition, correction for edge region and using of fixed bias and variable pulse are proposed to estimate the defect concentration (Zohta and Watanabe, 1982). Taken together all the above correction, the following equation is used to give accurate determination of the defect concentration:

$$
N_{T}=2\left(\frac{\Delta C}{C}\right) N_{D}\left[\left(\frac{w-\lambda}{w}\right)^{2}-\left(\frac{w_{p}-\lambda_{p}}{w_{p}}\right)^{2}\right]^{-1}
$$

Where $\lambda, \lambda_{P}$ and $w, w_{P}$ are the widths of the edge region and depletion region respectively before $(\lambda, w)$ and after $\left(\lambda_{P}, w_{P}\right)$ pulsing. Finally, the lambda factor can be expressed as follow: 


$$
\lambda=\left(\frac{2 \varepsilon \varepsilon_{0}\left(E_{T}-E_{f}\right)}{q^{2} N_{D}}\right)^{1 / 2}
$$

Where $q$ denotes the absolute electronic charge, $\varepsilon$ is the dielectric constant, $E_{f}$ is the bulk fermi level and $E_{T}$ is the activation energy of the trap.

\section{Activation Energy}

The second important parameter obtained by DLTS helping to identify the defect properties is the activation energy. By measuring DLTS spectra at different frequencies, one can deduce the activation energy. The peak shifts towards the lower temperature as the frequency decreased. The emission rates for electrons $\left(e_{n}\right)$ and holes $\left(e_{p}\right)$, kicked out of a defect into the conduction and valence bands respectively, are described by

$$
\begin{aligned}
& e_{n}=\sigma_{n}\left\langle V_{n}\right\rangle_{t h} N_{C} \exp \left(-\frac{\Delta G}{k T}\right) \\
& e_{p}=\sigma_{p}\left\langle V_{p}\right\rangle_{t h} N_{v} \exp \left(-\frac{\Delta G}{k T}\right)
\end{aligned}
$$

Where $\sigma_{\mathrm{n}}$ and $\sigma_{\mathrm{p}}$ represent the electron and hole capture cross sections. $\mathrm{N}_{\mathrm{C}}$ and $N_{V}$ refer to the effective densities of states of electrons and holes in the conduction and valence bands respectively. $\left\langle V_{n}\right\rangle_{t_{h}}$ and $\left\langle V_{p}\right\rangle_{t_{h}}$ denote the average thermal velocities for electron and holes. The change in Gibbs free energy $\Delta G$ is related to the associated changes in ionization enthalpy $(\Delta \mathrm{H})$ and entropy $(\Delta S)$ by the thermodynamic identity.

$$
\Delta G=\Delta H-T \Delta S
$$

Accordingly, the emission rate of electron and hole become

$$
\begin{aligned}
& e_{n}=\sigma_{n}\left\langle V_{n}\right\rangle_{t h} N_{C} \exp \left(-\frac{\Delta H}{k T}\right) \\
& e_{p}=\sigma_{p}\left\langle V_{p}\right\rangle_{t h} N_{v} \exp \left(-\frac{\Delta H}{k T}\right)
\end{aligned}
$$

The well known Arrhenius plot is drawn between In $\left(e_{n, p} / T^{2}\right)$ versus $1 / T$, giving a straight line, from which the slope is providing the activation 


\section{Chapter 2. Literature review}

energy. The factor $\mathrm{T}^{2}$ arises from the temperature dependence of thermal velocities and effective densities of states (Blood and Harris, 1984). One should remember that the emission rate is temperature dependent and this is the main reason for obtaining unreliable activation energy. Hence, it is necessary to apply a relevant correction to the apparent activation energy after determining the temperature dependent fraction of the capture cross section.

\section{Capture cross section}

The third important parameter which considered as a fingerprint for the defect is the capture cross section, $\sigma_{n, p}$. From the Arrhenius plot it is possible to calculate the energy of the deep level that is obtained from the slope of the line, whereas the capture cross section is extracted from the intercept with the In $\left(e_{n, p} / T^{2}\right)$-axis. Experimentally by extrapolation, to exclude the effect of temperature, cross section could be obtained at $T=\infty$ from the intercept if $1 / T=0$. Assuming that the capture cross-section of the defect is independent of temperature, in this case, the Arrhenius plot should yield a linear relationship from which the defect's energy $E_{T}$ and capture cross-section $\sigma_{n, p}$ should be calculated. However, in some cases the capture cross-section might be temperature dependent (Mooney, 1999), providing biased values that referred as apparent cross sections. Alternatively, there is a second way to measure directly the capture cross section by changing the fill pulse length and keeping the temperature constant using:

$$
\ln \left(\frac{\Delta C_{\infty}-\Delta C_{t}}{\Delta C_{\infty}}\right)=\sigma\langle V\rangle N_{d} t_{p}
$$

Where $\Delta \mathrm{C}_{\infty}$ and $\Delta \mathrm{C}_{\mathrm{t}}$ are the capacitance values respectively at equilibrium and time t. $N_{d}$ is the majority carrier concentration and $t_{p}$ is the pulse length.

\section{Electric field dependence of thermal emission rate}

Due to several reasons if you apply strong electric fields on samples containing deep traps, stimulation of ionization or capture is occurred. These reasons include PooleFrenkel effect (Tasch and Sah, 1970; Baber et al., 1992), the direct tunneling (Korol, 1977) and the phonon-assisted tunneling (Irmscher et al., 1983). The former effect operates only for charged metal impurities; however the latter two effects operate for charged and neutral 
metal impurities. Therefore, the emission rate could also change under electric field even if the sample contains neutral defects.

Historically, The Poole-Frenkel effect was firstly investigated by Frenkel (1938), and further developed by Hartke (1968) who modified the one dimensional theory into the three dimensional case. The electric field enhanced the emission rate of charge carriers. If the external electric field is applied on the trap whatever its type, the shape of the potential well is become irregular, making one potential barrier higher on one side and lower on the other side. The enhancement in the emission rate at low electric field as a result of lowering in the potential barrier height is called Poole-Frenkel effect.

It is well known that the experimentalists used the Poole-Frenkel effect to differentiate between donor and acceptor defects in semiconductors. In one dimensional theory, there is proportional relationship between the emission rate $(e)$ and the applied external electric field strength $(F)$ i.e $\log \left(e_{n, p}\right)$ proportional to $\mathrm{F}^{1 / 2}$. This relationship indicates that the defect will be donor in case of n-type material and an acceptor in case of p-type material (Bourgoin and Lannoo, 1983; Ganichev et al., 2000). 


\section{Experimental Procedures}

This chapter presents the general experimental details related to the work reported in this study. These include a description of the conditions and procedure for the preparation of the samples, iron in-diffusion and subsequent aluminum gettering process, fabrication of Schottky contact, and its electrical characterization and the equipments and measurements carried out for the properties of the investigated deep level defect systems.

\subsection{Material}

P-type silicon wafers were used in this study. Boron doped float zone (FZ) samples with low oxygen content and less crystallographic defects were chosen for our annealing experiment to prevent initiation of complicated defect reactions (Schmidt and Cuevas, 1999). FZ silicon samples (Wacker Chemitronic, Germany) of resistivity (7 to $10 \Omega \mathrm{cm}$ ); $3 \cdot 10^{15} \mathrm{~cm}^{-3}$ boron concentration, $520 \mu \mathrm{m}$ thickness, and (100) oriented silicon wafers were used in all experiments. Samples were cleaned prior to all annealing processes and etched to remove any surface damage and contamination.

\subsection{Wafer cleaning and wet etching}

Although silicon wafers are produced with highly cleaned surface, it is necessary to repeat cleaning to ensure that it contains no contaminants that would affect the etching process. The cleaning process is performed in concern for the presence of two main types of contaminants: organic compounds and heavy metal particles. There are many variations in the cleaning procedures used by various research groups. The following steps of cleaning procedure have been used to maintain an appropriate silicon (100) surface in this study.

1. Generally after cutting silicon samples into the appropriate sizes, rinsing in de-ionized water is carried out three times for four minutes each to clean the surface.

2. At the bigining of any process, a silicon surface is usually contaminated with organic substances. Rinsing in solvent will remove most of those contaminants and increase the effectiveness of the remaining cleaning procedures in this list. For complete removal of organic substances, washing in actone followed with methanol for four minutes was necessary. 
3. Rinse with de-ionized water in an ultrasonic water bath to wash out remaining organic solvents.

During solar cell production, different solutions are commonly used for wet chemical etching of silicon. The most widely etching solution is the mixture of $\mathrm{HF}-\mathrm{HNO}_{3}$ which leads to the dissolution of silicon. As a first step in the etching process, $\mathrm{HNO}_{3}$ oxidize silicon into $\mathrm{SiO}_{2}$ (equation 3.1), followed by dissolving of silicon dioxide by HF (equation 3.2) and the combination of whole etching process is illustrated in equation 3.3 (Robbins and Schwartz, 1959; Steinert et al., 2005).

$$
\begin{gathered}
3 \mathrm{Si}+4 \mathrm{HNO}_{3} \Leftrightarrow 3 \mathrm{SiO}_{2}+4 \mathrm{NO}+2 \mathrm{H}_{2} \mathrm{O} \\
\mathrm{SiO}_{2}+6 \mathrm{HF} \Leftrightarrow \mathrm{H}_{2} \mathrm{SiF}_{6}+2 \mathrm{H}_{2} \mathrm{O} \\
3 \mathrm{Si}+4 \mathrm{HNO}_{3}+18 \mathrm{HF} \Leftrightarrow 3 \mathrm{H}_{2} \mathrm{SiF}_{6}+4 \mathrm{NO}+8 \mathrm{H}_{2} \mathrm{O}
\end{gathered}
$$

4. The most serious contaminants located on the silicon surface are the transition metals such as gold, copper, nickel and iron. Wet chemical etching is widely used to convert these transition metal contaminants into the corresponding metal complexes. Therefore, the samples were rinsed in hydrofluoric acid, $1 \mathrm{HF}(40 \%)$ : nitric acid, $7 \mathrm{HNO}_{3}(65 \%)$ for 45 seconds to remove metallic impurities. Washing in de-ionized water is necessary to stop etching and eliminate the rest of the etching solution..

5. Rinse silicon samples in a $4 \%$ HF solution for 20 s. Normally, a thin layer of native oxide is formed in air on the silicon surface and etching with $\mathrm{HF}: \mathrm{HNO}_{3}$ leads to formation of chemical oxide layer. The use of a dilute HF solution removes the silicon dioxide layer and exposes a new silicon surface.

6. Finally, samples were washed with de-ionized water for 30 s several times before starting metal evaporation in a high vacuum chamber.

\subsection{Iron in-diffusion}

High purity iron metal (purity $99.999 \%$ produced by Johnson Matthey $\mathrm{GmbH}$, Germany) in the form of iron wire (1 $\mathrm{mm}$ diameter) was used for iron indiffusion. Both iron wires and tungsten boat (used for evaporation) were cleaned by immersion in acetone and etched afterwards in hydrochloric acid, $37 \%$ for 5 minutes. After cleaning, iron was evaporated in iron specific 


\section{Chapter 3. Experimental}

chamber under vacuum pressure of $2.5 \cdot 10^{-6}$ mbar. During annealing, $\mathrm{FeSi}_{2}$ is formed liberating iron into silicon depending mainly on the indiffusion temperature. Annealing was carried out in a vertical furnace that holds sample vertically inside a quartz tube through which argon gas flows (Riedel, 1994). Indiffusion temperature was monitored inside the furnace by using Pt/PtRh thermocouple. Please note that the furnace should be preheated before loading the samples for at least three hours. All samples were annealed in an Argon $(99.9999 \%)$ atmosphere to prevent oxide growth at a chosen temperature $\mathrm{T}_{\text {ind }}$ (between $950^{\circ} \mathrm{C}$ and $1100^{\circ} \mathrm{C}$ ). Argon cylinder directly connected to the furnaces through one meter long straight tube constructed from a transparent material preventing air penetration. The indiffusion time should be selected to establish the equilibrium of iron in silicon according to the published solubility data (Weber, 1983). Iron indiffusion process is terminated by quenching samples into silicon oil $(\sim 500 \mathrm{~K} / \mathrm{s})$ to freeze in the iron distribution and to prevent iron precipitation during cooling..

\subsection{Formation of Al-Si layer}

Quenched silicon samples were subjected to mechanical polishing to remove the $\mathrm{FeSi}_{2}$ layer, and then etched chemically in $\mathrm{HF}: 7 \mathrm{HNO}_{3}$ as described in section 3.2. It is also necessary to remove the native and/or chemical oxide layer by dipping the samples into dilute HF solution. Aluminum gettering experiments were performed through thermally evaporating $10 \mathrm{~nm}$ thick layer of highly pure aluminum metal $(99.999 \%)$ by using UHV- chamber at $10^{-6} \mathrm{mbar}$. The thickness of deposited Al layer on the sample surface was recorded by using a quartz oscillator of a layer thickness measuring instrument (Balzers). Simultaneously, the vertical furnace was preheated for 3 hours and standby at the chosen gettering temperature ( $T_{\text {gett, }}$, between 950 and $1100^{\circ} \mathrm{C}$ ) and as quickly as possible samples placed into the vertical furnace for 50 min under argon ambient. At the end of gettering time, gettered samples were expelled from the furnace in $10 \% \mathrm{NaOH}$ solution (cooling rate, $2000 \mathrm{k} / \mathrm{s}$ ) to avoid precipitate formation in silicon. Al: Si: Fe alloy layer which supposed to be formed on the sample surface during annealing should be mechanically polished before further analysis.

\subsection{Illumination and annealing}

Illumination experiments were undertaken to study the effect of light exposure on the nature of defect, defect reactions and transformations. The source of white light is indirectly oriented instrument containing a halogen lamp (halolux 90 Cold-Light Source with 90 Watt halogen reflector lamp, Streppel, Glasfaser-Optik, Germany). To control the intensity of light and to 
make it cold light, glass fiber filter is used to eliminate the infrared wavelengths below $0.5-0.7 \mathrm{eV}$, and the light intensity is determined by diode photo meter to be $50 \mathrm{~mW} / \mathrm{cm} 2$ in the spectra 0.7 to $2.5 \mathrm{eV}$. Illuminating the freshly etched samples with cold white light was carried out by exposing the light on the front surface of the silicon specimen for 15,30 or $45 \mathrm{~min}$. The illuminated area amounted to about $0.5 \mathrm{~cm}$ in diameter. During illumination the specimen was kept at room temperature. After illuminating the specimen for different durations, Schottky contacts were evaporated as described in Section 3.7.

To study the nature of defect, annealing experiments should be performed to give more information about the defect structure, stability, dissociation and location in interstitial or substitutional sites. It also highlights the transformation of one defect into the other. Gettered samples were annealed in a horizontal furnace under argon gas ambient for 0, 25 and 35min at $175^{\circ} \mathrm{C}$. It was not necessary to remove the electrical contacts from the sample surface before each annealing step at such lower temperature.

\subsection{Gold and Platinum diffusion used to monitor the vacancy concentration}

Platinum and gold diffusion experiments were performed to estimate vacancy concentrations in silicon samples with and without aluminum gettering. Platinum was deposited by evaporation after a standard cleaning procedure. In general, platinum was deposited onto the samples surface and annealed in a horizontal furnace in argon gas ambient. Samples were indiffused with platinum at $730^{\circ} \mathrm{C}$ for $30 \mathrm{~min}$ according to Jacob et al., (1997). A thin layer of $100 \mathrm{~nm}$ gold was evaporated on the surface of the second group of silicon samples, followed by a drive-in annealing of 2 hours at $850^{\circ} \mathrm{C}$ in an ambient of argon gas. After platinum or gold diffusion, samples were withdrawn from the appropriate diffusion tube into air (cooling rate, $4 \mathrm{k} / \mathrm{s}$ ).

\subsection{Preparation of Schottky contact}

Perfect diode without leakage currents is one of most requirements for DLTS technique. To prepare such diode is a little bit difficult task for silicon material and therefore needs more experience to produce high quality diode from which you will obtain reliable results. In this study, Schottky diodes were prepared as follows:

1. Clean and mirror surface was obtained by mechanically polishing. 
2. Wafer samples should be washed after polishing. The cleaning procedure was similar to that used for annealing treatment for indiffusion but without HF dip to leave the oxide layer.

3. Immediately after etching, samples were placed in the evaporator. $1 \mathrm{~mm}$ diameter aluminum spots representing Schottky barriers were formed on the etched surface by using holes in the deposition musk. All metallization was done by thermal evaporation performed in a pumped system under a vacuum pressure of about $2 \cdot 10^{-6} \mathrm{mbar}$.

4. Ohmic contact was made on the backside of the silicon sample Algallium alloy. Very fine gold wire is used to connect the barrier electrically using a small droplet of silver paste.

5. Following diode preparation, a necessary step is required to control the quality of Schottky diodes as well as its electrical properties. CV measurements were quite enough to fulfill these requirements.

\subsection{CV characteristics}

The capacitance-voltage (CV) characterization is the measurement of the capacitance as a function of the reverse bias. It is a fundamental technique to estimate the doping concentration and its depth profiles in semiconductor materials (Blood and Orton, 1992).

If the doping is homogenously in the semiconductor, the capacitance of Schottky contact is expressed normally like any planar capacitor (Sze, 1981).

$$
C=\left[\frac{\varepsilon \varepsilon_{0} A}{w}\right]
$$

Where $\varepsilon_{0}$ is the permitivity of free space, $\varepsilon$ is the dielectric constant of the semiconductor; $\mathrm{A}$ is the area of the Schottky contact and $w$ is the depletion region thickness which is related to the built-in voltage $V_{b i}$, the voltage $V$ and the total charge in the depletion region $\left(\mathrm{qN}_{\mathrm{A}}\right)$.

$$
w=\left[\frac{2 \varepsilon \varepsilon_{0}\left(V_{b i}-V\right)}{q N_{A}}\right]^{1 / 2}
$$

The following equation (3.6) is obtained from the combination of 3.4 and 3.5

$$
C=A\left[\frac{q N_{A} \varepsilon \varepsilon_{0}}{2\left(V_{b i}-V\right)}\right]^{1 / 2}
$$


The above equation is often expressed by the following form

$$
1 / C^{2}=\left[\frac{2}{q \varepsilon \varepsilon_{0} A^{2} N_{A}}\left(V_{b i}-V\right)\right]
$$

The carrier concentration and the built-in voltage, the important parameters for DLTS analysis, can be calculated from the slope of a 1/C2-V plot and the voltage intercept respectively. CV measurements were performed by using a Boonton 72B capacitance meter suitable to measure capacitance between $100 \mathrm{fF}$ and $3 \mathrm{nF}$. This meter has a high frequency $(1 \mathrm{MHz})$ sinusoidal measurement signal and one can use external power supply in the range of $10 \mathrm{~V}$ to $10 \mathrm{~V}$ for $\mathrm{CV}$ measurement.

\subsection{Deep Level Transient Spectroscopy measurements}

To determine the type and concentration of metal impurities in p-type silicon, Deep Level Transient Spectroscopy (DLTS), which is an experimental technique, developed by Lang (1974), with aluminum Schottky diodes was utilized. The standard DLTS setup used in this study was a computerized lock-in $1 \mathrm{MHz}$ DLTS system, including a lock-in amplifier as the correlator that used for deep level concentration measurement as previously described in details (Zoth, 1980).

To measure the transient capacitance, we used Boonton 72B capacitance meter. In addition, the lock-in amplifier is used to adjust the rate window. It is necessary to gate off the first $1-2 \mathrm{~ms}$ of the capacitance signal because of the $1 \mathrm{~ms}$ recovery delay time of the capacitance meter and the consequent overloading problems which occur when the filling pulse is applied. Furthermore, it is important to use the gating off-period control circuit and the sample-and-hold circuit (Blood and Orton, 1992) for a selected period to overcome baseline problems. Finally, the reference signal must be adjusted exactly in the middle of the gate-off signal.

Spectrum of DLTS is drawn by locating temperature versus the output signal of the lock-in amplifier. Maximum signal is obtained if the thermal emission rate is equivalent to the rate window of the lock-in amplifier (i.e. the reciprocal of the decay time constant approximates the lock-in frequency). The emission rates can be obtained by multiplying the lock-in frequency with a factor 2.36, a constant corresponding to correlation function (Khalil, 2004).

All spectra shown in this study have been measured at $5 \mathrm{~V}$ bias voltage, 4V pulse voltage; $17,85,261 \mathrm{~Hz}$ pulse repetition frequency and both filling 
Chapter 3. Experimental

pulse and recovery delay time of $100 \mu \mathrm{s}$. Under these conditions, the majority carrier defects i.e. hole traps, were recorded in the temperature range 50$300 \mathrm{~K}$. Calibrated platinum thermal sensor ( $\mathrm{Pt} 100$ ) next to the diode in the sample holder and a temperature controller are used for accurate temperature adjustment. 


\section{Results and Discussion}

This chapter is divided into four parts, firstly a description of CV characteristics at different stages of treatments. This is followed by the characterization of $\mathrm{FeB}$ pair in iron indiffused samples and subsequently the effects of different protocols of wet chemical etching. The interaction between hydrogen released from the wet chemical etching and iron, and its partial passivation of boron are discussed. The second part contains the detailed results obtained from aluminum gettering of iron in p-type $F Z$ silicon annealed at temperature range from $950-1100^{\circ} \mathrm{C}$. Gettering of iron is examined during different treatments of annealing. Simulated and experimental studies are performed to obtain a reliable segregation coefficient for iron. Some interesting properties of segregation coefficient are also discussed in regard to the phase diagram. In the third part, we briefly discuss a generalized belief that aluminum gettering injects vacancy. Clearly, the experimental data obtained from platinum and gold indiffusion was able to proof that aluminum gettering injects vacancies with homogenous depth profile. Finally, the last part of this chapter deals with the light-induced defects after aluminum gettering of iron doped samples. Particular attention will be given to the interaction of iron and vacancies released from aluminum gettering leading to a novel deep level produced under illumination namely FeD. The influence of experimental parameters such as iron concentration, anneal temperature, illumination time and possible association/dissociation of FeB are discussed. Detection of FeD by DLTS was firstly described in this study and currently a long discussion has been started about FeD components, importance, as well as its role in solar cell efficiency.

\subsection{Effect of wet chemical etching on iron-boron pair (FeB)}

\section{1.1 CV measurements}

All silicon samples have to be etched immediately before Schottky contact deposition. The etching process is essential to prevent metal contamination. However, by this process, the incorporation of hydrogen into sample surface is always unavoidable, and able to introduce an enough amount of atomic hydrogen (Sachse et al., 1997; Jost et al., 1996). It is not surprising that previous investigations which performed by using Schottky diodes have detected hydrogen related deep levels of transition metals-doped silicon. Therefore, we estimated the CV measurements at room temperature as well as $77 \mathrm{~K}$ to find out the effect of wet chemical etching. In this study, etching was performed using a mixture of hydrofluoric acid $(\mathrm{HF}, 40 \%)$, nitric 


\subsection{Effect of wet chemical etching on FeB}

acid $\left(\mathrm{HNO}_{3}, 65 \% ; 1: 7\right)$ for 20 and 100s. In addition, a cleaved sample was cleaned and forming the contacts directly onto the sample surfaces without any additional etching treatment. The cleaved samples are virtually free from hydrogen and are used as a reference.

From CV measurements, the capacitance at the DLTS reverse bias

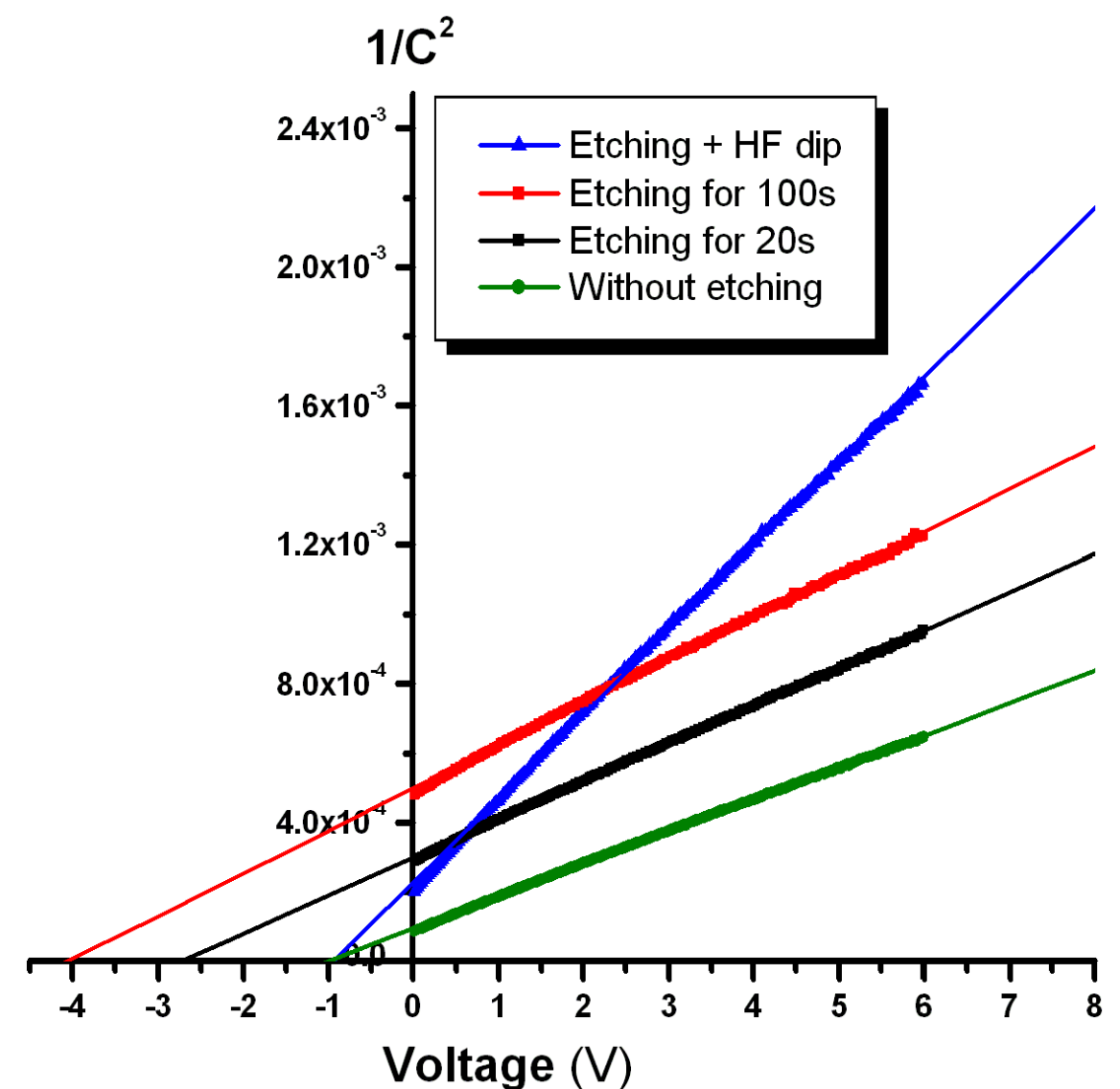

Figure 4.1: The capacitance-voltage measurement for Al/p-Si Schottky diodes showing the effect of wet chemical etching.

voltage, the built-in voltage and the shallow acceptor concentration were obtained. Figure 4.1 shows $\mathrm{CV}\left(\mathrm{C}^{-2}\right.$ plotted vs. V) an anomalous apparent barrier height. A built-in voltage in the range of $2-4 \mathrm{~V}$ has been observed after etching of the samples depending on the etching time. Note that all the etched substrates show the same behavior. The intercept gives the apparent built-in voltage which increased with longer etching time; however, the plot for the cleaved (without etching) specimen displayed a smaller barrier height. It is worth noting that the cleaved sample shows almost straight line. Normally, the slope of this line is corresponding to the boron concentration of our material. Similar phenomena have been observed by several authors (Adegboyega et al., 1989; Sullivan et al., 1993; Castaldini et al., 2002), and attributed to 
hydrogen passivation. Thus wet chemical etching introduces hydrogen into the sample surface leading to boron passivation which might explain the observed enhanced barrier height in our study.

It is not possible to measure lower concentration of hydrogen in silicon by the traditional analytical techniques. However, higher concentrations of hydrogen more than $10^{17} \mathrm{~cm}^{-3}$ are chemically detectable. Hydrogen passivation of boron is considered to be an indirect way to estimate hydrogen in silicon because it takes place at room temperature with high efficiency and diffuses deep in the sample (Sullivan et al., 1993). Accordingly, boron hydrogen pair is possibly formed in the area where hydrogen is diffused (Tavendale et al., 1988). Carrier depth profiles are necessary to investigate the incorporation of hydrogen in silicon samples. For example, previous studies have calculated boron depth profiles from the CV measurements after wet chemical etching, reporting a decrease on the surface of the sample as well as complete recovery of boron at $2.5 \mu \mathrm{m}$ depths as seen from figure 4.2 (Adegboyega et al., 1989; Castaldini et al., 2002). The boron passivation

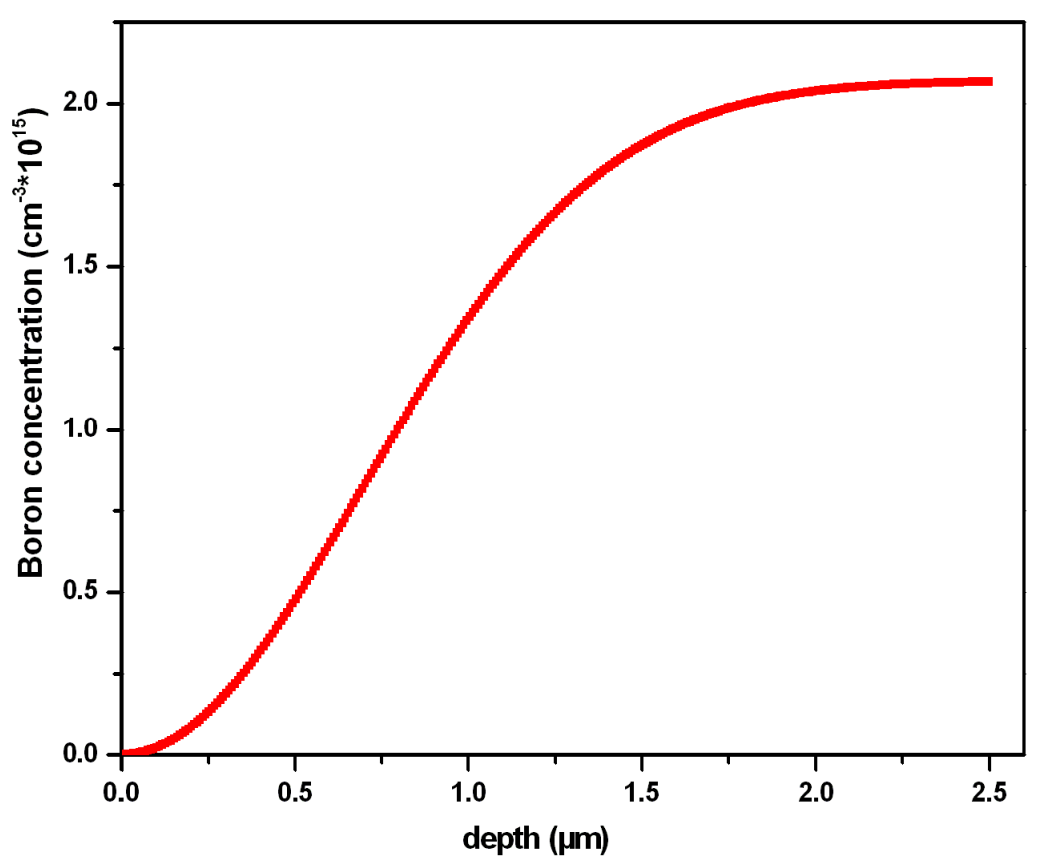

Figure 4.1: Boron concentration profiles evaluated from CV measurements after wet chemical etching of silicon wafers (Adegboyega et al., 1989; Castaldini et al., 2002).

increases with increasing the time of etching, reflecting the hydrogen profile incorporated from the surface. The longer the etching time, the more boron are passivated. It is generally believed that this decrease in boron is compensated by the formation of boron hydrogen pair and a rough estimate 
from the carrier concentration profiles of p-type samples gives a hydrogen concentration around $10^{15} \mathrm{~cm}^{-3}$ on the wafer surface (figure 4.2). However, other studies concluded that these calculations are insensitive and not quite accurate (Weber et al., 2003).

Most probably, the incorporation of hydrogen into silicon from wet chemical etching did not lead to damage of the surface (Tavendale et al., 1988); however, once free hydrogen is captured by boron forming the boron hydrogen pair, a neutral complex, which is able to change electrical properties of the material (Weber et al., 2003). Several previous studies have proposed different mechanisms for passivation of acceptors by hydrogen. The first mechanism depends mainly on the formation of neutral hydrogen acceptor complex such as $\mathrm{BH}$, as a result of the binding between the hydrogen positive ion and the negatively charged boron ion in p-type silicon (Sah et al., 1983). The second mechanism assumed a binding between hydrogen and one of the silicon atoms surrounding the boron. To support this assumption experimentally, a vibrational absorption band has been observed at $\sim 1870$ $\mathrm{cm}^{-1}$ of the IR spectra of hydrogenated p-type silicon sample, indicating that the atomic hydrogen is able to bind with one of the four silicon atoms to form Si-H (Pankove et al., 1985). To better understand the mechanism of hydrogen passivation, further investigations are warranted.

For conclusion, the deduction of the barrier height from $\mathrm{CV}$ measurements can be strongly influenced by surface passivation induced by wet chemical etching, and tends to provide higher values for the barrier height than the real one. In addition, our results indicate that wet chemical etching for 20 s at room temperature might cause considerable surface boron passivation. Similar results have been reported by previous studies (Adegboyega et al., 1989; Seager et al., 1987), suggesting that hydrogen passivation affects CV measurements of p-type substrate. Taken together, this study suggests that an etching period of about 15 s seems likely to be optimum for the production of good devices.

\subsubsection{DLTS measurements}

Figure 4.3 shows a series of DLTS scans at different frequency obtained by using a p-type FZ silicon wafer samples. A single DLTS line is observed at $55 \mathrm{~K}$, which is attributed to the $\mathrm{FeB}$ after iron indiffusion at $950^{\circ} \mathrm{C}$. We were not able to detect other lines, suggesting that our samples did not contain interstitial iron, $\mathrm{Fe}_{\mathrm{i}}$. The DLTS signals shifted towards the higher temperature as the frequency increased. The relationship between the position of DLTS line at different temperature and frequencies is required to 
determine the trap parameters. From the Arrhenius plot (inset) of $\ln \left(\mathrm{e}_{\mathrm{p}} / \mathrm{T}^{2}\right)$ versus $(1000 / T)$ according to the DLTS spectra in figure 4.2 , it is possible to produce both parameters for the DLTS line, where $\left(e_{p}\right)$ is the carrier emission rate and $T$ is the peak temperature. The slope of the line gives the activation energy $\left(E_{T}\right)$ of the carrier emission process, which is generally considered to

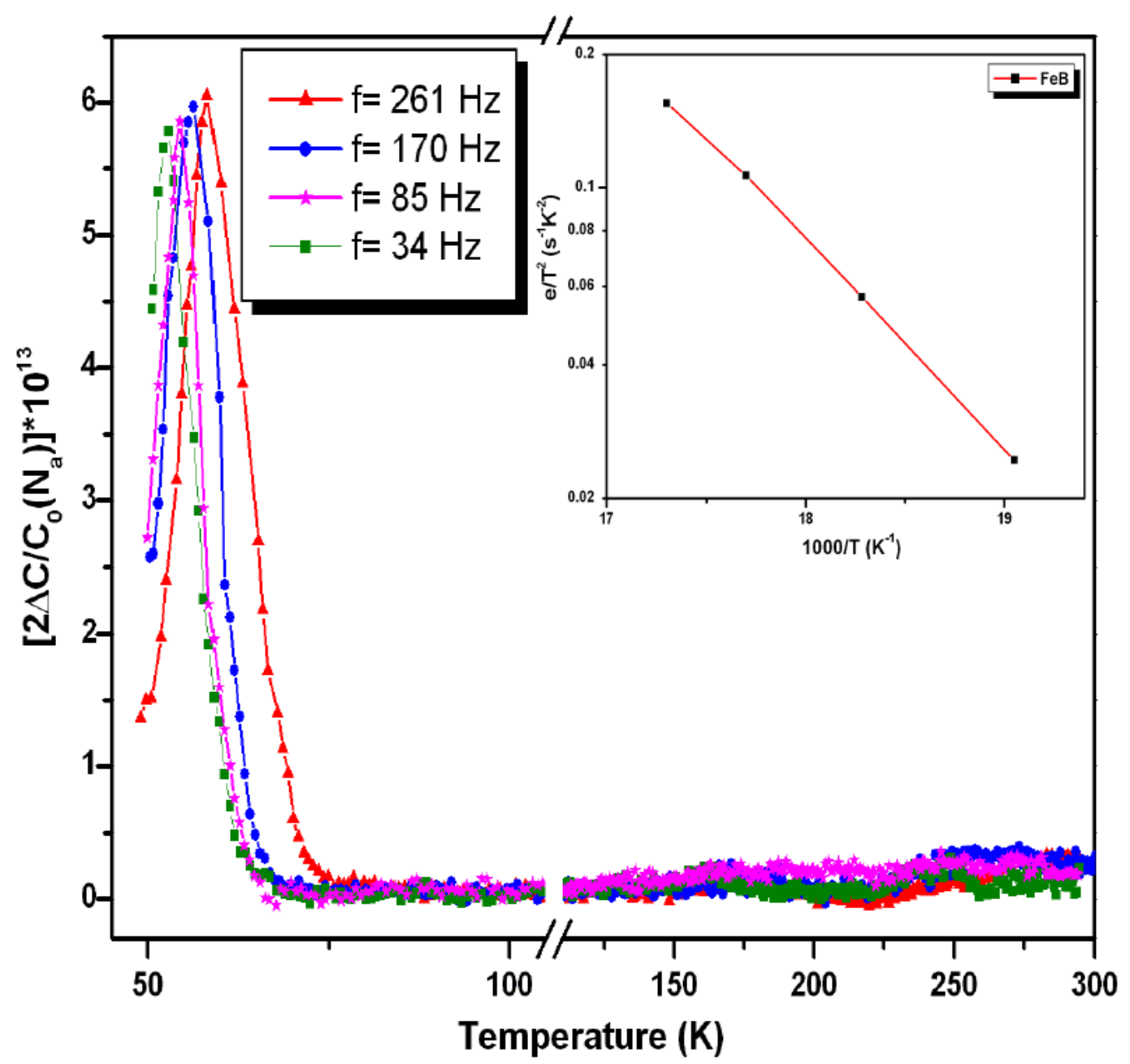

Figure 4.3: DLTS spectra were taken at different frequencies for iron-doped FZ ptype silicon. Iron diffused at $950^{\circ} \mathrm{C}$ for 60 minutes and samples were then stored in dark at room temperature for several days. Measuring conditions of DLTS: the filling pulse duration $t p=300 \mu \mathrm{s}$ and reverse bias $U_{B}=5 \mathrm{~V}$ and filling pulse bias $U_{P}=4.8 \mathrm{~V}$. Arrhenius plot (Inset) shows the thermal emission rates $\left(T^{2}\right.$ corrected) as a function of inverse temperature $(1000 / \mathrm{T})$ for FeB line.

be the location of the corresponding level from the band edge and its intercept which is usually expressed as an apparent cross-section, op. From the slope, an activation energy level of $\mathrm{E}_{\mathrm{T}}-\mathrm{E}_{\mathrm{V}}=0.097 \mathrm{eV}$ and a majority carrier capture cross section of $\sigma_{p}=2.4 \cdot 10^{-14} \mathrm{~cm}^{2}$ are extracted. These values are in a good accordance with the published values for FeB pair (Brotherton et al., 1985). Importantly, the capture cross section is calculated at infinite temperature and therefore should be considered as a rough estimation. 
In our experiment shown in figure 4.4 , the height of the voltage pulse is

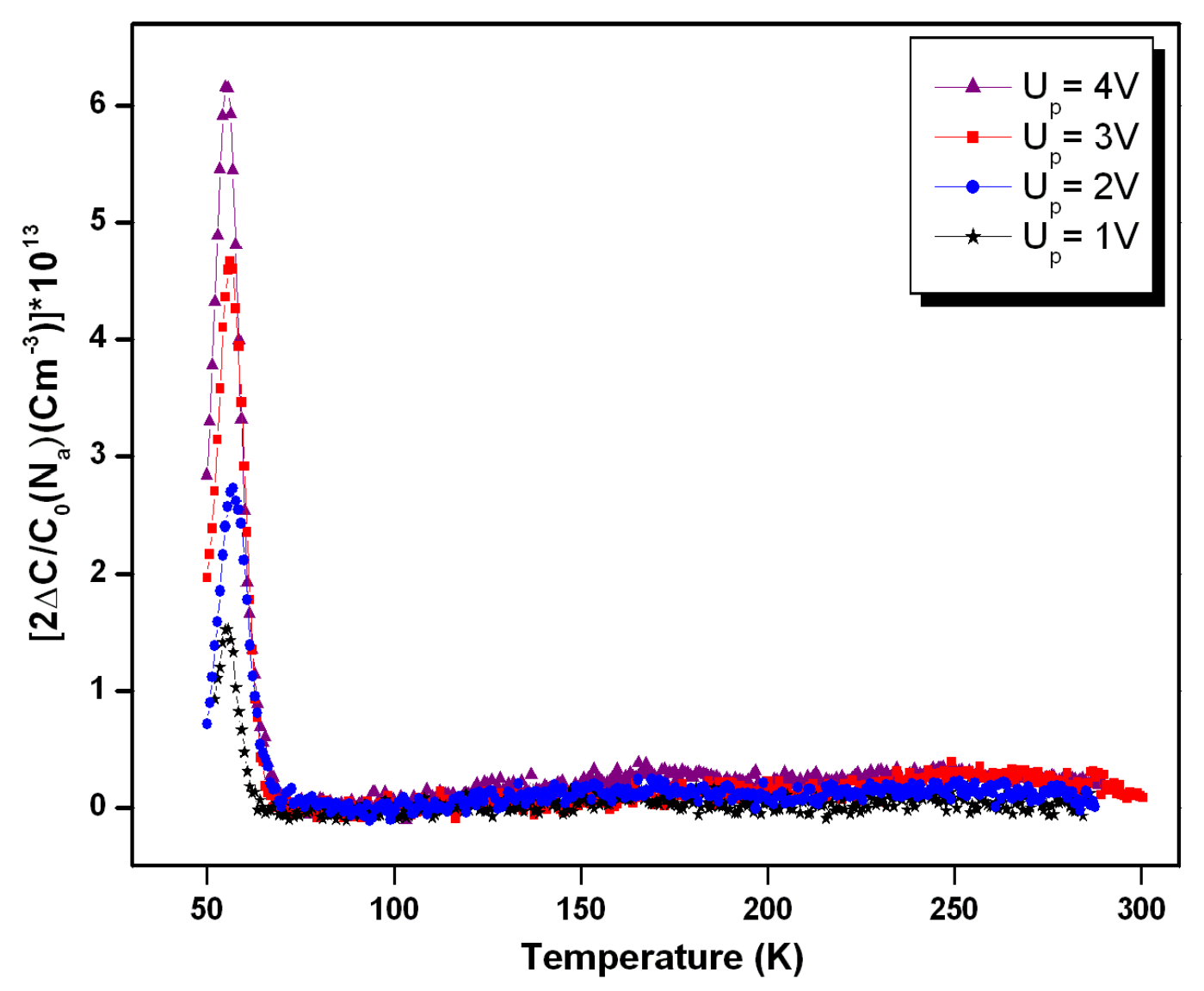

Figure 4.4: DLTS spectra of iron in silicon after indiffusion at $950^{\circ} \mathrm{C}$ for 60 minutes, recorded under different applied pulse voltage ( $1 \mathrm{~V}$ to $4 \mathrm{~V})$, the filling pulse duration $300 \mu \mathrm{s}$ at frequency $\mathrm{f}=85 \mathrm{~Hz}$ and the bias voltage $U_{B}=5 \mathrm{~V}$. The spectra show a dominant signal of iron as FeB pairs.

varied, and the reverse bias level is kept fixed. This is actually a method to determine concentration profiles of trap levels using DLTS (Blood and Orton, 1992). The amplitude of DLTS signal is increased with increasing the height of voltage pulse. A plot of the signal amplitude versus height of the voltage pulse therefore provides insight into a deep level concentration profile. To calculate the concentrations of iron, the DLTS spectra for every sample were measured and a FeB concentration was carefully calculated from DLTS data taking into account corrections coming from the effect of intersection of the defect level with Fermi level at the boarder of depletion region during emission period (Zohta and Watanabe, 1982).

The boron concentration of $F Z$ silicon wafer used in this study was The boron concentration of FZ silicon wafer used in this study was NB= $3 \cdot 10^{15} \mathrm{~cm}^{-3}$, while the concentration of iron, was mainly depending on indiffusion temperature ( $\left.T_{\text {ind }}\right)$ as well as time enough to achieve the 
equilibrium (see Table 4.1). Note, that concentration of iron in silicon measured by DLTS was close to the iron solubility measured by neutron activation analysis (NAA) (Weber, 1983). The ratio of iron (DLTS) / iron (NAA) was 0.89 for $\mathrm{T}_{\text {ind }}=1050^{\circ} \mathrm{C}, 0.88$ for $1000^{\circ} \mathrm{C}$ and 0.69 for $950^{\circ} \mathrm{C}$. However for $950^{\circ} \mathrm{C}$ the accuracy of NAA is already not high due to small iron concentration (about $10^{14} \mathrm{~cm}^{-3}$ ).

Table 4.1: Iron solubilities at different temperatures by NAA (Weber, 1983) and our DLTS measurements.

\begin{tabular}{|c|c|c|c|}
\hline $\mathrm{T}_{\text {ind }}\left({ }^{\circ} \mathrm{C}\right)$ & $\mathrm{C}_{\mathrm{Fe}}\left(10^{15} \mathrm{~cm}^{-3}\right) \mathrm{NAA}$ & $\mathrm{t}(\mathrm{min})$ & $\mathrm{C}_{\mathrm{Fe}}\left(10^{14} \mathrm{~cm}^{-3}\right) \mathrm{DLTS}$ \\
\hline 950 & 0.13 & 60 & 0.9 \\
\hline 1000 & 0.42 & 50 & 3.7 \\
\hline 1050 & 1.13 & 40 & 10.0 \\
\hline 1100 & 2.88 & 30 & Not measured \\
\hline
\end{tabular}

Figure 4.5 exhibits the etching time dependence of the FeB concentration. It can be observed that $\mathrm{FeB}$ concentration increases with decreasing etching time. The FeB values for the $45 \mathrm{~s}$ etched specimen is slightly higher than that of 70 s and 100 s etched samples. These lower relative values of $\mathrm{FeB}$ are probably connected with the higher hydrogen concentrations. Therefore, cleaved sample (without etching) did not expose to hydrogen penetration, displayed higher FeB concentration. It is difficult to achieve good diodes without etching because their quality becomes worse with time and care should be taken to clean interfaces to prevent leakage currents.

From our results, it is concluded that FeB concentrations extracted from the peak heights of the DLTS spectra are influenced by dilution of etching solutions. Figure 4.6 shows the effect of etching with different dilutions of $\mathrm{HF}: \mathrm{HNO}_{3}$ solutions on the $\mathrm{FeB}$ pair concentrations. The concentration of $\mathrm{FeB}$ increased gradually by decreasing the ratio of $\mathrm{HF}$ acid in the etching solutions. The ratio of HF (1:7) was the most aggressive producing the least FeB concentration. However, the cleaved sample without etching $(0: 0)$ displayed the highest concentration of FeB (figure 4.6, inset).

The results show that WCE is able to reduce the concentration of electrically active defects associated with iron impurities. Previous studies have been attributed the reduction in $\mathrm{FeB}$ concentration to the binding between iron and hydrogen in silicon (Kouketsu and Isomae, 1996). It has 
been demonstrated that positively charged iron could bind with the negatively charged boron forming FeB. An iron-boron pair, determined by our DLTS spectra, is electrically active and its level has been assigned as $E_{\mathrm{V}}+0.097 \mathrm{eV}$. This level is very close to the published FeB (Brotherton et al., 1985).

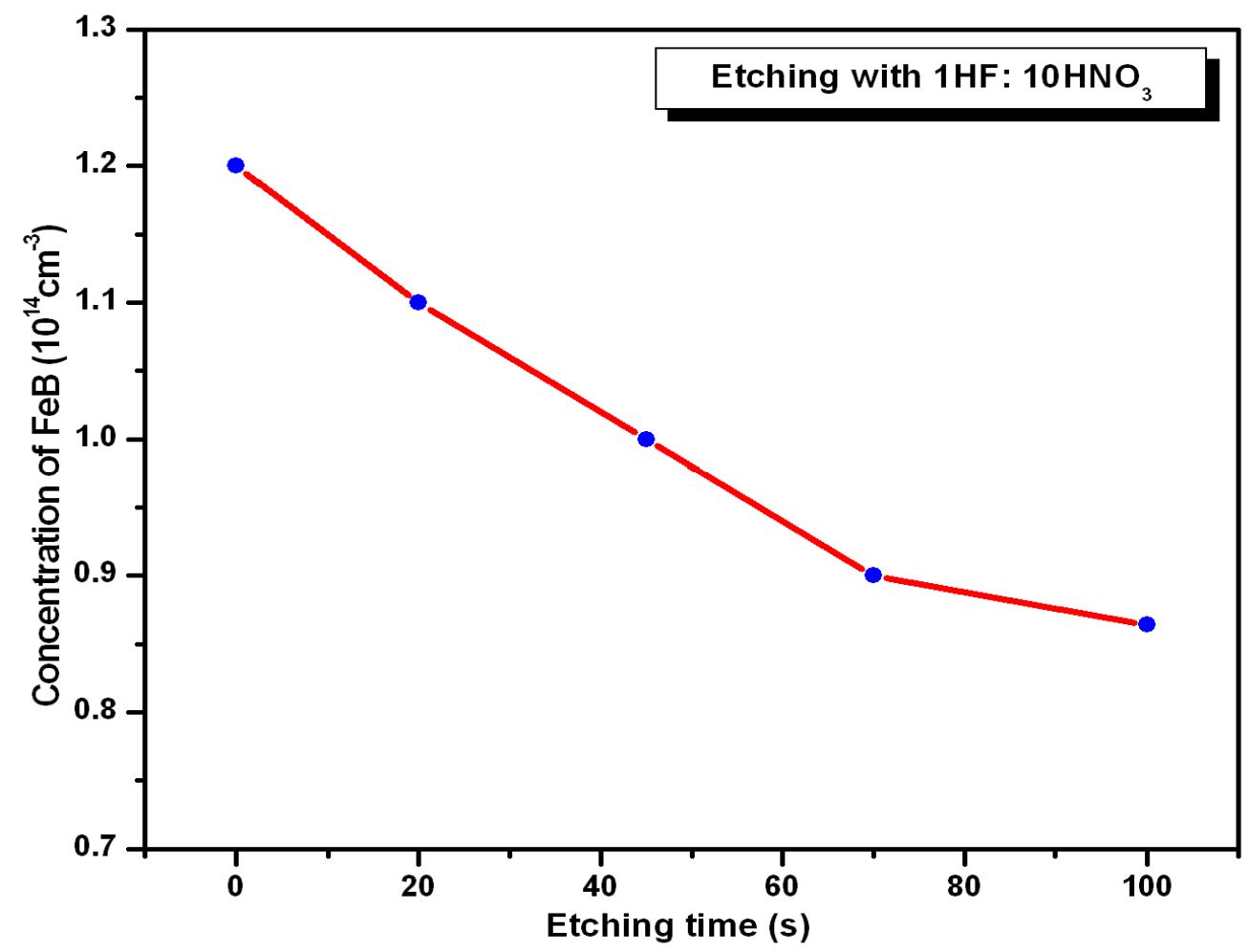

Figure 4.5: Etching-time dependence of FeB concentration in iron doped p-type silicon.

Moreover, this study was also successful to determine the concentration of FeB in cleaved and etched (20s) samples $(92.3 \%$ and $84.6 \%$ respectively of iron solubilities measured by NAA). This enable one to understand why previous studies found that the concentration of iron obtained by DLTS are 2 to 3 times lower than the values obtained by NAA (Weber, 1983; Istratov et al., 1999). During $\mathrm{WCH}$, a direct mechanism has been proposed that hydrogen ions diffuse and dissociate $\mathrm{FeB}$ pairs by forming $\mathrm{BH}$ pairs and generate $\mathrm{Fe}_{\mathrm{i}}$ (Yakimov and Parakhonsky, 1997; Feklisova et al., 2000; Tang et al., 2011), however, it is also surprising that these authors did not observe any iron-hydrogen-related deep levels.

All the data presented above provide clear evidence that hydrogen induced a decrease in the FeB deep level. A significant proportion of the boron concentration is neutralized in the surface region after wet chemical etching (Adegboyega et al., 1989; Castaldini et al., 2002). We find an almost identical behaviour of the etched samples with different dilutions of etchants 
and for different times. Taken together, a previous study reported that

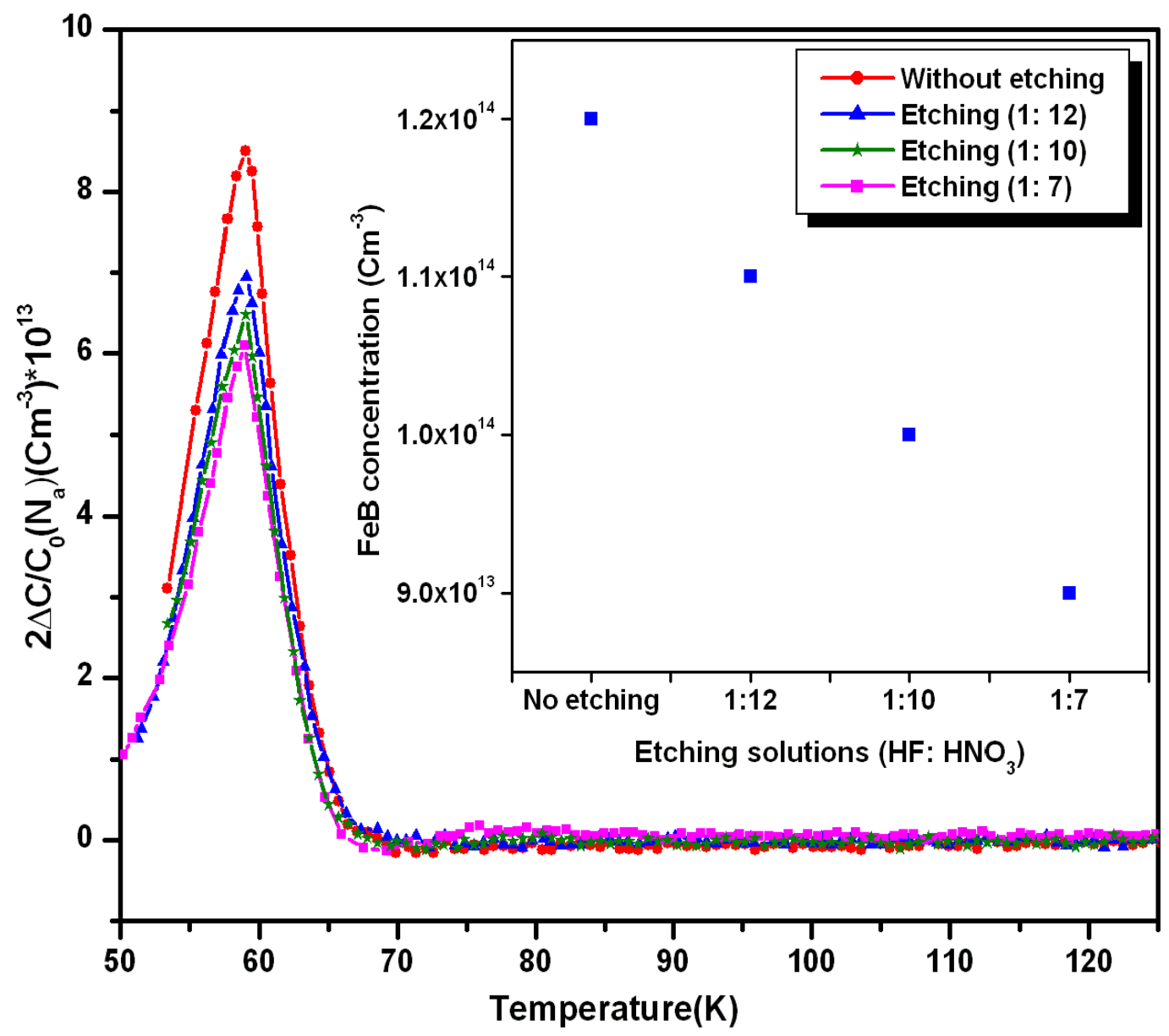

Figure 4.6: DLTS spectra of p-type iron-doped FZ silicon taken after 45s etching with different dilutions of $\mathrm{HF}: \mathrm{HNO}_{3}$ (1:7, squares; $1: 10$, stars; $1: 12$, triangles) and cleaved sample (without etching, circles) showed the highest peak at $59 \mathrm{~K}$. The calculated FeB concentrations are presented in inset. Lock-in correlation frequency $261 \mathrm{~Hz}$, reverse bias $5 \mathrm{~V}$, filling pulse voltage $4 \mathrm{~V}$, and filling pulse duration $100 \mu \mathrm{s}$.

hydrogen from WCE leads to release of $\mathrm{Fe}_{\mathrm{i}}$ and affecting $\mathrm{Fe}$ concentration detected by DLTS (Feklisova et al., 2000). Therefore, it was necessary to clarify the interaction between FeB and hydrogen. For this purpose, the most aggressive etching solution (1:7) was used to introduce more hydrogen into the samples that reveal the least concentration of FeB (figure 4.6). Theoretical research concerning iron-related defects in silicon was recently done by Sanati et al. (2007). In addition, they calculated the interaction between FeB and hydrogen. In most of their calculation, the $\mathrm{Fe}_{\mathrm{i}} \mathrm{H}$ pair is found to be at $\mathrm{E}_{\mathrm{V}}+0.36 \mathrm{eV}$ in the band gap. Experimentally, Sadoh et al., (1997) described a donor level related to $\mathrm{Fe}_{\mathrm{i}} \mathrm{H}$ at $\mathrm{E}_{\mathrm{V}}+0.31 \mathrm{eV}$ after wet chemical etching. Noticeably, both studies reported the formation of hydrogen and interstitial iron pair, suggesting that hydrogen is not able to passivate $\mathrm{Fe}_{\mathrm{i}}$. Note that 
addition of one more hydrogen atom to the $\mathrm{Fe}_{\mathrm{i}} \mathrm{H}$ pair might lead to its dissociation into $\mathrm{Fe}_{\mathrm{i}}$ and $\mathrm{H}_{2}$. Since no new defect levels are observed within our detection limit of the DLTS setup after hydrogen incorporation by wet etching, the formation of $\mathrm{Fe}_{\mathrm{i}} \mathrm{H}$ or $\mathrm{Fe}-\mathrm{B}-\mathrm{H}$ complexes, as predicted by Sanati et al. (2007), remains unlikely.

On the other hand, the data presented in this study on FeB levels are similar to the reported levels of FeB detected by DLTS (Istratov et al., 1999). By using another technique, Azzizi et al., (2004) measured lower FeB concentrations by factor of 3 in iron contaminated FZ wafer after SiNx coating, suggesting that iron might be a candidate to study hydrogen diffusion in silicon. Moreover, estimation of iron concentration by minority carrier diffusion length in the hydrogenated layer located on the surface of the sample was found to be lower by a factor of 3 compared to that measured in the remainder of the material (Dubois et al., 2006), indicating again the hydrogen passivation of iron related defects. It seems likely that formation of electrically active and passive complexes with hydrogen is a general property of iron related levels. Knowledge about hydrogen interaction with iron and iron-related complexes in $\mathrm{Si}$ is very poor especially that concerning transformation of iron related centers stimulated by hydrogen. Among the results obtained those demonstrating hydrogen passivates of some Fe related deep level centers (Pankove et al., 1983; Pearton and Tavandale, 1984; Kouketsu and Isomae, 1996). Using DLTS the latter authors observed an effective passivation of the FeB and Fe interstitial peaks. However, they found no experimental evidence of the existence of iron hydrides which would reduce the number of iron related hole traps.

To summarize, formation of iron hydrogen complexes has been demonstrated in silicon. Still under debate, the hydrogen passivation leading to neutralization of iron related traps. Our results show that wet chemical etching of Fe contaminated p-type Si leads to a decrease of electrically active FeB detected by DLTS. Based on these results, most probably hydrogen incorporation from wet chemical etching might be able to dissociate the FeB pairs, which associated with boron passivation on the surface of the sample. Unfortunately, such a process is difficult to verify. Understanding the mechanism of hydrogen interaction with iron related centers and the possible wet chemical etching-induced donor-like states in surface layer (Adegboyega et al., 1989) needs further investigations. 


\subsection{Aluminum gettering of iron in p-type silicon}

Due to several sources for metal contamination, there is a great possibility for metal impurities to get incorporated into solar cell materials especially during crystal growth and device processing. The amount of iron, as the most metal impurities found in solar cell feedstock, was found to be between $10^{14}$ and $10^{16} \mathrm{~cm}^{-3}$ in different silicon materials (Istratov et al., 2003b). Therefore, to produce solar cells with higher efficiency, it is necessary to remove these impurities by means of gettering. The main gettering techniques used for solar cell fabrication including phosphorus-diffusion and aluminum alloying were commonly used to minimize impurities in photovoltaic materials. Particularly, aluminum layer deposition followed by annealing above the eutectic temperature $\left(577^{\circ} \mathrm{C}\right)$ has been found to provide a gettering site during formation of a liquid Al-Si alloy. This Al alloy was considered to be a sink for metal impurities improving the efficiency of solar cell and device properties (Sundaresan et al., 1984; Verhoef et al., 1990a; Sana et al., 1994; Martinuzzi et al., 1995; Joshi et al., 1995). In addition, segregation of metal impurities has been demonstrated by the previous studies to be the main mechanism for Al gettering due to their higher solubility in Al-Si layer.

Unfortunately, the segregation coefficient is only studied so far for very little number of transition metals. Recently, few quantitative studies were performed to estimate the segregation coefficient as a main parameter affecting the gettering of metal impurities. Joshi et al., (1995) have determined a segregation coefficient of $10^{4}$, a value similar to that found earlier by Apel et al., (1994) for cobalt at $820^{\circ} \mathrm{C}$ gettering temperature. Mossbauer radioactive method was also used to determine the segregation coefficient for cobalt at different temperatures. For example, at $900^{\circ} \mathrm{C}$ the radiotracer measurement gave a value of about $6 \cdot 10^{5}$ (Sattler, 2002). However, a lower value of segregation coefficient $\left(10^{3}\right)$ was further determined by life time measurements for unknown contamination (Luque et al., 1996). A single trial to study the segregation coefficient for iron was done by Hieselmair et al., (1996). The authors used measurements of carrier diffusion length producing a segregation coefficient of about $5 \cdot 10^{5}$ at $950^{\circ} \mathrm{C}$ gettering temperature. The smaller values of segregation coefficient obtained at lower temperature were explained as a result of too short gettering time which was not enough for an equilibrium state. Therefore, to establish the equilibrium state and by using DLTS technique, this work was undertaken to determine a temperature dependent segregation coefficient for $\mathrm{Fe}$ and provides some quantitative characteristics for segregation mechanism. 
The general principle of all gettering techniques is to reduce the transition metal concentrations in the active layer or in silicon bulk. The reduced concentrations should be below the solubility concentrations depending on the gettering temperature. Furthermore, segregation coefficient, thickness of silicon and as well as thickness of aluminum layer were found to be important factors influencing the reduction of iron after aluminum gettering (Hieslmair et al., 1996). To fulfill these conditions and to test one or more of these hypotheses, we have quantitatively evaluated the reduction of iron concentration by aluminum gettering. A single-step gettering experiment was carried out by performing iron indiffusion and aluminum gettering at the same temperature $\left(\mathrm{T}_{\text {ind }}=\mathrm{T}_{\text {gett }}=1050^{\circ} \mathrm{C}\right)$. DLTS spectra measured in samples before and after aluminum gettering are shown in figure 4.7. As one can see from the spectra, only one DLTS line is detected at approximately $55 \mathrm{~K}$ with a

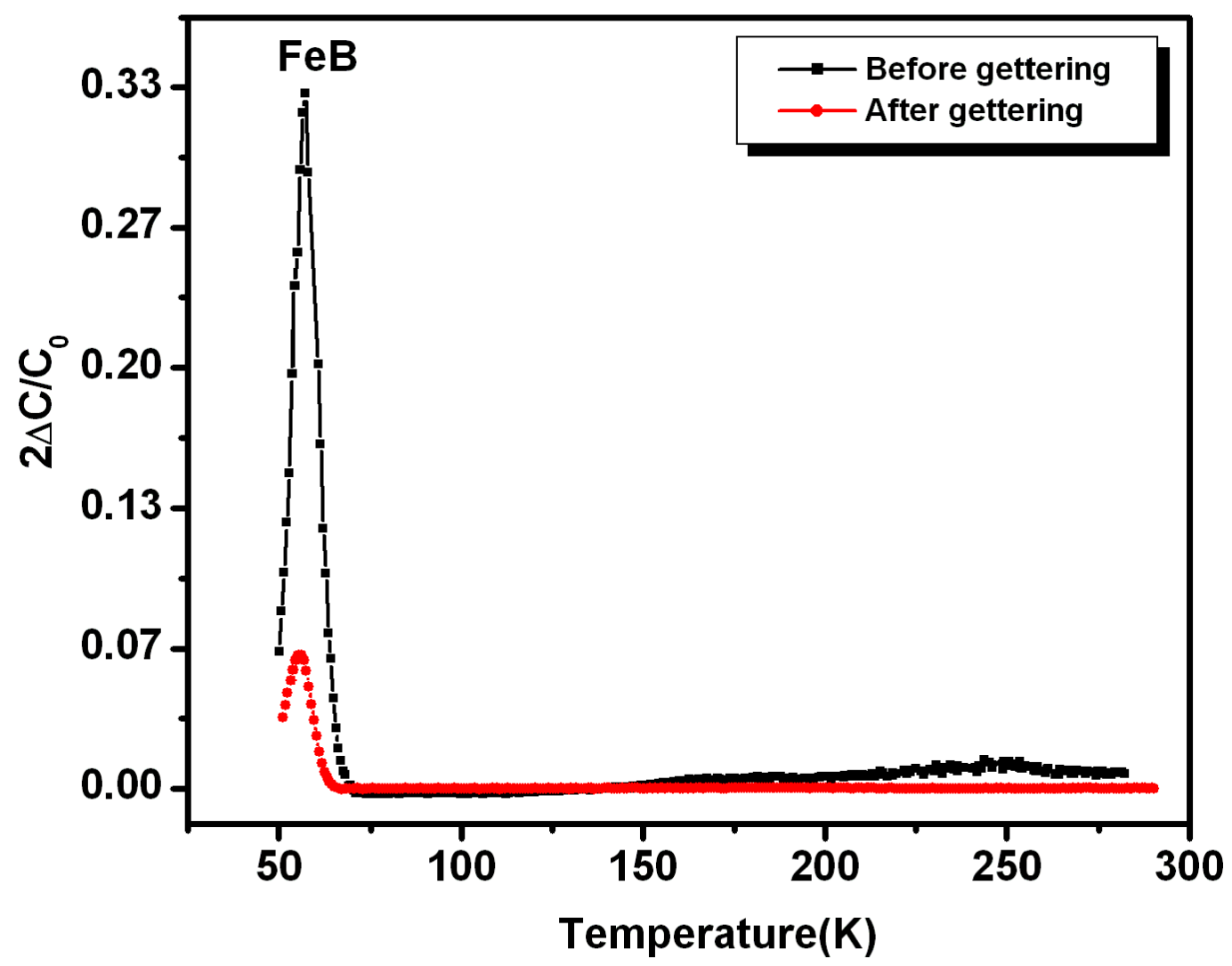

Figure 4.7: DLTS spectra of iron in silicon after indiffusion at $1050^{\circ} \mathrm{C}$ (square, black line) and after subsequent $\mathrm{AIG}$ at $1050^{\circ} \mathrm{C}$ (circle, red line); both high temperature treatments have been terminated by rapid quenching. Both spectra show iron as FeB pairs as the dominant signal. This figure was published by Abdelbarey et al., (2010).

calculated energy level at $E_{v}+0.097 \mathrm{eV}$ and corresponding to the FeB pairs. Note that a negligible amount of $\mathrm{Fe}_{\mathrm{i}}\left(\right.$ at $\left.\mathrm{E}_{\mathrm{v}}+0.39 \mathrm{eV}\right)$ could be observed at $250 \mathrm{~K}$ only in iron doped sample before gettering (black line) but not in 
samples subjected to aluminum gettering (red line). It is obviously clear that the concentration of FeB pair, the main electrically active form of iron, is reduced by more than one order of magnitude after aluminum gettering. It is noteworthy that figure 4.7 was previously published by Abdelbarey et al., (2010).

To get an accurate segregation coefficient, some conditions such as the equilibrium state of iron, path of equilibrium and the concentration of iron in silicon have to be considered. To be quite sure that we have established the equilibrium state of iron between silicon and gettering layer, gettering was performed for $50 \mathrm{~min}$ which is considered to be enough to reach the equilibrium. To fulfill these optimum conditions, we input our measured value

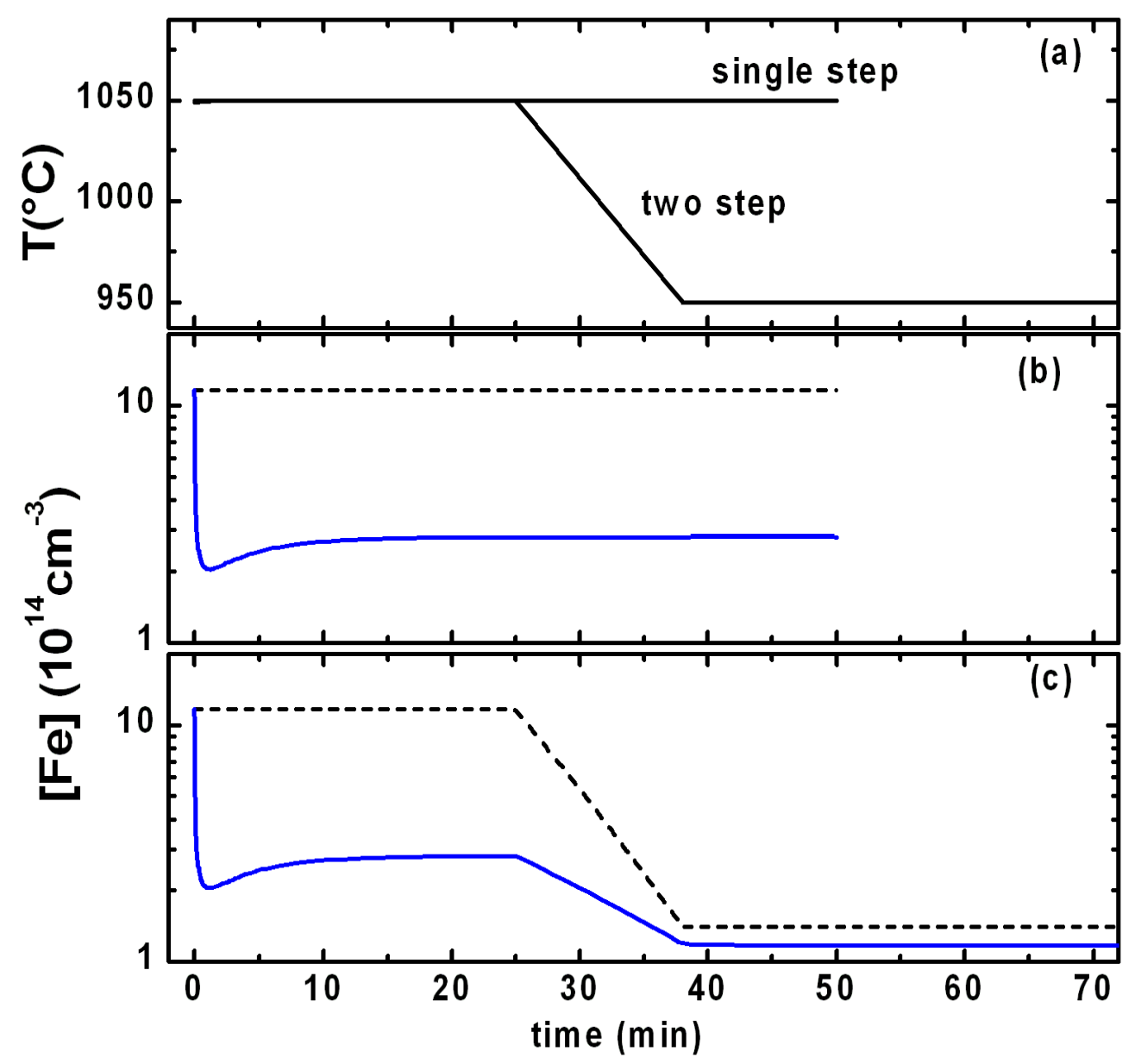

Figure 4.8: Simulation of AIG of Fe using the experimentally determined segregation coefficient. (a) temperature-time history shows single- and two-step gettering at $1050^{\circ} \mathrm{C}$. (b) One-step gettering at $1050^{\circ} \mathrm{C}$ for $50 \mathrm{~min}$. It should be noted that the final concentration has been reached within $2 \%$ after $15 \mathrm{~min}$. (c) Two-step gettering consisting of $\mathrm{AIG}$ at $1050^{\circ} \mathrm{C}$ for 25 min followed by ramping to $950^{\circ} \mathrm{C}$ within 13 min and final AIG there for another $35 \mathrm{~min}$. Solid lines (blue) show the Fe concentration at a depth of $25 \mu \mathrm{m}$; dashed lines show the $\mathrm{Fe}$ solubility in equilibrium with $\alpha-\mathrm{FeSi}_{2}$ according to Weber (1983). Part of this figure was published by Abdelbarey et al., (2009). 
of segregation coefficient into the simulation program of aluminum gettering to check the experimental conditions. Since the segregation coefficient is used as an input for such simulations one has to start from an initial guess and use simulations and experiments iteratively until self-consistent results are obtained.

To confirm the value of segregation coefficient obtained from one step gettering, another set of two-step gettering experiments were performed. Firstly, we used the measured value of segregation coefficient to produce simulation for one and two-step aluminum gettering of iron. Figure 4.8 (a) shows the temperature-time history profile at $1050^{\circ} \mathrm{C}$ for one step and two step gettering. To avoid precipitate formation during one step gettering, the indiffusion and gettering temperature were equal to each other and the gettering time was $50 \mathrm{~min}$. According to our AIG computer simulation and calculation of other studies (del Cañizo and Luque, 2000), the gettering time is sufficiently long to establish the equilibrium between iron concentration in a $\mathrm{Si}$ sample and in a liquid Al-Si alloy. A sharp decrease of iron concentration compared with its initial value has been observed after aluminum gettering (blue line in figure 4.8 (b)). Note that $15 \mathrm{~min}$ was enough to reach the final concentration of iron, indicating that the equilibrium is established under these conditions. Figure 4.8 (c) shows the two-step gettering consisting of aluminum gettering at $1050^{\circ} \mathrm{C}$ for 25 min followed by ramping down to $950^{\circ} \mathrm{C}$ within 13 min and final gettering there for another $35 \mathrm{~min}$. As one can see that the concentration of iron did not exceed its solubility (dashed line) measured by NAA analysis (Weber, 1983) during the gettering time. This means that our experimental conditions were successfully chosen to prevent precipitate formation. It should be mentioned that AIG simulations are carried out assuming that no kinetic barrier is involved in the incorporation of $\mathrm{Fe}$ into $\mathrm{Si}: \mathrm{Al}$ liquid, i.e kinetics of aluminum gettering was found to be limited by the diffusion of metal in silicon (del Cañizo and Luque, 2000; Kveder et al., 2000). This has also been further experimentally verified for cobalt (Sattler, 2002; Seibt et al., 2006).

The main important parameter for practical use of AIG is the segregation coefficient " $S$ ". $S$ is the ratio between iron concentration in a liquid $\mathrm{Al}: S i$ layer and a residual iron concentration in silicon sample after AIG. The segregation coefficient $S$ of iron between silicon and aluminum is given by

$$
S=\frac{[F e]_{A l: S i, g e t t}}{[F e]_{S i, g e t t}}
$$


Where $[\mathrm{Fe}]_{\mathrm{S} i \text {,gett }}$ is the concentration of iron in silicon after aluminum gettering measured by DLTS. [Fe] $]_{\text {AlSi,gett }}$ is the concentration of iron in Al-Si gettering layer calculated from the conservation of iron atoms. This assumption was also found to be valid in previous aluminum gettering experiments of cobalt in silicon (Sattler et al., 2004; Seibt et al., 2006).

For completeness and easy comparison with published data, figure 4.9 also includes the same data presented as the apparent segregation coefficient $S^{*}$ typically used for practical purposes. It is given by

$$
S^{*}=\frac{[F e]_{S i, \text { ind }}-[F e]_{S i, \text { gett }}}{[F e]_{S i, \text { gett }}} \cdot \frac{d_{S i}}{d_{A l}}
$$

where $d_{A l}$ is the thickness of the Al layer deposited at room temperature. However, for scientific discussion it is better to calculate segregation factor $S_{\text {at }}$ using atomic concentration of $\mathrm{Fe}$ in a liquid $\mathrm{Al}: \mathrm{Si}$ alloy which actually works as a gettering layer, taking into account variation of atomic fraction of $\mathrm{Si}$ in the alloy with temperature from 0.4 at $950^{\circ} \mathrm{C}$ to 0.5 at $1050^{\circ} \mathrm{C}$. The $\mathrm{S}^{*}$ is related to the 'true' segregation coefficient $S$ as

$$
\frac{S^{*}}{S}=\frac{\rho_{A l}}{\chi \rho_{S i}}=1.2 \frac{1}{\chi}
$$

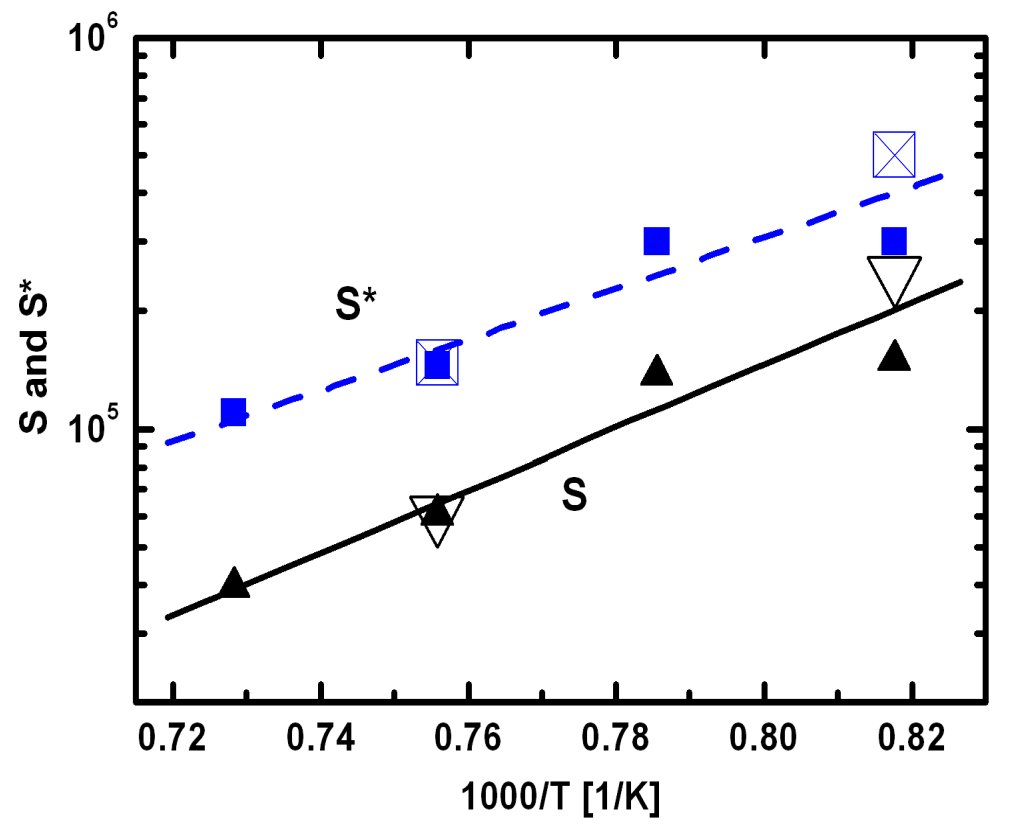

Figure 4.9: Arrhenius plots of the segregation coefficient $S$ (triangles) and the apparent segregation coefficient $S^{*}$ (squares). Open and closed symbols refer to single-step and two-step gettering, respectively. Solid and dashed lines show least-square fits of the respective data which yield $S=0.056$ $\exp \left(1.59 \mathrm{eV} / \mathrm{k}_{\mathrm{B}} \mathrm{T}\right)$ and $\mathrm{S}^{*}=1.87 \exp \left(1.29 \mathrm{eV} / \mathrm{k}_{\mathrm{B}} \mathrm{T}\right)$, respectively. This figure was published by Abdelbarey et al., (2009). 


\subsection{Aluminum gettering injects vacancy}

where $\mathrm{x}$ is the (temperature-dependent) atomic fraction of $\mathrm{Si}$ in the AISi liquid, $\rho_{\mathrm{Al}}=6 \cdot 10^{22} \mathrm{~cm}^{-3}$; the atomic density of $\mathrm{Al}$ and $\rho_{\mathrm{Si}}=5 \cdot 10^{22} \mathrm{~cm}^{-3}$; the atomic density of Si.

Figure 4.9 shows the Arrhenius plot of $S$ (triangles) together with a linear fit (solid line). Solid symbols refer to single-step gettering with $T_{\text {ind }}=T_{\text {gett }}$ where $\mathrm{Fe}$ atoms are present in the $\mathrm{Si}$ as a solid solution of $\mathrm{Fe}_{i}$ throughout the gettering process. Open symbols refer to two-step gettering and yield the same segregation coefficients as the single-step gettering which corroborates the conclusion that equilibrium has been established experimentally and that $\mathrm{S}$ is independent of the Fe concentration in $\mathrm{Si}$.

For comparison, figure 4.10 illustrates segregation coefficients of iron and cobalt. The value of segregation coefficients for $\mathrm{Fe}$ at $950^{\circ} \mathrm{C}$ was in a good agreement with that previously published by Hieslmair et al., (1996). It should be noted that the data of Hieslmair et al., (1996) for Fe showed a

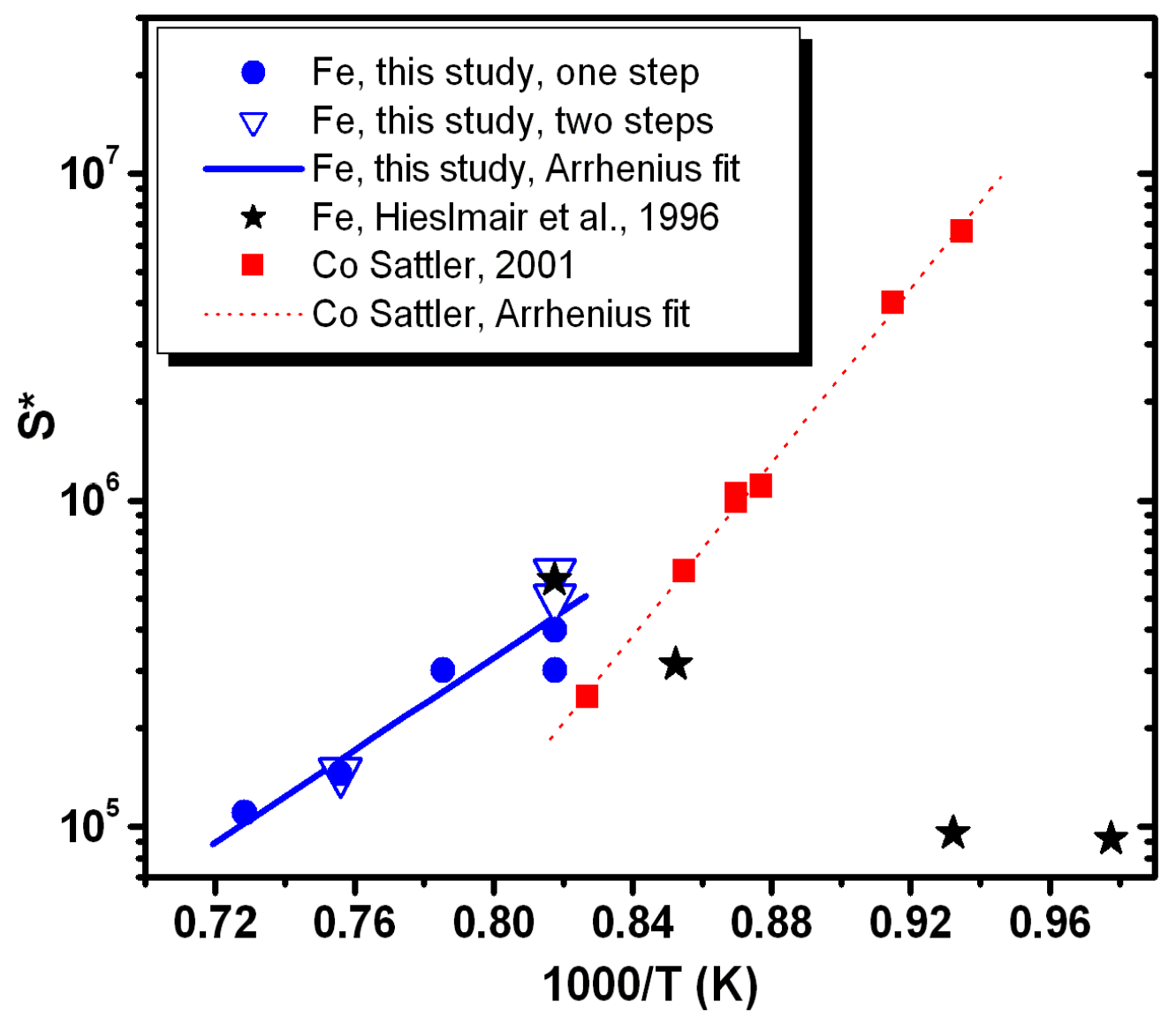

Figure 4.10: Comparison between values of segregation coefficients published in recent studies. References are specified in the text. Red indicates cobalt (Co), blue circles and triangles indicate iron (Fe, this study) and black stars iron data obtained from Hieslmair et al., 1996).

wrong temperature dependence which the authors take as evidence that 


\section{Chapter 4. Results and discussion}

equilibrium has not been reached in their experiments, especially at lower gettering temperature. Importantly, the segregation coefficient of cobalt at the same temperature was also found to be in the range of $10^{5}$. These results suggest that the segregation coefficient increases with decreasing the temperature due to the higher solubility of metal impurities in silicon compared to alloy at high temperature.

By using the solubility values extracted from binary phase diagrams at $1000^{\circ} \mathrm{C}$ to estimate the segregation coefficient of iron i.e. the ratio of iron concentration in the liquid $\mathrm{Al}: \mathrm{Si}$ to that in the solid silicon, values of about $10^{7}$ are calculated for iron. The iron solubility in $\mathrm{Si}$, in equilibrium with $\alpha-\mathrm{FeSi}_{2}$ is $4 \cdot 10^{14} \mathrm{~cm}^{-3}=8 \cdot 10^{-7}$ at. \% (Weber, 1983) and 8 at. \% in the binary (Al:Fe) melt. A calculated value of about $10^{7}$ is obtained while the measured $S \approx 1.5 \cdot 10^{5}$ which is smaller than the calculated value by two order of magnitude.

$$
\mathrm{S}=\frac{[\mathrm{Fe}]_{\mathrm{AlSi}}^{\mathrm{eq}}}{[\mathrm{Fe}]_{\mathrm{Si}}^{\mathrm{eq}}} \approx \frac{8 \text { at. } \%}{8 \cdot 10^{-7} \text { at. } \%} \approx 1 \cdot 10^{7}
$$

Experimentally, HiesImair et al., (1996) found segregation coefficients of $10^{5}$ $10^{6}$ for $\mathrm{Fe}$ at temperatures from $750^{\circ} \mathrm{C}$ to $950^{\circ} \mathrm{C}$. We have also quantitatively evaluated the temperature dependence of the segregation coefficient for $\mathrm{Fe}$ gettering reaction by $\mathrm{Al}$ alloy between 950 to $1100^{\circ} \mathrm{C}$. Our results show values between $4 \cdot 10^{4}$ and $2.5 \cdot 10^{5}$. Indeed, these values are also smaller than that the estimated values from the binary phase diagram. Taken together, the experimental values of segregation coefficient obtained from this study and others, for iron or even for cobalt are not in accordance with the estimated ones from binary phase diagram (Hieslmair et al., 1996; Sattler, 2002). As a result, this study suggests that there is a huge discrepancy between measured and calculated values of segregation coefficient that might be inconvenient for simulation programs (del Cañizo and Luque, 2000; Kveder et al., 2000; Hieslmair et al., 2001) which mainly designed to enhance gettering efficiency of solar cells.

To find possible reasons for the significant discrepancy between the estimates of $\mathrm{S}$ from the binary Al:Fe and Si:Fe phase diagrams and our data, one may consider modifications expected from the ternary character of Al:Si:Fe phases involved in aluminium gettering. In the literature an isothermal section of the ternary (Al:Si:Fe) phase diagram is available for $1000^{\circ} \mathrm{C}$ which is in the temperature range of our experiment (Rivlin and Raynor, 1981). It shows that the maximum content of $\mathrm{Fe}$ in the ternary melt is 18 at. \%, in equilibrium with $\alpha-\mathrm{FeSi}_{2}$ : $\mathrm{Al}$ (see figure 4.11), where $\alpha-\mathrm{FeSi}_{2}$ : Al refers a solid 
solution of $\mathrm{Al}$ in $\alpha-\mathrm{FeSi}_{2}$. At the same time, the solubility of $\mathrm{Fe}$ in $\mathrm{Si}$, determined as concentration of $\mathrm{Fe}$ in $\mathrm{Si}$ in equilibrium with $\alpha-\mathrm{FeSi}_{2}$ is about $8.10^{-7}$ at. $\%$ also at $1000^{\circ} \mathrm{C}$. Again by including parameters obtained from the ternary phase diagram, the segregation coefficient $\left(2.2 \cdot 10^{7}\right)$ is about 100 times higher than the experimental value. With this modification, the estimated value of $S$ increases and the discrepancy to our data becomes larger.

$$
\mathrm{S}=\frac{[\mathrm{Fe}]_{\mathrm{Al}: \mathrm{Si}: \mathrm{Fe}}^{\mathrm{eq}}}{[\mathrm{Fe}]_{\mathrm{Si}}^{\mathrm{eq}}} \approx \frac{18 \text { at. } \%}{8 \cdot 10^{-7} \text { at. } \%} \approx 2.2 \cdot 10^{7}
$$

It seems likely that the main reason for this discrepancy is that the Fe solubility in $\mathrm{Si}$ was measured as $\mathrm{Fe}$ concentration in $\mathrm{Si}$ in equilibrium with undoped $\alpha-\mathrm{FeSi}_{2}$, while the solubility of $\mathrm{Fe}$ in liquid $\mathrm{Al}: \mathrm{Si}: \mathrm{Fe}$ is calculated in equilibrium with $\alpha-\mathrm{FeSi}_{2}$ doped with aluminum.

Another evidence supporting our hypothesis is the solubility of $\mathrm{Al}$ in $\alpha$ $\mathrm{FeSi}_{2}$ which found in literature to be between 0.5 and up to 10 at.\% (Rivlin and Raynor, 1981). This wide range suggests that there is a significant solubility of $\mathrm{Al}$ in crystalline $\mathrm{FeSi}_{2}$ and the incorporation of $\mathrm{Al}$ into crystalline $\mathrm{FeSi}_{2}$ changes dramatically its properties. Unfortunately, the properties of $\mathrm{FeSi}_{2}$ doped by $\mathrm{Al}$ are not well investigated. However, it was shown that doping of $\mathrm{FeSi}_{2}$ by $\mathrm{Al}$ (from 0 to 6 at.\%) indeed strongly influence many of its physical properties, including its magnetic susceptibility and lattice parameters (Szymański et al., 1996).

By using our measured S value and applying in equation (4.5), then we got a solubility of iron in solid silicon of about $1016 \mathrm{~cm}-3$ which is larger by two orders of magnitude than solubility of iron measured in equilibrium with undoped $\alpha-\mathrm{FeSi}_{2}$ indicating that the chemical potential should be increased by $0.5 \mathrm{eV}$.

$$
\begin{aligned}
& {[\mathrm{Fe}]_{S i}^{e q}=\frac{[\mathrm{Fe}]_{\mathrm{Al}: \mathrm{Si}: \mathrm{Fe}}^{\mathrm{eq}}}{\mathrm{S}} \approx \frac{18 \text { at. } \%}{1.5 \cdot 10^{5}} \approx 1.2 \cdot 10^{-6}=6 \cdot 10^{16} \mathrm{~cm}^{-3}} \\
& c_{\mathrm{Fe}}^{\left(e q, F e S i_{2-x} A l_{x}\right)} \approx 6 \cdot 10^{16} \mathrm{~cm}^{-3}>c_{\mathrm{Fe}}^{\left(e q, F e S i_{2}\right)} \approx 4 \cdot 10^{14} \mathrm{~cm}^{-3}
\end{aligned}
$$

Assuming that our hypothesis is acceptable, one should expect that the iron concentration might be higher than its solubility at the corresponding 
temperature. Consequently, it is possible to generate $\alpha-\mathrm{FeSi}_{2}$ precipitates in $\mathrm{Si}$ bulk during $\mathrm{Fe}$ indiffusion from $\mathrm{a}-\mathrm{FeSi}_{2}: \mathrm{Al}$. Although this mechanism of precipitate formation has been verified experimentally by TEM investigation (Schwager, 2011), the iron supersaturation in undoped silicon could be varied at a given temperature by changing the composition of the ternary liquid.

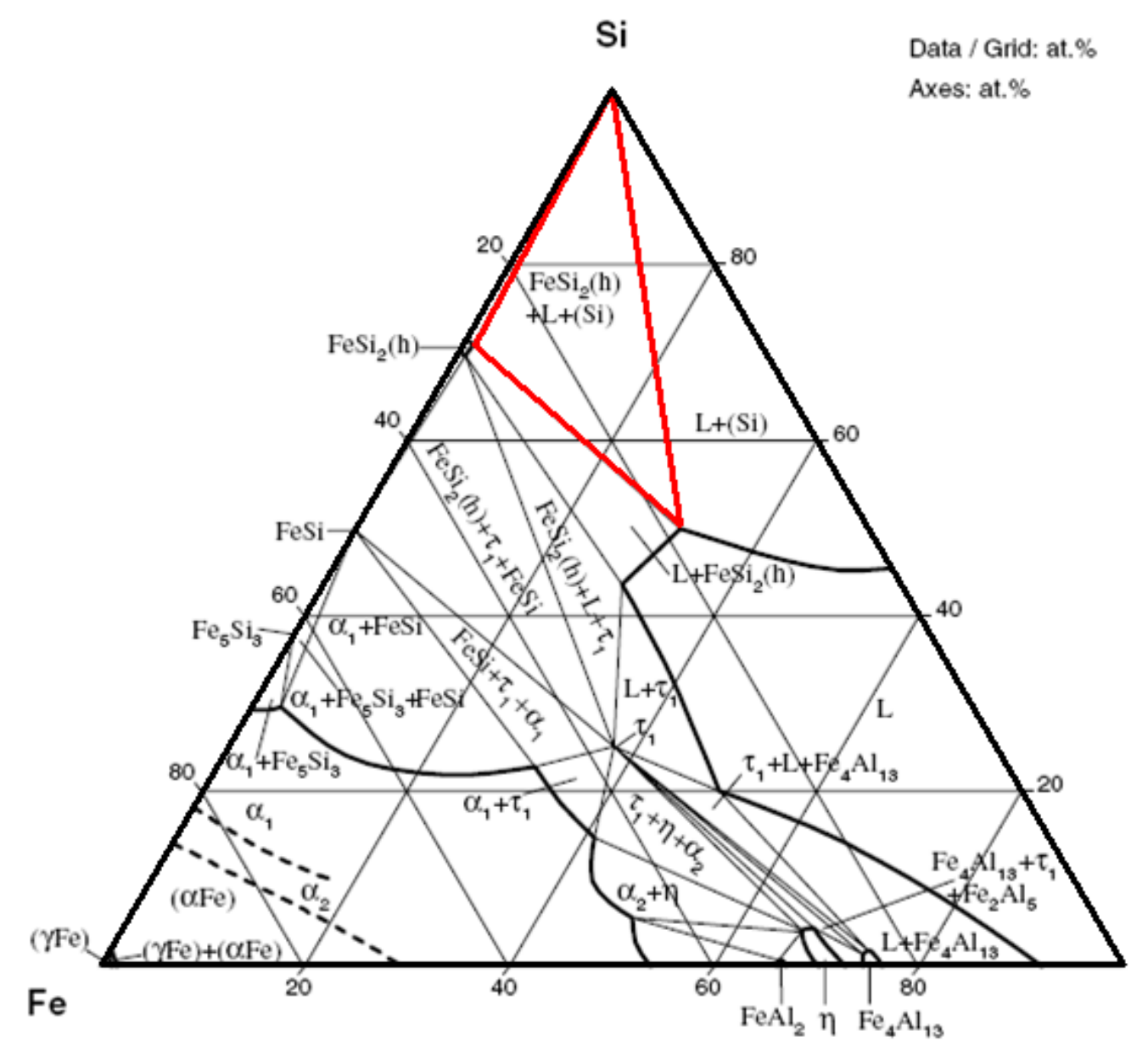

Al

Figure 4.11: Al-Fe-Si ternary phase diagram: isothermal section at $1000^{\circ} \mathrm{C}$ is taken from Rivlin and Raynor (1981).

To summarize this part, the segregation coefficient of iron is measured by using DLTS in the temperature range between 950 and $1100^{\circ} \mathrm{C}$ in Al:Si:Fe. A quantitative temperature dependent segregation coefficient which is the most important physical quantity describing aluminum gettering used in silicon photovoltaics, was observed and their values are smaller than that estimated from the binary phase diagram by two orders of magnitude. This discrepancy in the segregation coefficient originate from the ternary character of the system since the solubility of iron in silicon with respect to $\alpha-\mathrm{FeSi}_{2}: \mathrm{Al}$ is not available so far. Our hypothesis suggests that the existing Al amount could influence its chemical potential in the $\alpha-\mathrm{FeSi}_{2}: \mathrm{Al}$. 
Due to lack of experimental data, simulation models are widely used to estimate the effect of different parameters of aluminum gettering on solar cell efficiency (Hieslmair et al., 2001). Although the concepts and mechanisms of gettering are heavily studied, more questions marks still need to be answered. A unique predictive model, depending on measured experimental data, to optimize the solar cell performance is required to modify the existing gettering process that could be helpful to eliminate specific metal contaminant like iron. For example, recently measured segregation coefficients of iron in liquid $\mathrm{Al}: \mathrm{Si}$ with respect to crystalline silicon (Abdelbarey et al., 2009) are used in order to accurately estimate the limiting factors of aluminum gettering, predicting that at high temperatures the kinetics of AIG is mainly limited by metal impurity diffusion (Falkenberg et al., 2010). 


\subsection{Aluminum gettering injects vacancies}

The main target of photovoltaics manufacturing is to produce solar cells with higher efficiency and sustainable electrical properties. Such electrical properties are normally degraded by introduction of different metal impurities like $\mathrm{Fe}, \mathrm{Cu}$ and $\mathrm{Ni}$ during the processing steps. Therefore, different gettering like phosphorus diffusion and aluminum alloying as well as passivation steps are included into the currently production line. All these steps have recently considered being essential to getter metallic contamination and to improve material quality. For AIG, previous studies have been mainly focused on the redistribution of metal impurities from the silicon bulk to the Al-Si melt layer due to their high solubility in the Al-Si melt (Apel et al., 1994; Sattler, 2002; Verhoef et al., 1990b). On the other hand, little attention has been drawn so far to the possible generation of non-equilibrium intrinsic defects caused by the presence of Al-Si layer at the surface during AIG. Indeed, it has been demonstrated that AIG injects vacancies (Sopori et al., 1996; Rohatgi et al., 2002) that leads to more passivation of the extended defects and impurities (Debois et al., 2006; 2007; 2009). It is also proposed that simultaneous injection of vacancies from AIG together with hydrogen migration from SiN-H film leads to deep penetration of hydrogen ions into the silicon bulk, suggesting that vacancies enhances dissociation of molecular hydrogen (Estreicher et al., 1999). Such synergistic interaction was found to depend mainly on the generation of vacancies at the aluminum silicon surface, the rate of dissociation of molecular hydrogen by vacancies and the diffusion of hydrogen ions in the silicon. As a result of increasing hydrogen ions in the bulk and according to the model suggested by Jeong et al., (2000) the interaction of hydrogen with vacancies enhanced hydrogen diffusion leading to increased defect passivation and minority carrier life time.

The intrinsic point defects have an important role in defect agglomeration in silicon such as dislocation loops and vacancy complexes. Vacancies cannot survive long time at room temperature, so we obviously have them in a form of some complexes like $\mathrm{VO}, \mathrm{VO}_{2}, \mathrm{~V}_{2}, \mathrm{VH}_{\mathrm{n}}$ (Falster et al., 2000). Currently, there is a considerable clear picture about vacancy complexes in silicon, however, great differences between their basic parameter values such as diffusivities and equilibrium concentrations is still found in the literature (Voronkov and Falster, 2002). Although there is no direct evidence that AIG inject vacancies up to now, a single trial to determine vacancy concentrations by platinum diffusion was done by Karg et al., (2003). The authors have reported no indication that vacancies are formed or annihilated during Al alloying of Edge-defined Film-fed Growth (EFG) silicon. 
Therefore, this study was undertaken to measure experimentally the concentration of vacancies with and without AIG in FZ silicon. To obtain the most reliable results, the platinum and gold marker methods have been used. Our results show that AIG injects vacancies in non-equilibrium concentrations depending mainly on the thickness of Al layer (Abdelbarey et al., to be published).

Concentration of intrinsic point defects in silicon was monitored by platinum and gold diffusion at different temperatures. As general marker methods to estimate the concentration of vacancies, diffusion of platinum and gold was known to be most commonly used methods (Zimmermann and Ryssel, 1991a). Jacob and others described the more detailed procedure and ways for calculation of vacancy concentrations (Jacob et al., 1997). Very recently, platinum and gold diffusion was considered to be the standard methods to establish new ways for vacancy determination (Khorosheva et al., 2010). In this study, platinum indiffusion was performed at $730^{\circ} \mathrm{C}$ for $30 \mathrm{~min}$ and gold indiffusion was carried out at $850^{\circ} \mathrm{C}$ for $2 \mathrm{~h}$. We measured vacancy concentration before and after aluminum gettering (50 min at $1100 \mathrm{C}$ and $\mathrm{Al}$ layer thickness of $400 \mathrm{~nm}$ ). After removal of $30 \mu \mathrm{m}$ containing Al: Si alloy from the surface, gold or platinum was subsequently evaporated on the freshly prepared surface. After Au in diffusion, substitutional gold depth profile was determined using DLTS measurements. For platinum indiffusion at $730^{\circ} \mathrm{C}$ for $30 \mathrm{~min}$, a surface layer with a thickness of $20 \mu \mathrm{m}$ was removed by mechanical polishing and DLTS spectra were measured for substitutional Pt.

\subsubsection{Platinum diffusion to monitor vacancy}

Platinum can dissolve interstitially $\left(\mathrm{Pt}_{\mathrm{i}}\right)$ and substitutionally $\left(\mathrm{Pt}_{\mathrm{s}}\right)$ in silicon, but their solubility of in substitutional state is much larger than the solubility of in interstitial state. At the same time in interstitial state platinum diffuses much faster in comparison to substitutional state. Three deep levels for substitutional platinum have been found in silicon. The first donor level at $\mathrm{E}_{\mathrm{V}}=0.32 \mathrm{eV}$, the second level is an acceptor at $\mathrm{E}_{\mathrm{C}}=0.23 \mathrm{eV}$ (Brotherton et al., 1979) and the last one was a double donor level at $E_{V}=0.067 \mathrm{eV}$ (Zimmermann and Ryssel, 1991b). Two mechanisms have been proposed for platinum to convert from interstitial position into the electrically active substitutional site. The dissociative (Frank-Turnbull) suggests that the $\mathrm{Pt}_{\mathrm{i}}$ has to bind with a lattice vacancy, forming the substitutional atom $\mathrm{Pt}_{\mathrm{s}},\left(\mathrm{Pt}_{\mathrm{i}}+\mathrm{V} \leftrightarrow\right.$ $\mathrm{Pt}_{\mathrm{s}}$ ) (Frank and Turnbull, 1956). According to this mechanism, platinum atoms diffuse for $30 \mathrm{~min}$ or less in silicon at temperature $730^{\circ} \mathrm{C}$ or higher, was able to detect initial vacancy concentrations of about $10^{11} \mathrm{~cm}^{-3}$ (Jacob et al., 1997). The second pioneer mechanism is that discovered by Gösele et al., (1980) 
and named as kick out mechanism, where silicon self interstitial (I) is generated by kicking out silicon atom from its place and substitutional platinum is formed $\left(\mathrm{Pt}_{\mathrm{i}} \leftrightarrow \mathrm{Pt}_{\mathrm{s}}+\mathrm{I}\right)$. In fact, the vacancy concentration and diffusion temperature determine the working mechanism, however in case of higher initial concentrations of vacancy Frank-Turnbull is dominating.

The DLTS spectrum shown in figure 4.12 is recorded directly after the platinum indiffusion. Two dominant DLTS peaks are observed at 55 and 175K. All platinum doped p-type samples show the same pattern of DLTS peaks. The concentration of substitutional platinum (175K signal) is approximately $2.5 \cdot 10^{13} \mathrm{~cm}^{-3}$ which is in a good agreement with the previously published value (Zimmermann and Ryssel, 1992; Jacob et al., 1997).

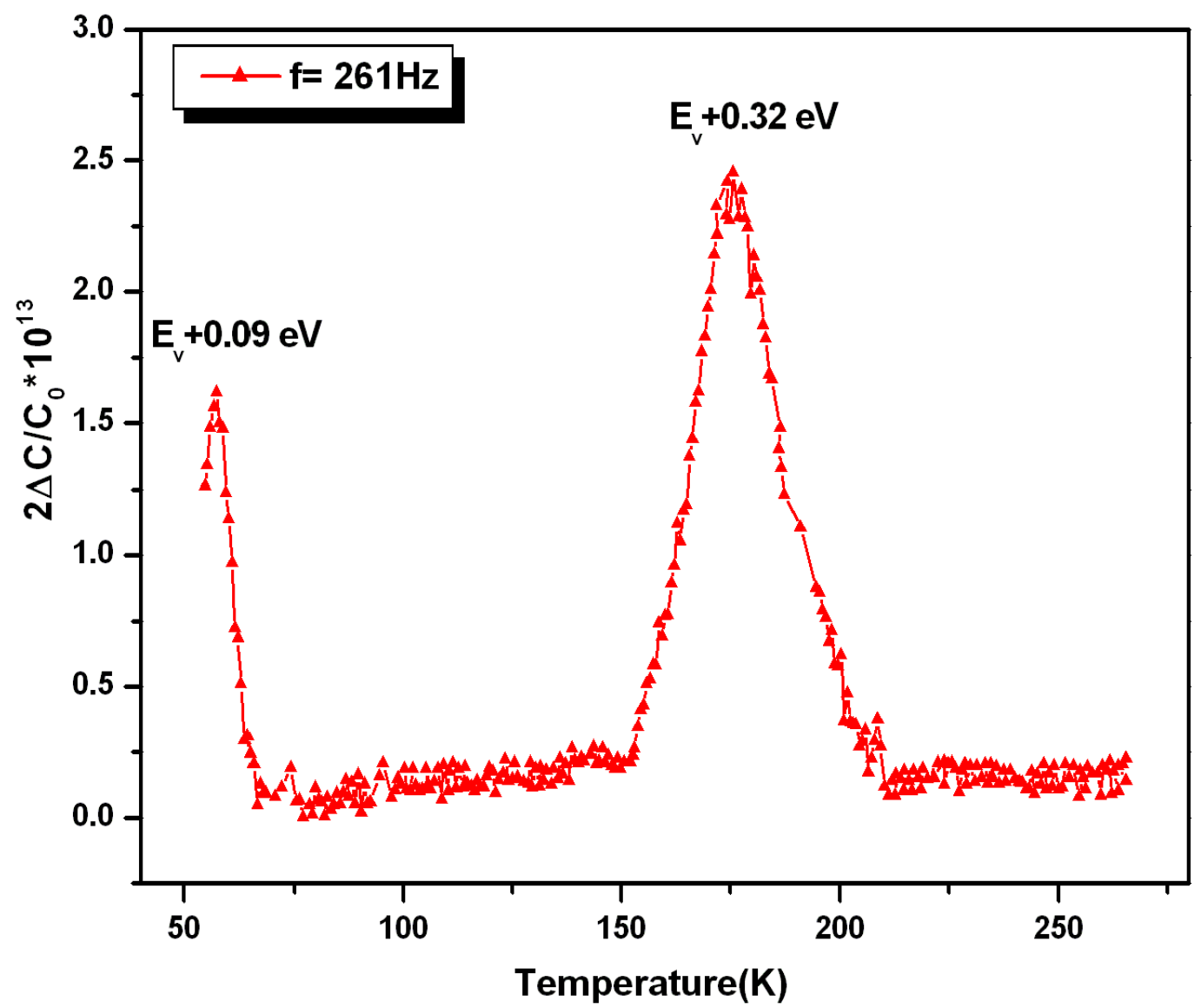

Figure 4.12: Majority carrier (hole) DLTS spectrum of platinum-doped FZ p-type silicon. Platinum was indiffused at $730^{\circ} \mathrm{C}$ for $30 \mathrm{~min}$. Measuring conditions of DLTS: the filling pulse duration $t p=100 \mu$ s and reverse bias $U_{B}=5 \mathrm{~V}$ and filling pulse bias $U_{p}=4 \mathrm{~V}$.

If platinum is diffused at $730^{\circ} \mathrm{C}$ into samples that had been previously subjected to AIG, deep level attributed to substitutional platinum is also 
detected however, in much higher concentration compared with that measured in samples without AIG. Figure 4.13 shows a typical DLTS measurement obtained from frequency scans at different temperatures. It can clearly be observed that the concentration of $\mathrm{Pt}_{\mathrm{s}}$ increased markedly by two orders of magnitude $\left(1.6 \cdot 10^{15} \mathrm{~cm}^{-3}\right)$ in p-type samples exposed to AIG before platinum indiffusion. The $\mathrm{Pt}_{\mathrm{s}}$ concentration has been calculated by using equation (2.9), giving a correct order of magnitude and an accuracy of factor 2 according to Pons's model (Pons, 1984).

To identify the substitutional platinum levels in our samples shown in figure 4.13, their emission rates in the Arrhenius plot have compared with those described previously in the literature (see figure 4.14). The thermal activation energy determined from the slope of this plot lead to the positions of a hole level as $E_{v}+0.32 \mathrm{eV}$ and extrapolated capture cross section of about

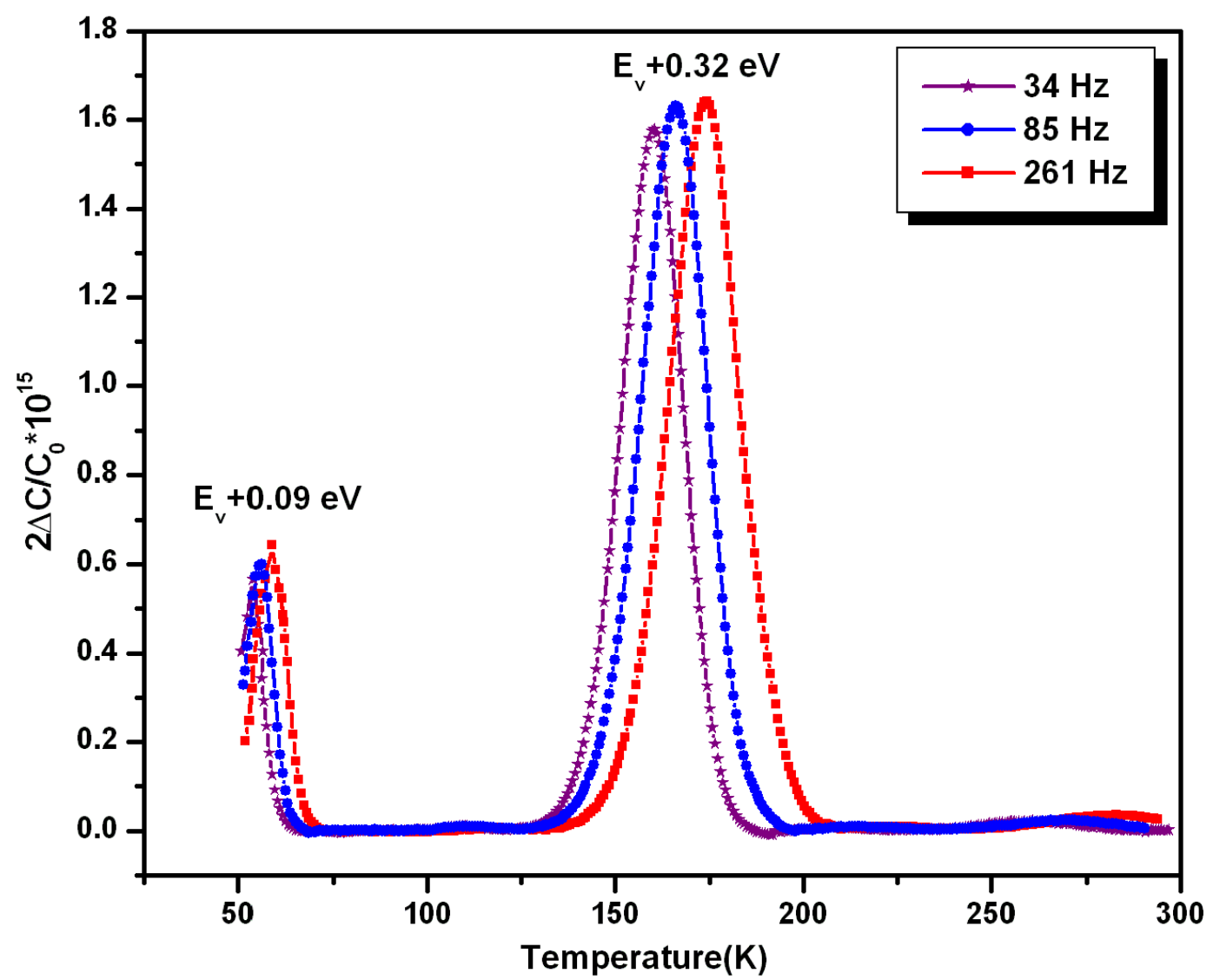

Figure 4.13: DLTS spectra were taken at different frequencies for platinum-doped FZ ptype silicon. Samples were subjected to AIG prior to platinum indiffusion at $730^{\circ} \mathrm{C}$ for 30 min after removal of $A l$ alloy. The filling pulse duration $t_{p}=100 \mu s$ and reverse bias $U_{B}=5 \mathrm{~V}$ and filling pulse bias $\mathrm{U}_{\mathrm{p}}=4 \mathrm{~V}$.

$1.5 \cdot 10^{-14} \mathrm{~cm}^{2}$. We interpret this level as corresponding to the substitutional platinum with activation energy of $0.32 \mathrm{eV}$ reported by previous studies 
(Zimmermann and Ryssel, 1991b; Brotherton et al., 1979). Thus our level is the substitutional platinum donor state at $\mathrm{E}_{\mathrm{v}}+0.32 \mathrm{eV}$, observed in all p-type $\mathrm{Si}$ and monitoring vacancy concentration.

If the concentration of the highly mobile $\mathrm{Pt}_{\mathrm{i}}$ atoms reaches its equilibrium value and local equilibrium is established for the dissociative mechanism, the initial vacancy concentration and the concentration of $\mathrm{Pt}_{\mathrm{s}}$ are related by

$$
[V(t=0)]=\left[P t_{S}\right]\left(1+[V]^{e q} /[P t]^{e q}\right)
$$

$[\mathrm{V}]^{\mathrm{eq}}$ and $[\mathrm{Pt}]^{\mathrm{eq}}$ denote the equilibrium concentrations of vacancies and substitutional platinum, respectively.

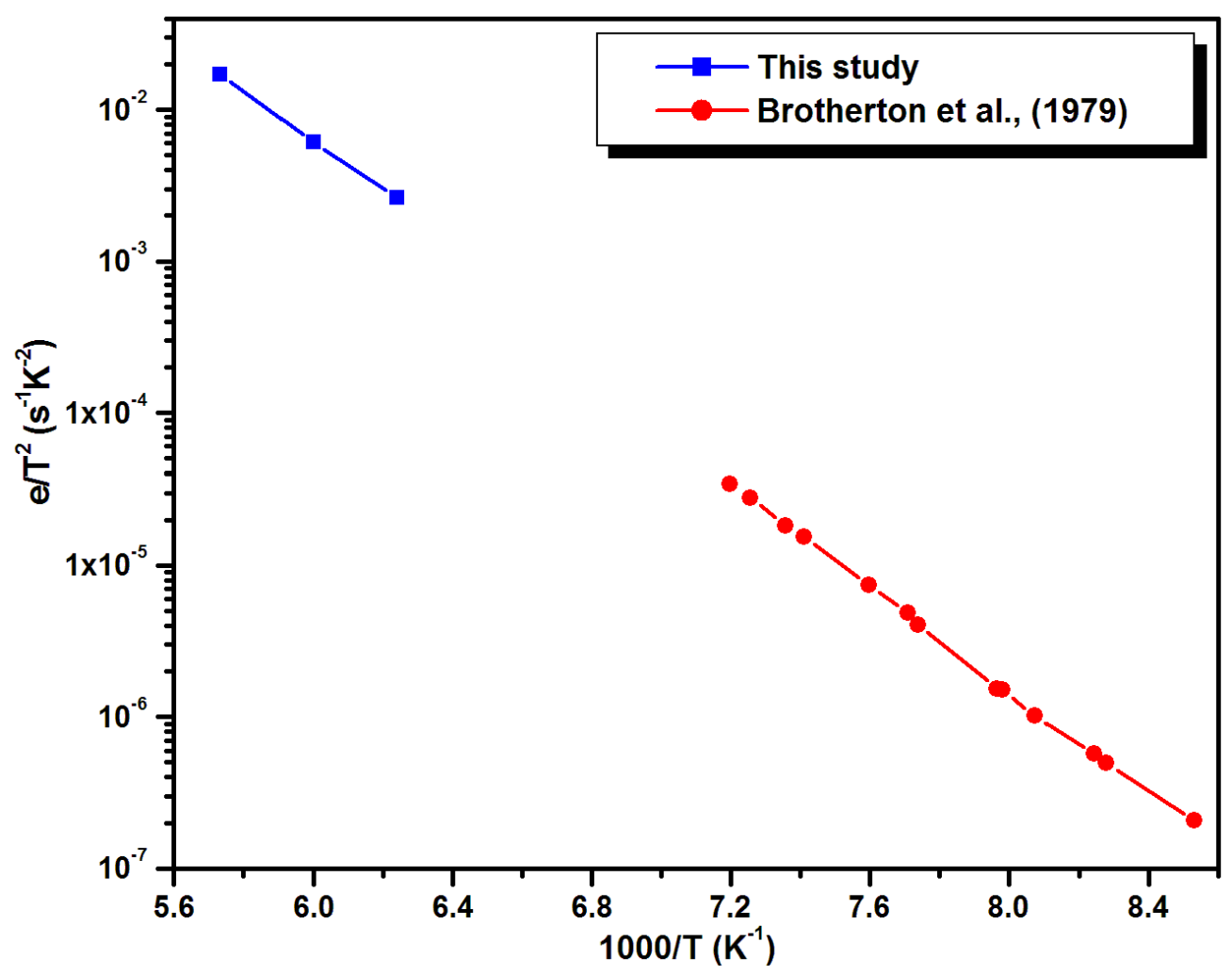

Figure 4.14: Thermal emission rates (T2 corrected) as a function of inverse temperature for the platinum donor level at $E_{v}+0.32 \mathrm{eV}$ compared with published data from Brotherton et al., (1979).

$$
\begin{gathered}
{[\mathrm{V}]^{e q}=1.7 \cdot 10^{21} \exp [-2.00 \mathrm{eV} / \mathrm{kT}] \mathrm{cm}^{-3}} \\
{\left[P t_{S}\right]^{e q}=6.4 \cdot 10^{29} \exp \left[-3.45 \mathrm{eV} / \mathrm{kT}^{\mathrm{c}} \mathrm{cm}^{-3}\right.}
\end{gathered}
$$


From equations (4.4), (4.5) and (4.6) proposed by Jacob et al., (1997), we therefore could easily estimate the concentration of vacancies in our samples.

Table 4.2: Platinum concentration at different depth after in-diffusion for $30 \mathrm{~min}$ at $730^{\circ} \mathrm{C}$ in samples before and after AIG $\left(50 \mathrm{~min}\right.$ at $\left.1100^{\circ} \mathrm{C}\right)$

\begin{tabular}{|l|c|c|c|}
\hline & {$\left[\mathrm{Pt}_{\mathrm{s}}\right]$ at $10 \mu \mathrm{m}$} & {$\left[\mathrm{Pt}_{\mathrm{s}}\right]$ at $50 \mu \mathrm{m}$} & {$\left[\mathrm{Pt} \mathrm{s}_{\mathrm{s}}\right]$ at $150 \mu \mathrm{m}$} \\
\hline Without AIG & $2.5 \cdot 10^{13} \mathrm{~cm}^{-3}$ & $2.01 \cdot 10^{13} \mathrm{~cm}^{-3}$ & $2.03 \cdot 10^{13} \mathrm{~cm}^{-3}$ \\
\hline AIG, 400nm Al layer & $1.6 \cdot 10^{15} \mathrm{~cm}^{-3}$ & $1.0 \cdot 10^{15} \mathrm{~cm}^{-3}$ & $1.0 \cdot 10^{15} \mathrm{~cm}^{-3}$ \\
\hline
\end{tabular}

As one can see from the Table 4.2, platinum diffusion was able to detect the initial concentration of vacancy of FZ p-type silicon at about 2$3 \cdot 10^{13} \mathrm{~cm}^{-3}$, which is in a good agreement with previous studies (Zimmermann and Ryssel, 1992; Jacob et al., 1997; Karg et al., 2003). According to the calculation, there was a slight increase in the vacancy concentration on near from the surface (at $10 \mu \mathrm{m})$. In addition, vacancy concentrations estimated at $50 \mu \mathrm{m}$ and $150 \mu \mathrm{m}$ from platinum depth profile were equal to each other. On the other hand, much higher concentrations of $\mathrm{Pt}_{\mathrm{s}}$ are detected deep in the samples subjected to AIG. Indeed, AIG for $50 \mathrm{~min}$ at $1100^{\circ} \mathrm{C}$ with $400 \mathrm{~nm}$ Al layer was able to induce a huge concentration of vacancies of about $1.05 \cdot 10^{15} \mathrm{~cm}^{-3}$. Our results obtained from platinum experiments suggest that under our experimental conditions AIG results in generation of rather large concentration of vacancies in the sample.

\subsubsection{Gold diffusion to monitor vacancy}

Similar to platinum sites in silicon, gold atoms diffuse in both interstitial $\left(A u_{i}\right)$ and later with time in the substitutional site $\left(A u_{s}\right)$. It is well known that gold has two deep levels in silicon. The first donor level at $E_{v}+0.347 \mathrm{eV}$ and the second acceptor level at $E_{c}-0.554 \mathrm{eV}$ (Collins et al., 1957), have been demonstrated to belong to the same center (Ledebo and Wang, 1983; Utzig and Schröter, 1984). Generally, the transition between interstitial gold and substitutional in defect-free silicon was described to occur via kick out mechanism generating self-interstitials (Frank et al., 1984). Furthermore, the concentration of $\mathrm{Au}_{\mathrm{s}}$ was found to be sensitive to the rate of annihilation and generation of silicon self-interstitials because the sample surface supposed to be a good sink for their annihilation (Feklisova and Yakimov, 2009a). However, again in defect free silicon, concentration of $\mathrm{Au}_{\mathrm{s}}$ was found to be smaller compared with that in silicon samples containing more vacancy or vacancy related complexes, indicating that vacancies could lead to increased concentration of $\mathrm{Au}_{\mathrm{s}}$ via dissociative mechanism (Feklisova and Yakimov, 2009b). 
Figure 4.15 shows typical DLTS results of gold-diffused Si samples at $850^{\circ} \mathrm{C}$ for $2 \mathrm{~h}$. One major peak at approximately $175 \mathrm{~K}$ was obviously observed after gold indiffusion, and a small one related to gold acceptor at $290 \mathrm{~K}$, indicating the concentration of $\mathrm{Au}_{\mathrm{s}}$ of about $8.0 \cdot 10^{13} \mathrm{~cm}^{-3}$ which is in accordance with the corresponding published data (Zimmermann and Ryssel, 1992; Feklisova and Yakimov, 2009a).

In figure 4.16, DLTS spectra at different frequencies of the gold doped p-type silicon sample are given. Samples were subjected to AIG before gold indiffusion at $850^{\circ} \mathrm{C}$ for $2 \mathrm{~h}$. Two peaks can be seen. The large one at about

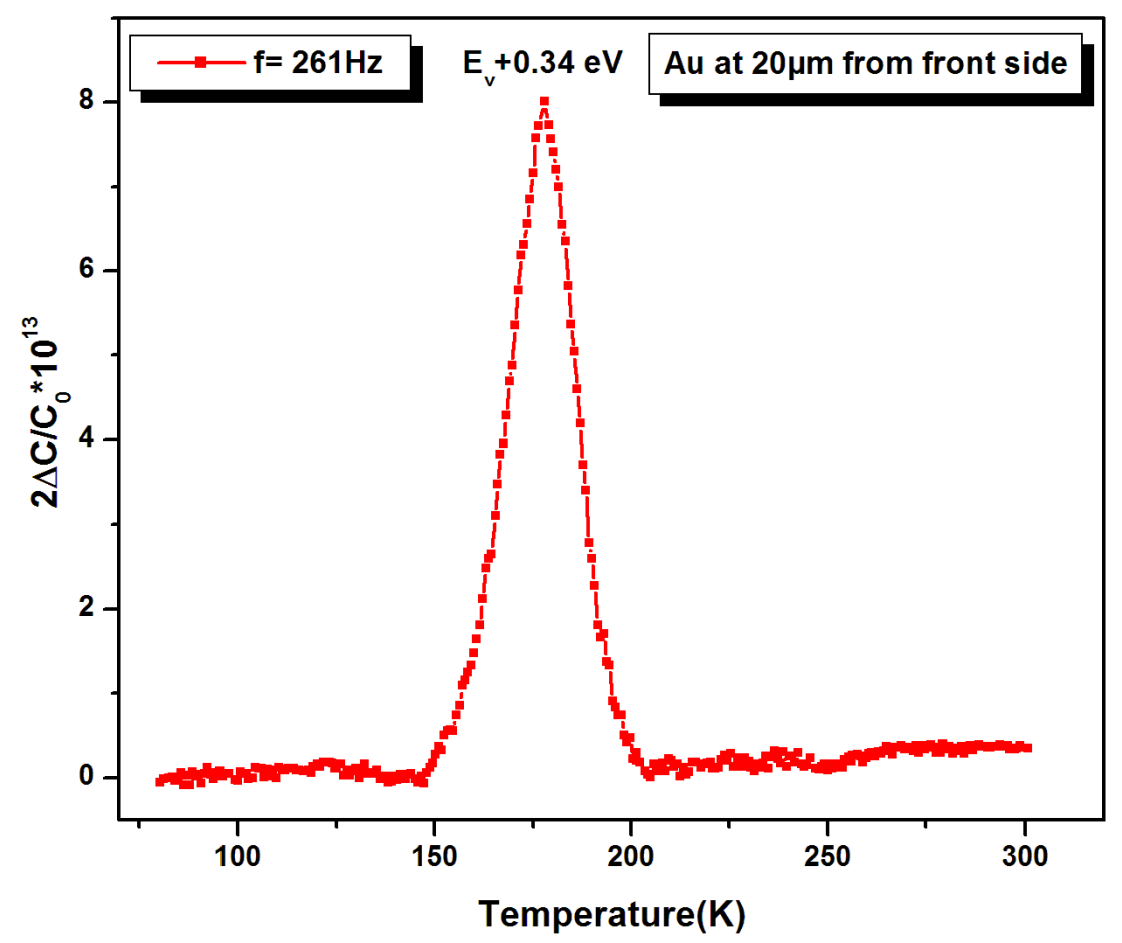

Figure 4.15: DLTS spectrum of gold-doped FZ p-type silicon. Gold was indiffused at $850^{\circ} \mathrm{C}$ for $2 \mathrm{~h}$. Measuring conditions of DLTS: the filling pulse duration $\mathrm{tp}=100 \mu \mathrm{s}$ and reverse bias $\mathrm{U}_{\mathrm{B}}=5 \mathrm{~V}$ and filling pulse bias $\mathrm{U}_{\mathrm{p}}=4 \mathrm{~V}$.

$175 \mathrm{~K}$ belongs to the gold donor level and the smaller one at about $290 \mathrm{~K}$ to the acceptor level. The donor level attributed to $\mathrm{Au}_{\mathrm{s}}$ is detected in much higher concentration compared with that measured in samples without AIG shown in figure 4.15. The $\mathrm{Au}_{\mathrm{s}}$ concentration at a depth of about $20 \mu \mathrm{m}$ is of $2.2 \cdot 10^{15} \mathrm{~cm}^{-3}$ for samples exposed to AIG and of about $8.0 \cdot 10^{13} \mathrm{~cm}^{-3}$ for non AIG-samples.

Figure 4.17 shows the Arrhenius plot, from which we obtain the following activation energies $0.34 \mathrm{eV}$ and $0.55 \mathrm{eV}$ and the extrapolated capture cross sections of $\sigma_{p}=1.1 \cdot 10^{-14} \mathrm{~cm}^{2}$ and $\sigma_{n}=9.0 \cdot 10^{-17} \mathrm{~cm}^{2}$ for the 


\subsubsection{Gold diffusion to monitor vacancy}

substitutional gold donor and acceptor levels respectively. These values are found to be in a good agreement with the emission rate signatures of the donor and acceptor levels reported earlier by Brotherton and Lowther, (1980) suggesting that they correspond to the same defect level.

Substitutional gold depth profiles measured after gold diffusion at $850^{\circ} \mathrm{C}$ in p-type Si samples prior to and subsequent to AIG are presented in figure 4.18. The $A u_{s}$ concentration at a depth of about $20 \mu \mathrm{m}$ is of $8 \cdot 10^{13} \mathrm{~cm}^{-3}$ for samples without AIG and of about $2.2 \cdot 10^{15} \mathrm{~cm}^{-3}$ for samples exposed to AIG. Deeply in the bulk at $250 \mu \mathrm{m}$, the $\mathrm{Au}_{\mathrm{s}}$ concentration in the untreated samples does not exceed $2.5 \cdot 10^{13} \mathrm{~cm}^{-3}$ showing the flat bottom of the $U$ -

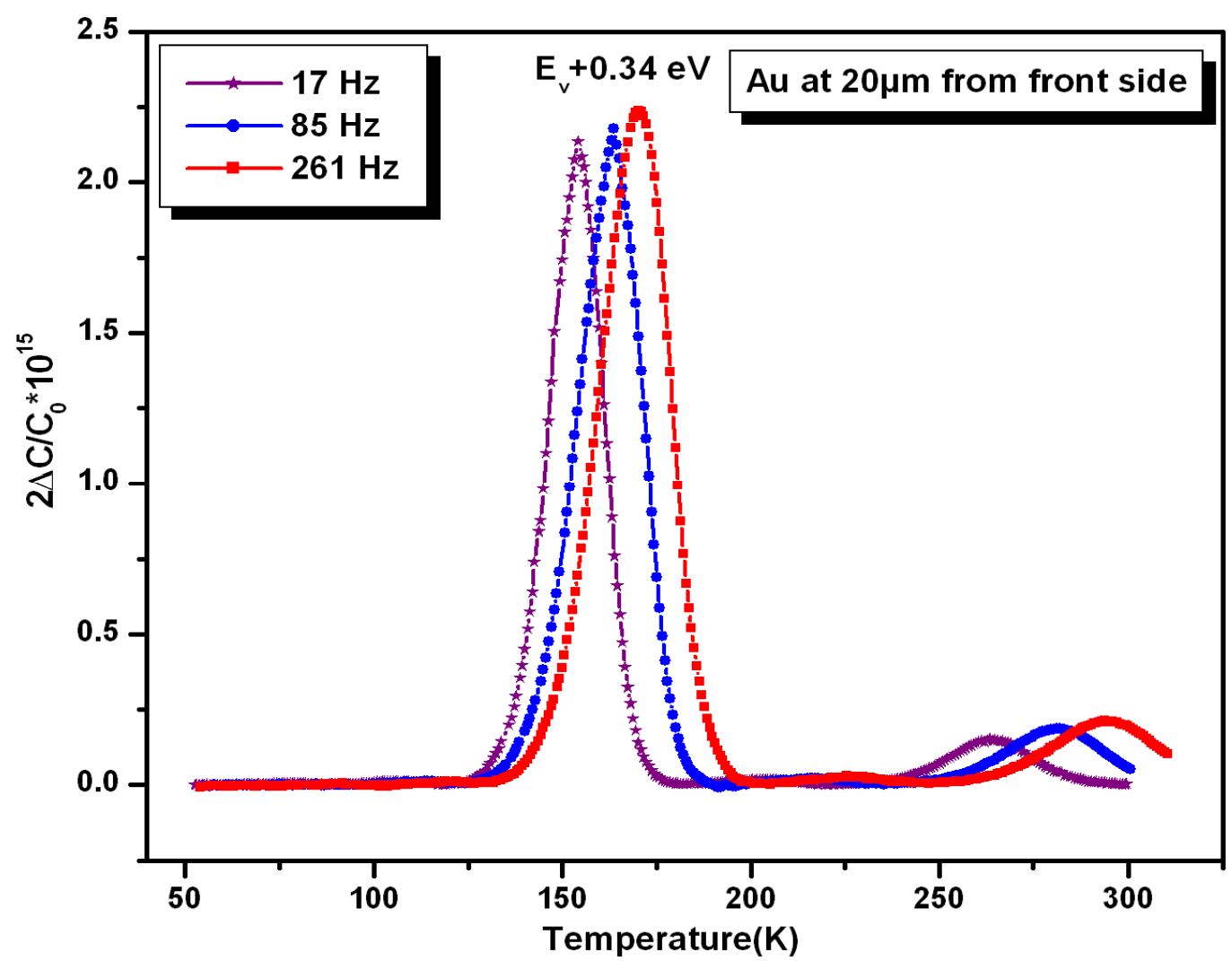

Figure 4.16: DLTS spectra were taken at different frequencies for gold-doped FZ p-type silicon. Samples were subjected to AIG prior to gold indiffusion at $850^{\circ} \mathrm{C}$ for $2 \mathrm{~h}$ after removal of $\mathrm{Al}$ alloy. The filling pulse duration $\mathrm{t} p=100 \mu \mathrm{s}$ and reverse bias $\mathrm{U}_{\mathrm{B}}=5 \mathrm{~V}$ and filling pulse bias $\mathrm{U}_{\mathrm{p}}=4 \mathrm{~V}$.

shaped profile. This profile has been demonstrated in the same temperature range and explained by the dominance of the kick-out mechanism and outdiffusion of self-interstitials (Zimmermann and Ryssel, 1992; Feklisova and Yakimov, 2009a). On the other hand, the gold profile which was measured in samples subjected to AIG after Au-diffusion at $850^{\circ} \mathrm{C}$ for $2 \mathrm{~h}$; however, show a quite different shape. Obviously a trough profile is observed in Al gettered 
samples, in which DLTS measurements of $\mathrm{Au}_{\mathrm{s}}$ at the same depth $(250 \mu \mathrm{m})$ give a concentration of $1 \cdot 10^{15} \mathrm{~cm}^{-3}$. Thus, it could be concluded that the AIG under our experimental conditions (for $50 \mathrm{~min}$, at $1100^{\circ} \mathrm{C}$ with $400 \mathrm{~nm}$ Al layer) has efficiently introduced high concentration of vacancies in p-type Si equal to that measured by platinum diffusion.

We measured the concentration of non-equilibrium vacancies in our $\mathrm{Al}$

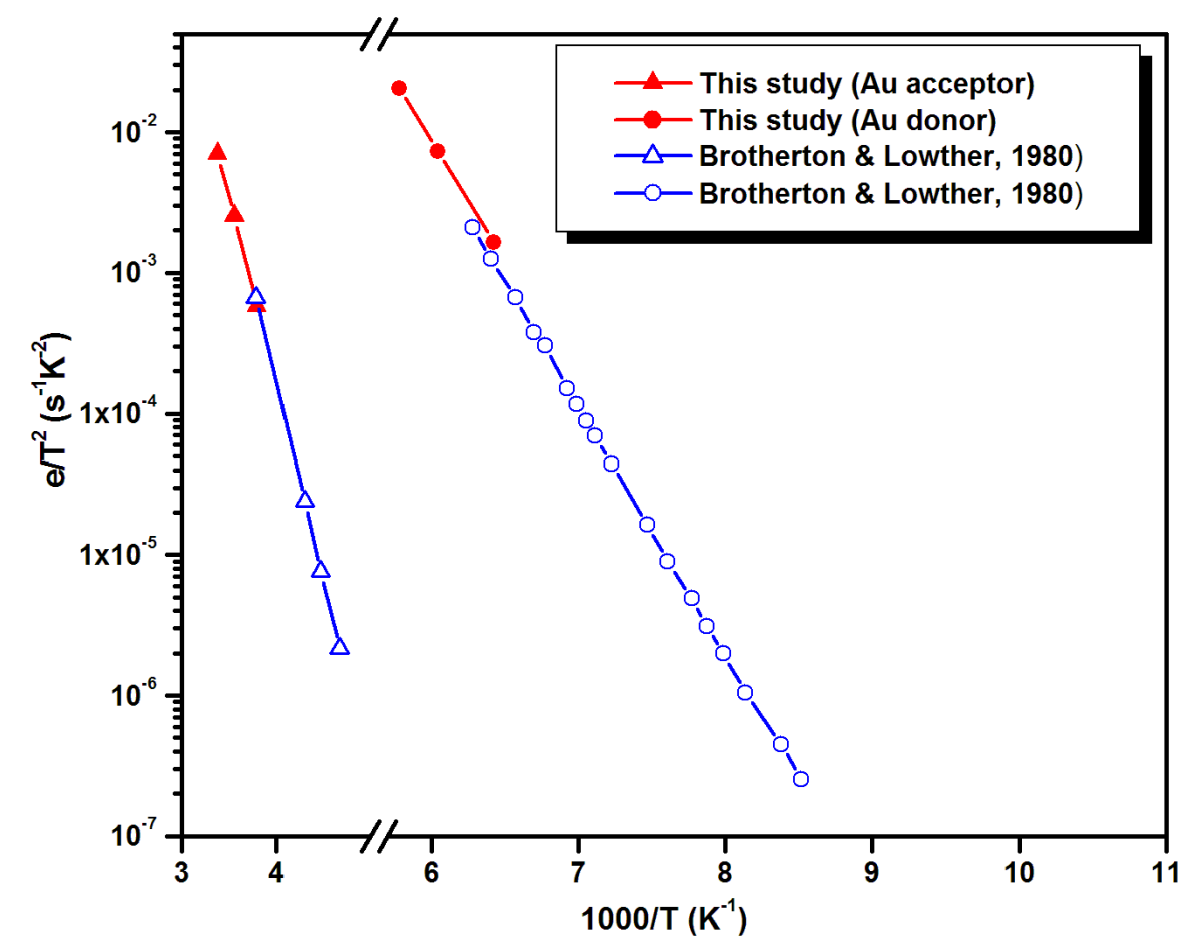

Figure 4.17: Thermal emission rates for the substitutional gold donor level at $\mathrm{E}_{\mathrm{v}}+0.34 \mathrm{eV}$ (circles) and the gold acceptor level at $\mathrm{E}_{\mathrm{c}}-0.55 \mathrm{eV}$ (triangles) both obtained from the same p-type sample indiffused with gold at $850^{\circ} \mathrm{C}$ for $2 \mathrm{~h}$. Also included are the data from Brotherton and Lowther, (1980).

gettered samples by using a well-known method, based on in-diffusion of substitutional metals, like $\mathrm{Pt}$ and $\mathrm{Au}$. Our results showed direct evidence that under our experimental conditions the AIG indeed results in generation of huge concentration of vacancies in the sample. For the Al layer thickness of $400 \mathrm{~nm}$ and very high annealing temperature $\left(1100^{\circ} \mathrm{C}\right)$, the vacancy concentration was about $10^{15} \mathrm{~cm}^{-3}$. The vacancy concentration measured by platinum diffusion was found to be identical to that obtained from gold diffusion although annealing carried out at different temperatures, suggesting the contribution of the same mechanism.

It is generally known that there are only two possible lattice sites available for gold atoms. $\mathrm{Au}_{i}$ diffuses very fast compared with substitutional gold; however $\mathrm{Au}_{\mathrm{s}}$ concentration is higher than the interstitial gold 
concentration. As mentioned previously in the case of platinum, the dissociative mechanism is working by involving vacancies together with the interstitial atoms via the reaction: $A u_{i}+V \leftrightarrow A u_{s}$. On the other hand, kick out mechanism produced self-interstitial by exchange between interstitial gold and substitutional gold atoms: $\mathrm{Au}_{\mathrm{i}}=\mathrm{Au}_{\mathrm{s}} \leftrightarrow \mathrm{l}$.

It seems likely that one substitutional gold atom is formed from one interstitial atom and one vacancy disappeared. The most important parameter affecting this reaction is the rate of vacancy generation in silicon. Therefore, it is reasonable to assume that the number of substitutional gold atoms might be related to the number of vacancies disappeared, indicating an indirect way

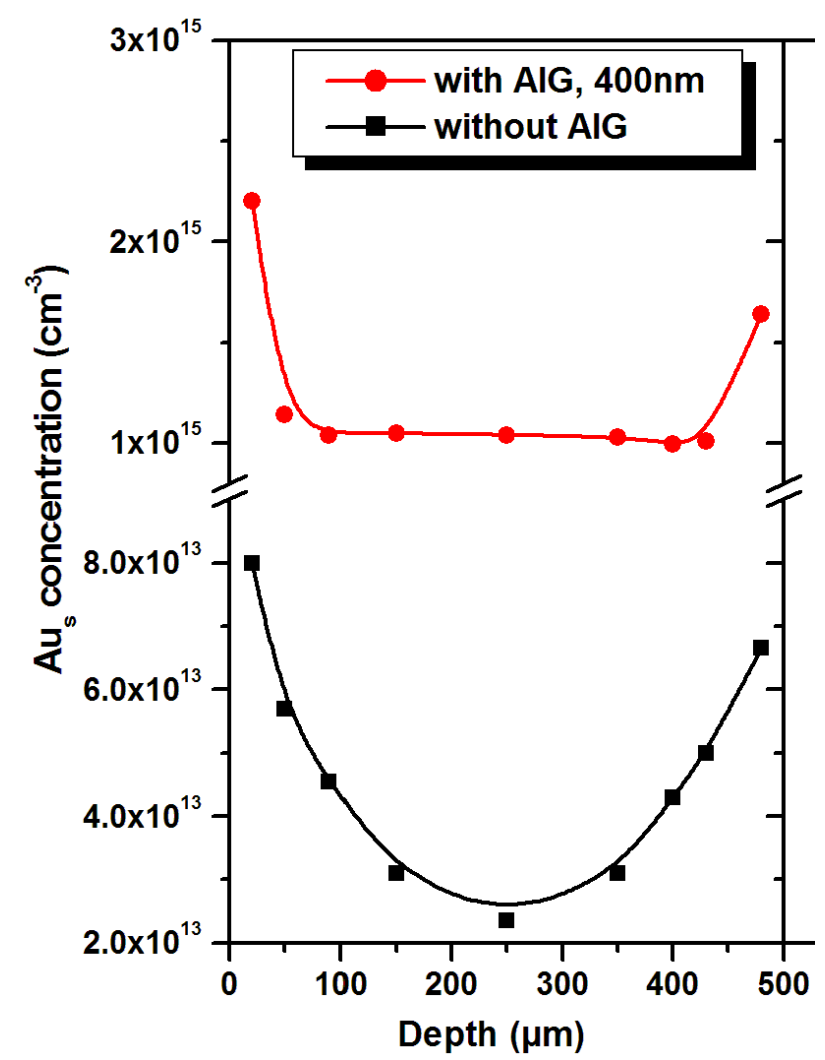

Figure 4.18: Substitutional gold profile measured by DLTS after diffusion in FZ silicon wafers. $\mathrm{Au}_{\mathrm{s}}$ diffusion profile for samples without AIG seems to show a kick-out diffusion limited by the self-interstitial diffusion to the specimen surface, namely, a U-shaped profile (rectangles). However, in Si samples those were first subjected to AIG and thereafter annealed at the same temperature $\left(850^{\circ} \mathrm{C}\right.$ for $\left.2 \mathrm{~h}\right)$; the profile shows a different shape and verifying Frank-Turnbull mechanism (circles). According to the dominance of the Frank-Turnbull mechanism, the concentration of $\mathrm{Au}_{\mathrm{s}}$ in the bulk of a sample to a good degree of accuracy corresponds to the initial vacancy concentration determined by platinum diffusion $\left(1 \cdot 10^{15} \mathrm{~cm}^{-3}\right)$.

to estimate the concentration of vacancies. Taken into account that the concentration of $A u_{s}$ is able to be measured by DLTS, the technique used to monitor substitutional gold at different depths in the silicon bulk, thus 
estimation of $\mathrm{Au}_{\mathrm{s}}$ might be a good tool to monitor vacancy concentration in silicon.

A depth profile of substitutional gold is not quite simple to declare only one mechanism: Frank-Turnbull or Kick out. Gold atoms diffuse into silicon according to the kick out mechanism for temperature higher than $800^{\circ} \mathrm{C}$ (Zimmermann and Ryssel, 1992; Zimmermann, 1998). However, in a presence of high, non-equilibrium concentration of vacancies, the FrankTurnbull mechanism (Frank and Turnbull, 1956) becomes dominating. Importantly, the temperature and the initial vacancy concentrations determine the working mechanism. Moreover, generation of vacancy and recombination of self interstitial should be considered above $850^{\circ} \mathrm{C}$, a temperature at which the vacancy diffusion coefficient is small to allow migration of vacancy from the surface to the bulk implying that the increase in the substitutional gold is corresponding to the initial vacancy concentration in the bulk (Zimmermann, 1998). In this case the concentration of substitutional gold at high depth becomes proportional to initial non-equilibrium vacancy concentration (Zimmermann and Ryssel, 1991c). These circumstances enable us to conclude that the gold diffusion temperature at $850^{\circ} \mathrm{C}$ may follow FrankTurnbull mechanism. Similar mechanisms have been postulated for simulation of the diffusion of gold at $900^{\circ} \mathrm{C}$ for $1 \mathrm{~h}$, showing identical gold depth profile with an initial vacancy concentration of $2 \cdot 10^{14} \mathrm{~cm}^{-3}$ (Pichler, 2004). Our experimental data correlated well with these conclusions and further suggest that there is a significant role for silicon vacancies to obtain such observed behavior. As an example, the low concentration of vacancies in FZ p-type silicon prior to AIG can be used to explain the kick-out mechanism dominated for $\mathrm{Au}$ diffusion at $850^{\circ} \mathrm{C}$, whereas in samples subjected to $\mathrm{AIG}$, the concentration of vacancies was high and the dissociative mechanism dominated in the same temperature range for gold diffusion.

At room temperature, vacancies are mobile in silicon and could be found in form of complexes like $\mathrm{VO}$ and $\mathrm{VO}_{2}$, the latter form is the dominant one (Voronkov and Falster, 2002). Such complexes could play a role in the dissociative reaction capturing interstitial gold or platinum. These trapped atoms are converted into the substitutional site and their concentrations reflect the concentration of vacancies. In addition, the depth profiles of substitutional metal represent the distribution of vacancy in the silicon bulk. For example, Falster et al., (1997) demonstrated that the concentration of vacancy complex $\left(\mathrm{VO}_{2}\right)$ is well correlated with the concentration of substitutional platinum suggesting that interstitial platinum filled the existing vacancy in the samples at $730^{\circ} \mathrm{C}$. Therefore, our depth profile of $\mathrm{Pt}_{\mathrm{s}}$ or $\mathrm{Au}_{\mathrm{s}}$ (traced by DLTS) 
reproduces the concentration of vacancy injected by $400 \mathrm{~nm}$ Al layer which is about of $10^{15} \mathrm{~cm}^{-3}$. These results are reliable simply because we were able to have the same results by using two different metals and temperatures. On the basis of the present results, together with those of the literature, we propose that vacancies injected by AIG are homogenously distributed in the silicon bulk and possible formation mechanisms of the vacancies during Al-Si alloy need further investigations.

The basic mechanism of vacancies generation during AIG is unknown. Vacancy injection has been attributed to the Al-Si alloy formation, which proceeds at the interface between Al-layer and Si-wafer during heating to gettering temperature. At a temperature below the melting point of $\mathrm{Al}$ : $\mathrm{Si}$ eutectic, when Al: Si-layer is solid, injection of vacancies into silicon sample must take place, because a quantity of silicon atoms migrate into the aluminum layer to form Al-Si alloy. The migrating silicon atoms leave vacancies behind in silicon that not occupied by aluminum atoms due to its negligible solubility in silicon. Such kind of phenomena was investigated in details many years ago when the Kirkendall effect and formation of Kirkendall voids were investigated (Smigelskas and Kirkendall, 1947). Importantly, using of this phenomenon has been suggested to improve AIG efficiency (Tan and Li, 2008).

A preliminary study using HRTEM showed the presence of intermediate layer of oxide membrane between Si and liquid Al-Si alloy, which can explain generation of large number of vacancies in $\mathrm{Si}$ by diffusion of $\mathrm{Si}$ into Al via solid layer leaving vacancies in $\mathrm{Si}$, a process previously described as kirkendall phenomena. However, further studies need to be conducted to clarify the role of the interface layer. To clarify the effect of $\mathrm{SiO}_{2}$, current studies in our laboratory are aimed to investigate the silicon dioxide layer under our sample preparations. Whether the reaction of an oxide layer with the Al-Si alloy might also contribute to the generation of vacancies at the Al$\mathrm{Si} / \mathrm{SiO}_{2} / \mathrm{Si}$ interface, is still an open question.

It has been reported that aluminum gettering has a synergistic effect increasing the usefulness of hydrogen passivation for silicon defects (Sopori et al., 1996; Rohatgi et al., 2002). Our results show for the first time that aluminum gettering inject vacancy reflected by marked increases in the substitutional platinum or gold concentration. Similar marker methods have been used to monitor vacancy injection after aluminum geterring in EFG silicon; however, the authors were not successful to detect any increase in the vacancy concentration (Karg et al., 2003). Recently, Bostelmann (2011) reported in her bachelor thesis that $\mathrm{Pt}_{\mathrm{s}}$ concentrations decreased after AIG, 
Chapter 4. Results and discussion

which apparently contradicts our observations, and she suggested that the oxidation of Al layer could be the reason to prevent vacancy injection. This inconsistency could be due to different processing conditions as well as silicon materials used in this work (FZ) which might lead to different results. In conclusion, we confirmed our initial hypothesis that the vacancy concentration is higher in silicon samples subjected to AIG, and we enlarged this observation to encompass homogeneously distribution in the silicon bulk. 


\subsection{Light-induced formation of metastable defect in iron- contaminated $\mathrm{p}$-type silicon after aluminum gettering}

Contamination with large group of transition metals is drastically diminishing the performance of photovoltaic devices such as integrated circuits and solar cells. One of these transitions metals reducing cell efficiency at low concentration is iron which considered being the major cause of degradation of minority life time (Istratov et al., 2000a). Particularly, even very minute concentration of iron less than $1 \mathrm{ppb}$ was found to reduce dramatically the diffusion length especially in p-type silicon (Buonassisi et al., 2005). Formation of iron complexes in p-type silicon are of significant interest for semiconductor industry and solar cell technology. Therefore, there have been a huge number of studies devoted to indentifying iron complexes in silicon in order to better understand their impact on devices. Chemically, the formation of FeB complexes in p-type silicon occurs via the electrostatic attraction forces between positively charged interstitial $\mathrm{Fe}$ atoms and negatively charged boron atoms in silicon, thus forming FeB pairs which naturally found in boron-doped, iron-contaminated wafers (Istratov et al., 2000a). Importantly, interstitial $\mathrm{Fe}$ point defect, $\mathrm{Fe}_{\mathrm{i}} \mathrm{B}_{\mathrm{s}}$ is stable at room temperature; however, its dissociation and association is highly sensitive to several factors such as annealing, illumination and bias voltage.

In addition to complexes with shallow acceptors, interstitial iron is known to form electrically active complexes with phosphorus (Mchedlidze and Suezawa, 2004), gold (Brotherton et al., 1984; Utzig and Schröter, 1984; Ali et al., 2007), oxygen (Trushin et al., 2009), and platinum (Czaputa, 1989). Besides pairing with gold, pairing iron with zinc has been also observed (Lemke, 1982). The authors demonstrated in the latter study two new energy levels in DLTS spectra obtained after diffusion of iron in n- and p-type silicon co-doped with zinc. Some of these complexes are also proved to bind together with hydrogen by ESR measurements such as FePH (Mchedlidze, 2005).

Moreover, it is possible for iron to form complexes with different kinds of intrinsic defects like dislocation, vacancies, and grain boundaries. It becomes very difficult to better understand the complex formation and to study the interaction between iron and such intrinsic defects in mc- silicon. A recent comprehensive study has reported that the mobile vacancies have been proposed to play a bivotal role in the formation of the iron complexes especially together with interstial iron atoms (Mchedlidze and Suezawa, 2002). 
Iron-related point defect in silicon samples have been investigated by the high-resolution photoinduced transient spectroscopy (HRPITS) and ESR. Iron vacancy pair $\left(\mathrm{Fe}_{\mathrm{i}} \mathrm{V}\right)$ and iron vacancy complex $\left(\mathrm{Fe}_{\mathrm{i}}\right)_{2} \mathrm{~V}$ were found at $\mathrm{E}_{\mathrm{V}}+0.5 \mathrm{eV}$ and $\mathrm{E}_{\mathrm{V}}+0.53 \mathrm{eV}$ respectively in electron irradiated high-resistivity silicon samples (Kaminski et al., 2003). Annealing at $400^{\circ} \mathrm{C}$ was able to dissolve the latter trap; however the former one containing one iron atom was stable at the same temperature. Moreover, transformation of these iron vacancy complexes leads to formation of new iron-related levels with smaller activation energies (Mchedlidze and Suezawa, 2002; Kaminski et al., 2003). EPR measurements was also used to investigate similar iron doped, electron irradiated silicon samples. NL19 and NL20 EPR spectra have been detected, the first contains only one iron atom and the second NL20 contains two iron atoms and both of them were described as $\mathrm{Fe}_{\mathrm{i}} \mathrm{V}$ and $\left(\mathrm{Fe}_{\mathrm{i}}\right)_{2} \mathrm{~V}$ respectively. Importantly, both NL19 and NL20 annealed out at $160^{\circ} \mathrm{C}$ (Muller et al., 1982). Furthermore, a complex of three different components could also form in $n$ type silicon. The interaction of iron with A center, E center and the divacancy have been observed by using DLTS leading to appearance of new ironvacancy-oxygen complex at $\mathrm{E}_{\mathrm{C}}-0.36 \mathrm{eV}$. In addition to the formation of new trap, iron affects the annealing characteristic of $E$ center and divacancy (You et al., 1988). Thus, the importance, and drawbacks of iron vacancy complexes on the key parameters of solar cell efficiency needs further investigation.

Recently, a pioneer theoretical study has been published by Estereicher and others (2008). The authors used the first principal theory to calculate the interaction between iron and vacancy related defects in silicon. They also predicted that metastable defects might be produced through the interaction between vacancy and iron atoms leading to the change in the electrical activity of the original species. For example, $\mathrm{Fe}_{\mathrm{i}} \mathrm{V}$ pair has been described to be a donor level in the gap at $E_{V}+0.35 \mathrm{eV}$, annealed out theoretically at $160^{\circ} \mathrm{C}$ and in accordance with the experimentally found NL19 EPR center.

Aluminum gettering (AIG) has been demonstrated to reduce the iron concentration in silicon wafer (Abdelbarey et al., 2009) and recently its efficiency to remove iron was estimated to be $99 \%$ (Phang and Macdonald, 2011). Moreover, section 4.3 shows that AIG was able to inject vacancies measured by standard marker methods with homogenous distribution in silicon bulk. Based on these finding, this part was carried out to investigate the interaction between iron and induced vacancies from aluminum gettering at high temperatures under light illumination. Furthermore, formation of iron vacancy complexes under different illumination time with and without 


\section{Chapter 4. Results and discussion}

aluminum gettering, their dissociation under different annealing time, and their theoretically calculated counterparts have been discussed in detail in this part and published elsewhere (Abdelbarey et al., 2010).

To study the effect of illumination on the interaction between FeB and vacancy, we have to consider that exposure to light leads to dissociation of FeB. Not only light exposure but also annealing at $200^{\circ} \mathrm{C}$ might lead to the dissociation of $\mathrm{FeB}$ (Hayamizu et al., 1991). The dissociation reaction can also be performed by minority carrier injection in a pn junction (Kimerling and Benton, 1983) or more significantly by illumination (Graff and Pieper, 1981). We exposed our AIG samples to white light produced by halogen tungsten lamp for different time interval. To cut out the infrared components of light and prevent heating, a glass filter has been used and the measured light intensity was about $50 \mathrm{~mW} / \mathrm{cm}^{2}$ which was previously reported to be enough to dissociate all the FeB (Geerligs and Macdonald, 2004).

It is well known that if the $\mathrm{Fe}_{i}$ concentration is much below the boron concentration in $\mathrm{p}-\mathrm{Si},\left(\left[\mathrm{Fe}_{\mathrm{i}}\right]<<\mathrm{N}_{\mathrm{B}}\right)$ nearly all $\mathrm{Fe}_{\mathrm{i}}$ atoms, which are mobile even at room temperature, with some characteristic time $\tau_{\text {ass }}$ becomes trapped by boron atoms forming a complex $\left\{\mathrm{Fe}_{i}{ }^{+} \mathrm{B}\right\}$ bound by Coulomb interaction. The characteristic time constant $\tau_{\text {ass }}$ of this first-order reaction is given by

$$
\tau_{\text {ass }}=\frac{C T}{N_{B}}\left(\exp \frac{0.68 \mathrm{eV}}{K_{B} T}\right)
$$

Where $\mathrm{N}_{B}$ is boron concentration, $\mathrm{T}$ is the temperature in $\mathrm{K}$, and the coefficient $C$ is given by $C \approx 4.3 \cdot 10^{5} \mathrm{sK}^{-1} \mathrm{~cm}^{-3}$ (Zoth and Bergholz, 1990). The estimated time for our samples is of about 2.5 hours. Since usually we made all DLTS measurements in a time more 3 hours after annealing or light illumination, we could expect to observe in our sample mainly the well-known DLTS signal of FeB pairs with energy position of about $\mathrm{E}_{\mathrm{v}}+0.1 \mathrm{eV}$.

\subsubsection{Light-induced transformation of FeB into new trap}

This section demonstrates the interaction between AlG-induced vacancy-related defects and FeB under illumination. DLTS spectra of illuminated p-type float zone silicon Al gettered and non-gettered samples are demonstrated in figure 4.19. Samples were illuminated with cold light for $45 \mathrm{~min}$ at room temperature. The light intensity was monitored to be $50 \mathrm{~mW} /$ $\mathrm{cm}^{2}$. The striking feature of figure 4.19 is the appearance of an additional new trap in the DLTS spectra after illumination, however, control samples (indiffused sample containing the same Fe concentration) without aluminum 


\subsubsection{Reversible dissociation of FeD}

gettering did not produce this new trap, suggesting that this trap is associated with aluminum gettering process. The appearance of this new trap leads to a

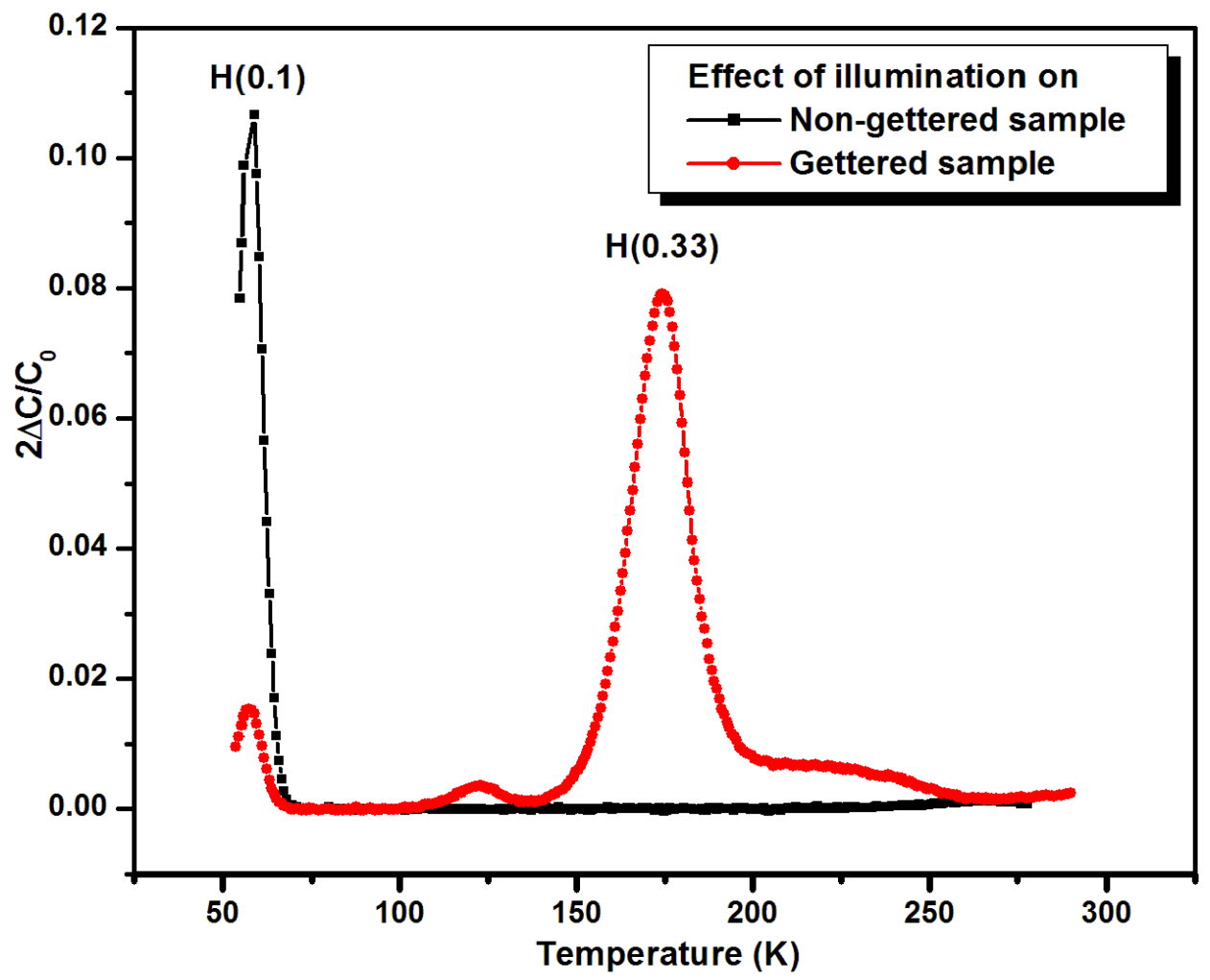

Figure 4.19: Effect of light illumination on the p-type silicon sample contaminated with iron. DLTS spectrum of iron in silicon after indiffusion at $1000^{\circ} \mathrm{C}$ (rectangles), non gettered sample show iron in the form of $\mathrm{FeB}$ pairs as the dominant signal $H(0.1)$, however light illumination induced a new trap at $175 \mathrm{~K}$ in Al gettered sample (circles) containing similar residual concentration of iron.

reduction of the $\mathrm{FeB}$ peak to about $14 \%$ of its original concentration, suggesting that the FeB pair is transformed into the new trap at $175 \mathrm{~K}$. Although not mentioned explicitly, such a transformation most probably involves the $\mathrm{FeB}$ dissociation into $\mathrm{B}$ and $\mathrm{Fe}_{i}$ as an intermediate step (Geerligs and Macdonald, 2004).

In order to determine the activation energy and the capture cross section of the newly developed trap after illumination, we have measured several DLTS spectra at different frequencies to calculate the trap parameters. As one can see in figure 4.20, the amplitude of DLTS corresponding to FeB pairs, $\mathrm{H}(0.1)$ has strongly decreased after illumination for $45 \mathrm{~min}$ and at the same time a second DLTS line has appeared around $175 \mathrm{~K}$. The activation energy for new trap, obtained from analysis of DLTS spectra measured at different frequencies, is $0.33 \mathrm{eV}$. The apparent capture cross-section calculated from pre-exponential factor of the thermal emission rate is $\sigma_{\mathrm{p}}{ }^{*}=3 \cdot 10^{-14} \mathrm{~cm}^{2}$. 
In the previous experiment, we observed the reduction of the $\mathrm{FeB}$ concentration by light illumination in iron doped samples which were

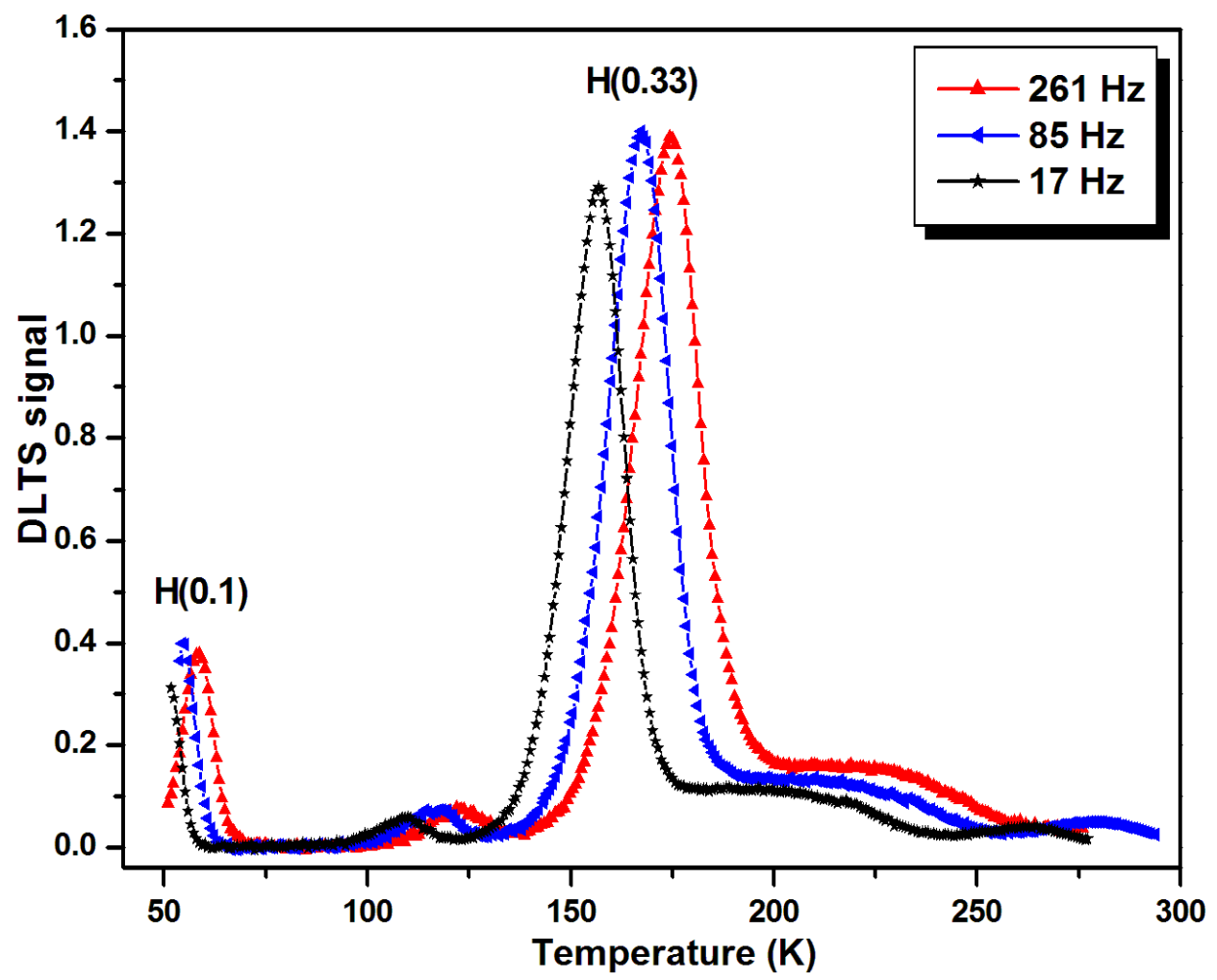

Figure 4.20: DLTS spectra were taken at different frequencies for iron-doped $\mathrm{p}$ type silicon. Iron diffused at $1100^{\circ} \mathrm{C}$, then AIG was performed at the same temperature and samples were then exposed for cold light illumination at room temperature for $45 \mathrm{~min}$. Measuring conditions of DLTS: the filling pulse duration $t_{p}=100 \mu$ s and reverse bias $U_{B}=5 \mathrm{~V}$ and filling pulse bias $U_{p}=4 \mathrm{~V}$.

subjected to aluminum gettering. To find out if the reduction in FeB is correlated with the illumination time, a new set of experiments was carried out to investigate the effect of different illumination time on the formation of the new level $\mathrm{H}(0.33)$, subsequently referred to as the FeD defect. Briefly, three iron doped samples were subjected to AIG $\left(T_{\text {gett }}=T_{\text {ind }}=1100^{\circ} \mathrm{C}\right)$, the first was measured directly after AIG (spectrum 1) without illumination, and the second and third samples were exposed to light illumination for 30 (spectrum 2) and 45 min (spectrum 3) respectively. Changes in intensities of various DLTS signals detected in the samples upon illumination are presented in fig. 4.21. As seen in this figure, substantial increase in the concentration of $\mathrm{FeD}$ complex, correlates well with a decrease of the concentrations of FeB pairs. By using various time of light illumination to the samples before DLTS measurement, different concentrations of $\mathrm{FeB}$ pairs and $\mathrm{FeD}$ are obtained. In our experiments, the total iron concentration is known from the sample before illumination (spectrum 1), and so the sum of the FeB and FeD levels have 


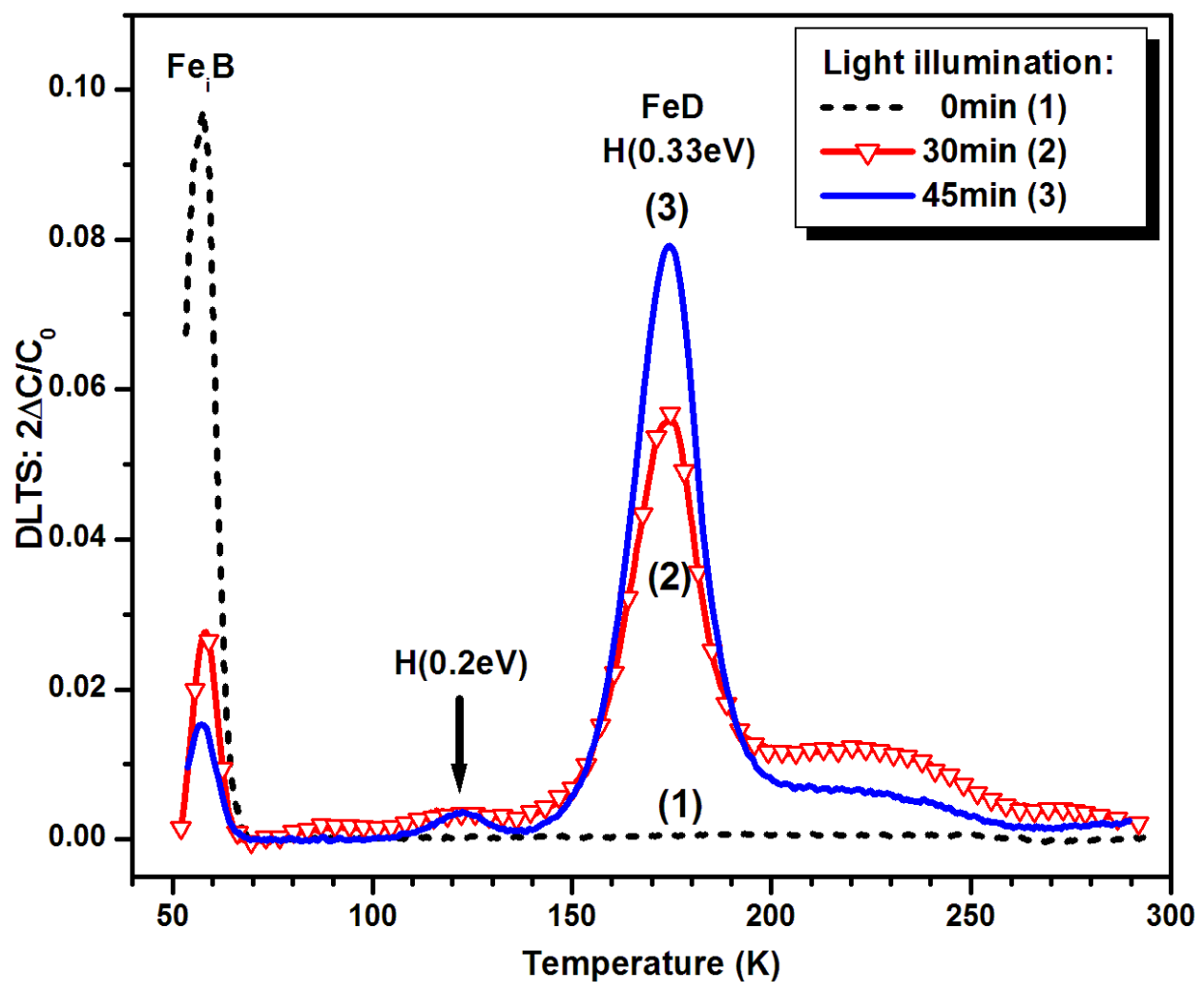

Figure 4.21: DLTS spectra show the effect of cold-light illumination on residual iron after AIG at $1100^{\circ} \mathrm{C}$. Initially, iron is found in form of $\mathrm{Fe}_{\mathrm{i}} \mathrm{B}$ pairs [(1), dashed line]. Illumination at room temperature using white light $\left(50 \mathrm{~mW} / \mathrm{cm}^{2}\right)$ for $30 \mathrm{~min}$ [(2), solid line and triangles], leads to a decrease in the FeB-line and a simultaneous increase in the line labeled "FeD" at $\mathrm{E}_{V}+0.33 \mathrm{eV}$. After $45 \mathrm{~min}$ of illumination [(3), solid line] nearly all iron is found in the FeD line, in addition to a small DLTS signal corresponding to a defect at $\mathrm{E}_{V}+0.2 \mathrm{eV}$. This figure was published by Abdelbarey et al., (2010).

increasing light illumination time, while the FeD increase. This indicates that the concentration of $\mathrm{FeD}$ is light dependent. Thus, light illumination leads to transformation of the FeB $(0.1 \mathrm{eV})$ level into FeD $(0.33 \mathrm{eV})$ level after AIG. FeD concentration depends mainly on the illumination time and highly correlated with the reduction of $\mathrm{FeB}$. It is noteworthy to mention that an additional small DLTS signal appears at $120 \mathrm{~K}$, indicated by an arrow, having an activation energy of about $(\mathrm{H} 0.2 \mathrm{eV})$, and an apparent cross-section of $\sigma_{p}{ }^{*}=3 \cdot 10^{-15} \mathrm{~cm}^{2}$ where $S$ is the ionization entropy of the defect which attributed to divacancy (Brotherton et al., 1983; Trauwaert et al., 1995).

\subsubsection{Reversible dissociation of FeD}

To study the nature of defect, annealing experiments should be performed to give more information about the defect structure, stability, dissociation and location in interstitial or substitutional sites. Hence, it is very 
important to get knowledge of annealing behavior of $\mathrm{FeD}$ and the annealing work in this thesis is partially motivated by this consideration and it might be helpful in the identification of the FeD. Since annealing might lead to some iron precipitation, we made a few experiments with samples containing smaller residual iron concentration after aluminium gettering.

Figure 4.22 shows the results of annealing experiment with a sample which was gettered at $1000^{\circ} \mathrm{C}\left(\mathrm{T}_{\text {gett }}=\mathrm{T}_{\text {ind }}=1000^{\circ} \mathrm{C}\right)$, and therefore had much

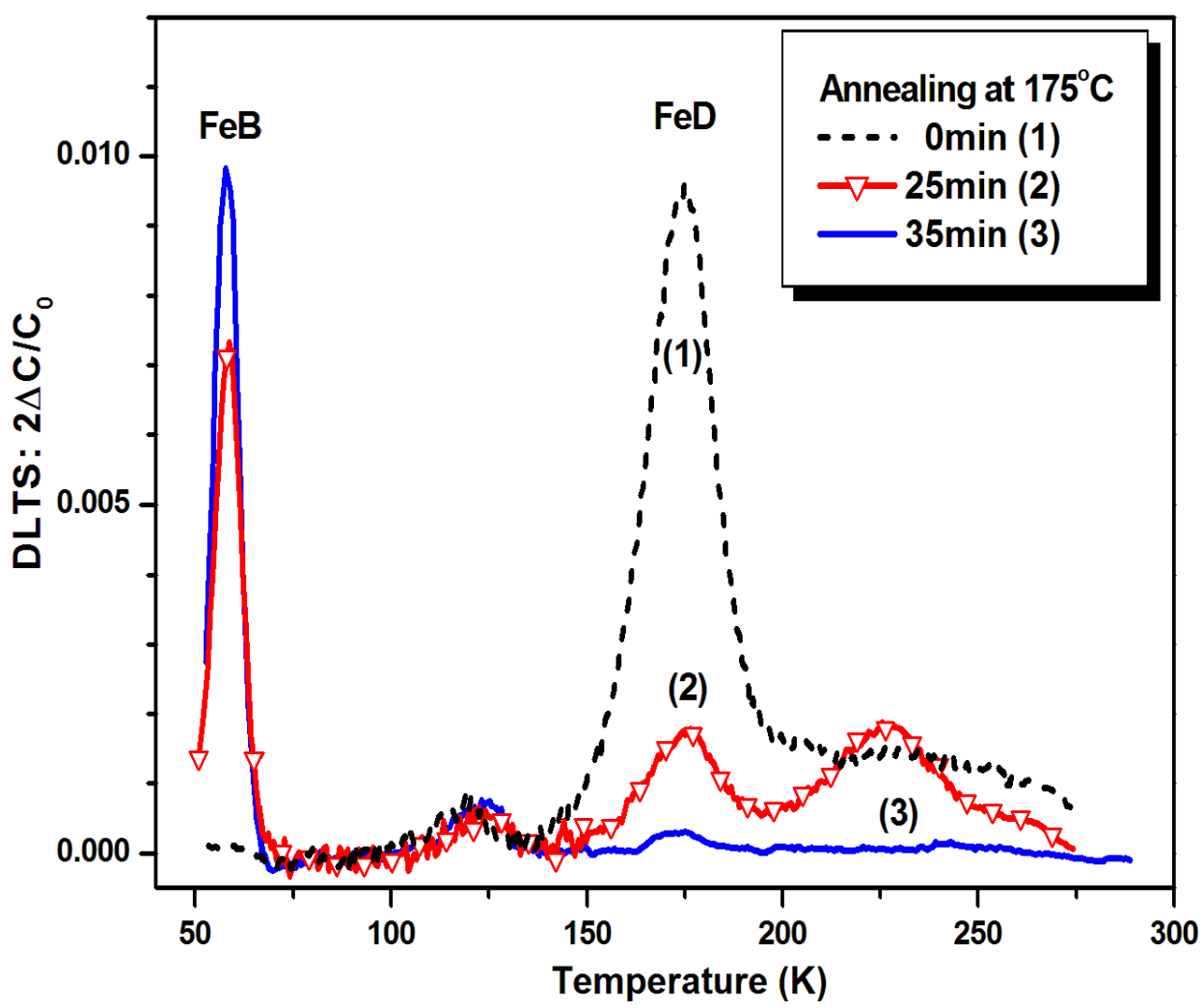

Figure 4.22: Effect of thermal annealing at $175^{\circ} \mathrm{C}$ for the case of small iron concentration $\left(\mathrm{Fe}=4 \cdot 10^{13} \mathrm{~cm}^{-3}\right)$. The initial DLTS spectrum [(1), dashed line] measured after white-light illumination shows the $\mathrm{FeD}$ defect as the dominant species of iron. After annealing at $175^{\circ} \mathrm{C}$ for $25 \mathrm{~min}$ [(2), triangles and solid line] and 35 min [(3), solid line] the FeD signal has decreased which is accompanied by a respective increase in the FeB signal. Hence, the thermal dissociation reaction is reversible for small iron concentrations. This figure was published by Abdelbarey et al., (2010).

smaller Fe concentration after AIG, of about $4.0 \cdot 10^{13} \mathrm{~cm}^{-3}$. These samples were first illuminated for $45 \mathrm{~min}$ to generate the $\mathrm{FeD}$ defect and thereafter annealed at $175^{\circ} \mathrm{C}$ for different times 0,25 and $35 \mathrm{~min}$. A reduction in the concentration of FeD after annealing for 25 min was detected. Further long annealing caused more decrease in FeD trap density. After annealing at $175^{\circ} \mathrm{C}$ for $35 \mathrm{~min}, \mathrm{FeD}$ defect completely disappears, and simultaneously FeB pair reappears. These results suggest that $\mathrm{FeB}$ is transformed into $\mathrm{FeD}$ under 
illumination and annealing at $175^{\circ} \mathrm{C}$ dissociate $\mathrm{FeD}$ defect producing mobile $\mathrm{Fe}_{\mathrm{i}}$ which then bind with boron forming $\mathrm{FeB}$ again, proving the reversible reaction between FeD and FeB.

\subsubsection{Irreversible dissociation of FeD}

To produce samples containing higher concentrations of iron, samples were indiffused with $\mathrm{Fe}$, followed by $\mathrm{AIG}\left(\mathrm{T}_{\text {gett }}=\mathrm{T}_{\text {ind }}=1100^{\circ} \mathrm{C}\right)$. The iron concentrations before illumination was estimated to be about $3.6 \cdot 10^{14} \mathrm{~cm}^{-3}$. Thereafter, gettered samples were illuminated for $45 \mathrm{~min}$ to generate the FeD.

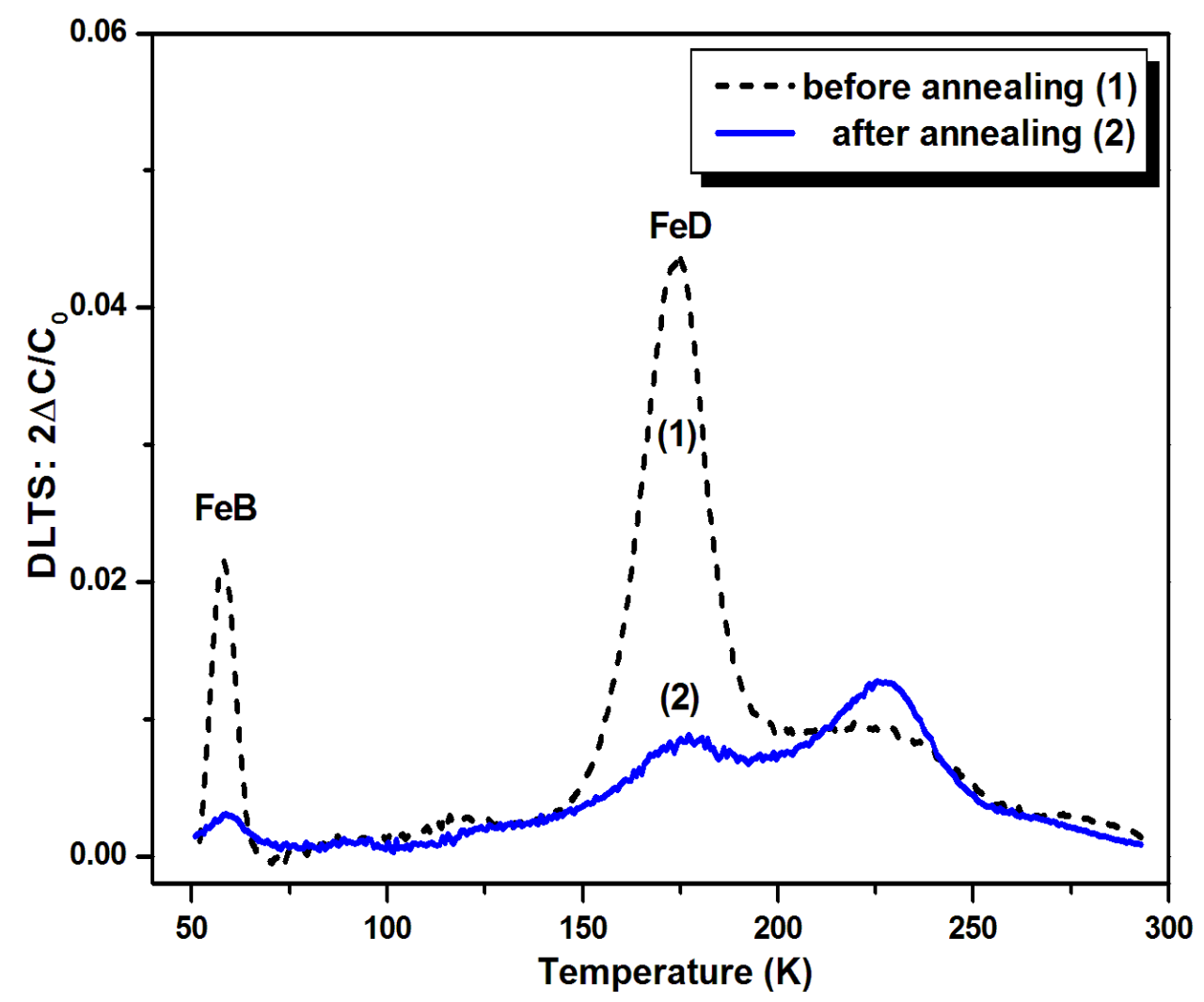

Figure 4.23: Effect of thermal annealing at $175^{\circ} \mathrm{C}$ for $35 \mathrm{~min}$ for the case of high iron concentration $\left(\mathrm{Fe}=3.5 \cdot 10^{14} \mathrm{~cm}^{-3}\right)$. The initial DLTS spectrum (dashed line) measured after white-light illumination shows the FeD defect as the dominant species with some iron still as FeB pairs. After annealing (solid line) both lines have almost disappeared indicating that iron has mainly precipitated. This figure was published by Abdelbarey et al., (2010).

It is noticeable in figure 4.23 that the annealing behaviour of the FeD was affected by the concentration of iron in the sample. Annealing at $175^{\circ} \mathrm{C}$ for 35 min showed dramatic reductions in both $\mathrm{FeB}$ and $\mathrm{FeD}$ defect concentrations. For comparison, spectra 1 and 2 represent the concentrations of FeB and FeD before and after annealing at $175^{\circ} \mathrm{C}$ respectively. From the above consideration, the present experimental result obtained from thermal annealing could be explained as follows: FeD dissociates becoming unstable 
through annealing, liberating mobile interstitial $\mathrm{Fe}$ which subsequently precipitates (Khalil et al., 2005b). The second possibility is the transformation of FeD into the more stable configuration substitutional iron (Estreicher et al., 2008) which, however, should occur independent of the iron concentration contradicting the reversible FeD dissociation described in 4.4.2.

\subsubsection{Characteristics of FeD}

Combining the results of the light illumination and thermal dissociation experiments, a more coherent picture of the FeD defect emerges. Some experimental observations should be considered as key stone and to be very helpful to explore the features of FeD. This may often be of importance for predicting and identifying the FeD defect. Indeed, the following section presents some experimental evidence that help identifying the FeD:

1. After iron in-diffusion, DLTS exclusively shows the FeB pair and illumination does not change the DLTS spectra. Thus, the FeD defect was not observed in our samples without AIG, suggesting that FeD defect is associated with AIG.

2. White light illumination at room temperature induces a decrease of the FeB concentration and a simultaneous increase of FeD, indicating that $\mathrm{FeB}$ is transformed into $\mathrm{FeD}$ under illumination. $\mathrm{FeD}$ concentration depends mainly on the illumination time and highly correlated with the reduction of $\mathrm{FeB}$.

3. For small iron concentrations, annealing at $175^{\circ} \mathrm{C}$ reduces the concentration of $\mathrm{FeD}$, which correlates with the increase of the $\mathrm{FeB}$ pair concentration. This is attributed to the dissociation of $\mathrm{FeD}$ at $175^{\circ} \mathrm{C}$ producing $\mathrm{Fe}_{\mathrm{i}}$ and its subsequent pairing with boron, indicating the reversible dissociation of $\mathrm{FeD}$.

4. For high iron concentrations, annealing at $175^{\circ} \mathrm{C}$ irreversibly reduces the concentration of $\mathrm{FeD}$ and $\mathrm{FeB}$ which is attributed to the dissociation of both defects at $175^{\circ} \mathrm{C}$ producing $\mathrm{Fe}_{i}$ and its subsequent precipitation at this temperature.

5. White light illumination leads further to the formation of a defect with a level at $\mathrm{E}_{\mathrm{v}}+0.2 \mathrm{eV}$, attributed to the donor level of divacancy. This indicates that AIG induced vacancy might be in the form of complex which is sensitive to light exposure.

\subsubsection{Possible candidates for FeD}

The first candidate for $\mathrm{FeD}$ could be $\mathrm{Fe} \mathrm{H}$. A deep level of $\mathrm{Fe}_{\mathrm{i}} \mathrm{H}$ is one potential candidate, since it has been observed at $E_{v}+0.31 \mathrm{eV}$ in $n$-type silicon subjected to chemical etching and its signal disappears after annealing at $175^{\circ} \mathrm{C}$ for $30 \mathrm{~min}$ (Sadoh et al., 1997). Noticeably, a donor level at $\mathrm{E}_{\mathrm{v}}+0.31 \mathrm{eV}$, believed to be associated with the interstitial $\mathrm{Fe}_{\mathrm{i}} \mathrm{H}$ pair, has been reported by 
thermally stimulated capacitance. Positive and negative charges of transition metals have been reported to play a role in the formation and strength of chemical bonds between them and hydrogen. The bonds between neutral hydrogen and positive transition metals were found to be weaker than that between neutral metals and the same neutral hydrogen (Sadoh et al., 1997). Of course, there is no chance for chemical bonding between $\mathrm{Fe}_{i}{ }^{+}$and bond centered hydrogen $\mathrm{H}^{+}$in p-type silicon due to coulomb repulsion (Sanati et al., 2007). This point is further illustrated by the comparison of the emission characteristic of both $\mathrm{FeD}$ and $\mathrm{FeH}$ (see figure 4.24). It is obviously clear from the figure that the emission rate of both $\mathrm{FeD}$ and $\mathrm{FeH}$ are significantly different by more than one order of magnitude. To exclude the inaccuracy in the determination of sample temperature between our setup and that used for $\mathrm{FeH}$ study, data measured for $\mathrm{Fe}_{\mathrm{i}}$ obtained from both studies have been included and were found to be quite comparable to each other. Therefore, it should be noted that FeD is not FeH.

Since the FeD defect was not observed in our samples without AIG, we can speculate that another partner of defect reaction producing $F e D$ is vacancy or some vacancy-related complex. This suggestion seems to be reasonable because according to our experiments with $\mathrm{Au}$ and $\mathrm{Pt}$ indiffusion, the Al layer produces rather high concentration of vacancies in a sample during AIG procedure in our experimental conditions (see section 4.3). Another evidence to support this suggestion is the appearance of a DLTS line corresponding to divacancy after light illumination (see figure 4.21 and 4.22). This line has the same emission characteristic of divacancy (see figure 4.24) of the previous studies (Brotherton et al., 1983; Trauwaert et al., 1995). Moreover, the iron-related FeD defect is stable at room temperature and can be destroyed during annealing at about $175^{\circ} \mathrm{C}$ leaving the $\mathrm{V}_{2}$-defects unaffected in accord with literature data (Hatakeyama et al., 1995). This may often be of importance for suggesting that iron could bind to vacancy or vacancy-related complexes to form FeD.

Iron-vacancy pair $\left(\mathrm{Fe}_{\mathrm{i}} \mathrm{V}\right)$ should be the second candidate for $\mathrm{FeD}$ due to some reasons. Experimentally, $\mathrm{Fe}_{\mathrm{i}} \mathrm{V}$ and other several EPR centers have been detected in iron contaminated silicon following electron irradiation. This treatment leads to the formation of $\mathrm{Fe}_{\mathrm{i}} \mathrm{V}$ which dissociates after annealing at $160^{\circ} \mathrm{C}$ (Muller et al., 1982). These criteria are in a good agreement with our experimental results for FeD. Theoretically, it has been demonstrated that the $\mathrm{Fe}_{\mathrm{i}} \mathrm{V}$ pair could have a donor level at $\mathrm{E}_{\mathrm{v}}+0.35 \mathrm{eV}$ and again anneals out at $160^{\circ} \mathrm{C}$ (Estreicher et al., 2008). Therefore, it was necessary to find out whether our FeD defect is a donor or acceptor. To answer this question, we have measured the hole emission rate of $\mathrm{FeD}$ defect at two different average electric fields in the depletion region of the Schottky contact: $\varepsilon_{1}=3.9 \cdot 10^{4} \mathrm{~V} / \mathrm{cm}$ 


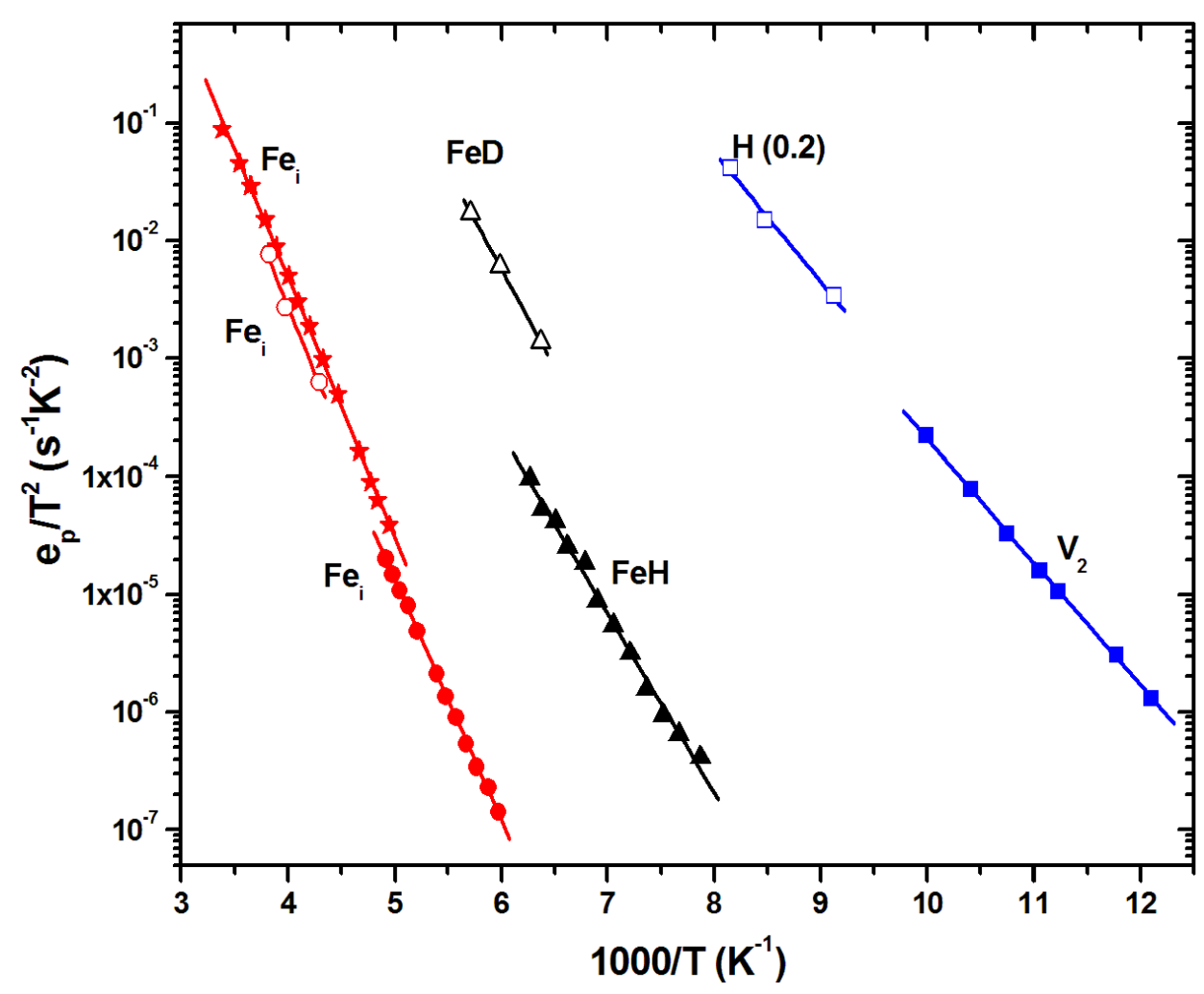

Figure 4.24: Thermal hole emission rates $e_{p}$ of DLTS lines measured in this work (open symbols) compared to literature data. Our data for $\mathrm{H}$ (0.2) (open squares) are in agreement with emission rates reported by Brotherton et al., (1983) (filled squares), whereas those of FeD (open triangles) differ significantly from data reported for FeH by Sadoh et al., (1997) (filled triangles). The comparison of data for the $\mathrm{Fe}_{i}$ donor shows the coincidence of our data (open circles) with those of Sadoh et al., (filled circles) and those of Wünstel and Wagner (1982) (stars) which corroborates the conclusion that FeD cannot be identified with $\mathrm{FeH}$ reported Sadoh et al., (1997). This figure was published by Abdelbarey et al., (2010).

emission rate was $613 \mathrm{~s}^{-1}$ at $\varepsilon_{1}$ and $603 \mathrm{~s}^{-1}$ at $\varepsilon_{2}$, that is the same within experimental accuracy implying the FeD defect to be a donor. For an acceptor level one expects an increase in emission rate by about factor 1.35 with increase in electric field from $\varepsilon_{2}$ to $\varepsilon_{1}$ due to the Poole-Frenkel effect (Kimerling and Benton, 1981). Taken all together, FeD is a donor level at $E_{v}+0.33 \mathrm{eV}$, fits perfectly with all published criteria of $\mathrm{Fe}_{\mathrm{i}} \mathrm{V}$ pair. However, in contrast to Estreicher model of calculation, the observed increase of FeB concentration during annealing of a sample with low iron concentration (see figure 4.22) suggests that our FeD complex can be dissociated to produce free $\mathrm{Fe}_{i}$ atoms that can form $\mathrm{FeB}$ pairs again.

The theoretical calculations estimate the binding energy for $\mathrm{Fe}_{\mathrm{i}} \mathrm{V}$ relative to isolated $\mathrm{Fe}_{i}$ and $\mathrm{V}$ as $1.5 \mathrm{eV}$. So, kinetically the thermal dissociation seems to be possible especially at $175^{\circ} \mathrm{C}$ for $35 \mathrm{~min}$. The dissociation of $\mathrm{Fe}_{\mathrm{i}} \mathrm{V}$ 


\subsubsection{Possible candidates of FeD}

pair produces $\mathrm{Fe}_{\mathrm{i}}$ and isolated vacancies that could form other complexes at the same temperature. The second possibility for this dissociation is the transformation of $\mathrm{Fe}_{\mathrm{i}} \mathrm{V}$ to $\mathrm{Fe}_{\mathrm{s}}$, leading to a substitutional iron. Taken into account that $\mathrm{Fe}_{i}$ is forced to move only along special pathways and with certain velocity into the vacancy of $\mathrm{Fe}_{\mathrm{i}} \mathrm{V}$ complex as shown in figure 4.25 (Estreicher et al., 2008). The former possibility to produce $\mathrm{Fe}_{i}$ is in accord with our experimental observation, assuming that $\mathrm{Fe}_{i} \mathrm{~V}$ moves as a whole and reacts with oxygen to form the stable $\mathrm{VO}_{2}$ complex and liberates $\mathrm{Fe}_{\mathrm{i}}$. Since there is no available data in literature so far about the mobility of $\mathrm{Fe}_{\mathrm{i}} \mathrm{V}$, further investigations are needed to answer this open question.

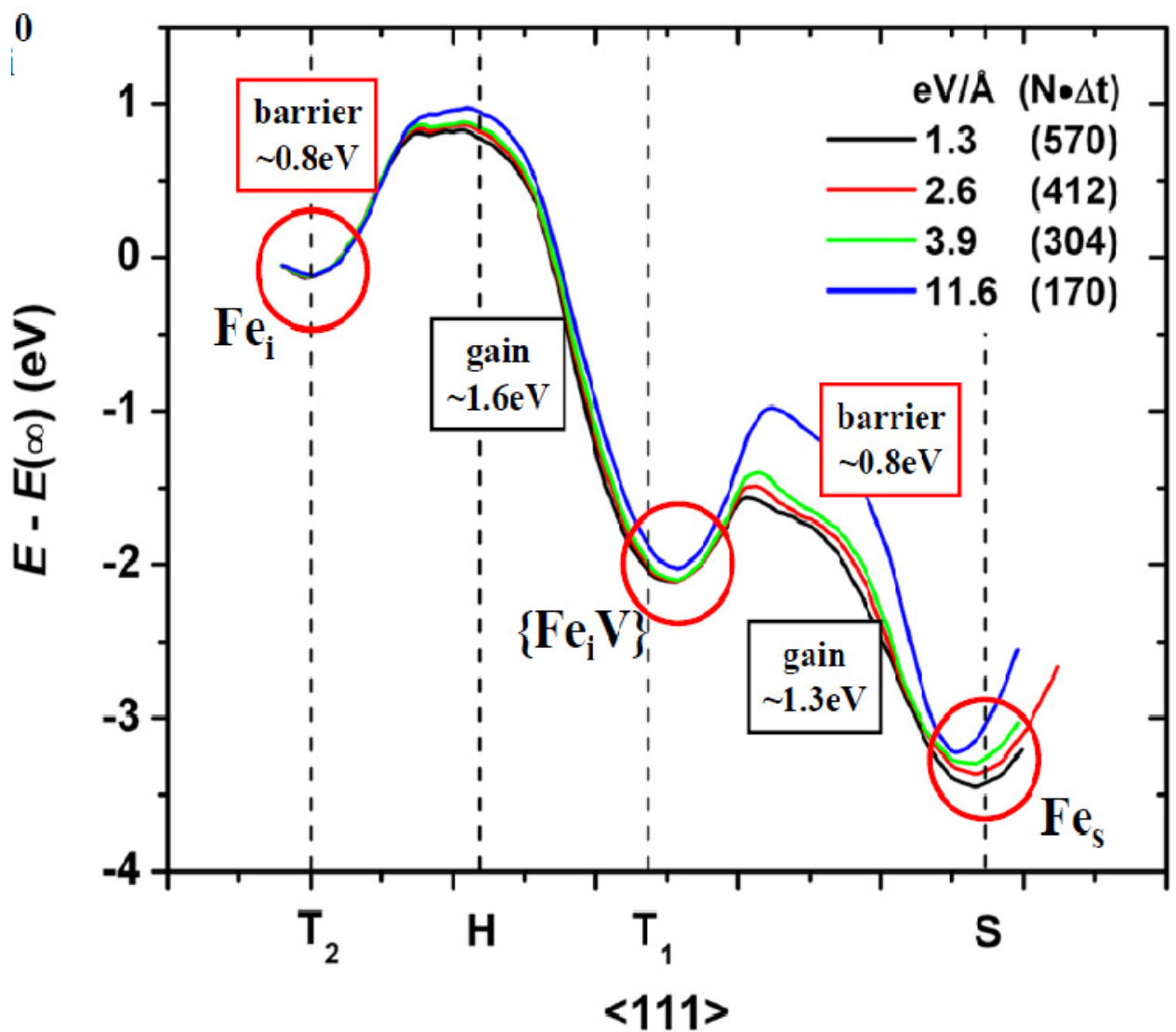

Figure 4.25: Energetics of $\mathrm{Fe}_{i}$ forced to move at constant speed along the $\{111\}$ direction from a $T$ site $\left(T_{2}\right)$ over the hexagonal site $(H)$ to the $T$ site $\left(T_{1}\right)$ nearest to the vacancy, then into the vacancy past the substitutional site (S). The constant force $(e V / \AA)$ used and the number $(N)$ of time steps along the trajectory are indicated. A large force (small $\mathrm{N}$ ) means that the crystal has little time to relax as Fe moves. The zero of the energy $E(\infty)$ corresponds to $\mathrm{Fe}_{i}$ infinitely far away from the vacancy. This figure is quoted from Estreicher et al., (2008).

To conclude, the present extensive study of iron-related defects by means of DLTS has drawn a quite complete picture towards better understanding of AIG. Light-illumination induced transformation of FeB into 
FeD in iron doped FZ p-type crystalline silicon after AIG. A reaction between the $\mathrm{Fe}_{\mathrm{i}}$ released from $\mathrm{FeB}$ and vacancy complex injected by AIG probably occurs since illumination enhanced $\mathrm{FeB}$ dissociation and lead to radiation enhanced defect reactions (Kimerling, 1978). The anneal out of the donor level $\mathrm{FeD}$ at $\mathrm{E}_{\mathrm{v}}+0.33 \mathrm{eV}$ in iron-doped samples with small iron concentration at around $175^{\circ} \mathrm{C}$, together with recovery of $\mathrm{FeB}$ implying a reversible reaction and suggests that $\mathrm{FeD}$ is metastable defect. On the other hand, for samples containing high iron concentrations, annealing at $175^{\circ} \mathrm{C}$ irreversibly reduces the concentration of $\mathrm{FeD}$ and $\mathrm{FeB}$ which is attributed to the dissociation of both defects producing $\mathrm{Fe}_{i}$ and its subsequent precipitation at this temperature. Information obtained from light illumination induced formation of $\mathrm{FeD}$ and its thermal annealing characteristics are supposed to shed light on the understanding of the nature of this defect. Because of the enhanced vacancy concentration observed after AIG, we have proposed that the donor level $\mathrm{FeD}$ defect is assigned to the metastable iron-vacancy pair and according to our knowledge it is the first time to detect the DLTS signal most likely associated with the metastable $\mathrm{Fe}_{\mathrm{i}} \mathrm{V}$ complex. Currently a long discussion has been started about FeD components, importance and its effect on the minority carrier lifetime and diffusion length to optimize the efficiency of solar cell. Clearly a detailed understanding of the precise mechanism of dissociation and the nature of this defect reactions involved would require further experiments. 


\section{Summary and outlook}

The properties of silicon starting materials and its contamination by metal impurities are considered to be the major concern in silicon processing. Even extremely small concentrations of impurities, when present in a harmful form in the device area, can have a detrimental effect on the device yield. In particular, $\mathrm{Fe}$ is incorporated as a highly mobile and soluble species during device processing. To improve device performance, we need to understand the properties of Fe-related defects in silicon and to design efficient processing methods to remove iron from active device region. One of the most important techniques used to determine the electrical characteristics of a defect is known as Deep Level Transient Spectroscopy (DLTS). DLTS is therefore extensively used to study the concentrations and electrical properties of iron-related defects and mechanisms for their formation as well as its depth distribution. This study has revealed some exciting new aspects of the well-studied Fe impurity in silicon. As a result of the present studies, our knowledge on aluminum gettering has become substantially more systematic. The main results obtained from this thesis and conclusions are summarized below.

This thesis is divided into four parts, firstly a description of CV characteristics at different stages of treatments. This is followed by the characterization of FeB pair in iron indiffused samples and subsequently the effects of different protocols of wet chemical etching. The interaction between hydrogen released from the wet chemical etching and iron, and its partial passivation of boron are discussed. To summarize, wet chemical etching of $\mathrm{Fe}$ contaminated p-type $\mathrm{Si}$ leads to decrease of electrically active $\mathrm{FeB}$ detected by DLTS. The most probable reason for this decrease is the direct dissociation of $\mathrm{FeB}$ pairs by hydrogen, which associated with boron passivation of the surface of the sample. Unfortunately, a rough estimate of hydrogen concentration calculated from the carrier concentration profiles of $p$ type samples is not unique. This gives guidelines for future work. For example, the hydrogen concentration with such etchant dilutions is usually substantially limited by temperature and therefore, it is necessary to measure the $\mathrm{pH}$ value before starting the wet chemical etching at the appropriate temperature. These experimental observations indicate that it is crucial to know the hydrogen activity for each mixture of the etchant solution; a process needs new technology other than the conventional analytical chemistry ways.

DLTS is used to study the segregation of Fe from crystalline $\mathrm{Si}$ to an $\mathrm{Al}: \mathrm{Si}$ liquid at its surface, which is the basic mechanism of aluminum gettering 
used in silicon photovoltaics. The second part contains the detailed results obtained from aluminum gettering of iron in p-type $F Z$ silicon annealed at temperature range from $950-1100^{\circ} \mathrm{C}$. Gettering of iron is examined during different treatments of annealing. Simulated and experimental studies are performed to obtain a reliable segregation coefficient for iron. Some interesting properties of segregation coefficient are also discussed in regard to the phase diagram. The measured segregation coefficient is smaller than estimates from the binary Fe:Si and Al:Fe phase diagrams. This apparent discrepancy originates from the ternary character of the system where the solubility of $\mathrm{Fe}$ in $\mathrm{Si}$ in equilibrium with the $\mathrm{Al}$-doped $\alpha \mathrm{FeSi}_{2}$ has to be taken as a reference. Our data suggest that this solubility exceeds that in the binary Fe:Si system by two orders of magnitude. However, it would be beneficial for a future study to confirm this with complementary studies, such as DLTS and Neutron Activation Analysis. Since quantitative data on this effect are not available, experimentally measured values of segregation coefficients are required if predictive simulations of $\mathrm{Al}$ gettering shall yield reliable results.

In the third part, we briefly discuss a generalized belief that aluminum gettering injects vacancy. In this work, the quantitative marker methods, platinum and gold diffusion, are used to profile the concentration of vacancies in the bulk formed by Al alloying. Undoubtedly, the experimental data obtained from platinum and gold indiffusion was able to proof that aluminum gettering injects vacancies with homogenous depth profile. Depth profiles of $\mathrm{Au}$ in $\mathrm{p}$ type Si have been studied by the DLTS after diffusion at $850^{\circ} \mathrm{C}$ for $2 \mathrm{~h}$ prior to and subsequent to $\mathrm{AIG}$. The donor levels attributed to $\mathrm{Pt}_{\mathrm{s}}$ and $\mathrm{Au}_{\mathrm{s}}$ are detected in much higher concentrations compared with that measured in samples without $\mathrm{AIG}$. The increase in $\mathrm{Pt}_{\mathrm{s}}$ or $\mathrm{Au}_{\mathrm{s}}$ concentration in the silicon bulk provides the most direct evidence so far that AIG with 400nm Al layer, for $50 \mathrm{~min}$ at $1100^{\circ} \mathrm{C}$ injects vacancies with non-equilibrium concentrations $\left(10^{15}\right.$ $\mathrm{cm}^{-3}$ ). The obtained results show not only the increase of vacancy concentration as a result of used AIG procedure, but also its homogenous distribution. The interface between aluminum and silicon and the formation of silicon dioxide and aluminum oxide after annealing has been investigated by HRTEM and EDX. The underlying mechanism of vacancy injection during AIG is not known so far and needs further investigations.

Longer-term future research including the combination of different techniques such as DLTS and HRTEM, which has already been started, should be continued to answer the question whether the reaction of an oxide layer with the AISi alloy might also contribute to the generation of vacancies at the AISi/Si interface. In addition, future work will focus on understanding what 


\section{Chapter 5. Summary and outlook}

forms vacancies exist after AIG and the dependence of their profile on the cooling rate or the gettering duration. For example, we will attempt to answer whether vacancies exist in the form of some complex like $\mathrm{VO}_{2}$ or as agglomerations and what concentration produced by different thickness of $\mathrm{Al}$ layer. This work will be accomplished using techniques such as positron annihilation spectroscopy. Based on the experimental results, AIG was able to inject vacancies into Si-wafers; consequently it can strongly influence the process of impurity gettering by Al-Si alloy and should be taking into account during computer simulation of AIG.

Finally, the last part of this thesis deals with the light-induced defects after aluminum gettering of iron doped samples. The influence of experimental parameters such as iron concentration, anneal temperature, illumination time and possible association/dissociation of $\mathrm{FeB}$ are discussed. Particular attention has been given to the interaction of iron and vacancies released from aluminum gettering leading to a novel deep level produced under illumination. One of the most interesting results obtained was the discovery of a new Fe-related defects which has been proofed to be a metastable complex of iron-vacancy pair. It is a donor level with energy position $E_{v}+0.33 \mathrm{eV}$, named FeD. This FeD defect is stable up to about $175^{\circ} \mathrm{C}$ where it dissociates reversibly in case of small iron concentrations and irreversibly for high iron concentrations. Owing to the enhanced vacancy concentration observed after AIG, we have described a tentative scenario of light-induced FeD formation and thermal dissociation involving the reaction of $\mathrm{Fe}_{i}$ and $\mathrm{V}$ to the metastable $\mathrm{Fe}_{i} \mathrm{~V}$ pair described theoretically in the literature. In order to be consistent with these calculations we have proposed that $\mathrm{Fe}_{\mathrm{i}} \mathrm{V}$ is a mobile complex which is a hypothesis that needs to be verified or disproved by further experiments or theoretical investigations. According to our knowledge, detection of FeD by DLTS was firstly described in this study and currently a long discussion has been started about FeD components and importance. Future work will be conducted to determine the roll of FeD on the minority carrier lifetime and diffusion length to optimize the efficiency of solar cell. A copy of published papers containing the discussed results and conclusions, have been included at the end of the thesis. 


\section{References}

Abdelbarey D., Kveder V., Schröter W., Seibt M., Aluminum gettering of iron in silicon as a problem of the ternary phase diagram. Appl. Phys. Lett. 94, 061912 (2009).

Abdelbarey D., Kveder V., Schröter W., Seibt M., Light-induced point defect reactions of residual iron in crystalline silicon after aluminum gettering, J. Appl. Phys. 108, 043519 (2010).

Abdelbarey D., Kveder V., Schröter W., Seibt M., Platinum and gold diffusion monitor vacancy profiles induced into silicon wafers by aluminum alloying, to be published.

Adegboyega G. A., Poggi A., Susi E., Castaldini A., Cavallini A., Schottky contact barrier height enhancement on p-type silicon by wet chemical etching, Appl. Phys. A 48, 391(1989).

Ali A., Majid A., Saleh M. N., Iron and gold related defects in water quenched silicon, J. Mater. Sci: Mater. Electron 18, 421(2007).

Apel M., Hanke I., Schindler R., Schröter W., Aluminum gettering of cobalt in silicon, J. Appl. Phys. 76, 4432 (1994).

Ayad F. and Remram M., Modelling of gettering by mechanical damage of metallic impurities in silicon, Chinese Phys. Lett. 23, 3058 (2006).

Azzizi A, Geerling L. J., Macdonald D., Hydrogen passivation of iron in crystalline silicon. Proc. $19^{\text {th }}$ Europ. PVSEC, Paris, pp 1021-1024 (2004).

Baber N., Scheffler H., Ostmann A., Wolf T., Bimberg D., Field effect on electron emission from the deep Ti donor level in InP, Phys. Rev. B 45, 4043 (1992).

Baldi L., Cerofolini G. F., Ferla G., Frigerio G., Gold solubility in silicon and gettering by phosphorus, Phys. Status Solidi A 48, 523 (1978).

Blood P. and Harris J., Deep states in GaAs grown by molecular beam epitaxy, J. Appl. Phys. 56, 993 (1984).

Blood P. and Orton J. W., In Techniques of Physics, Electrical Characterization of Semiconductors: Majority Carriers and Electron States, Academic Press Limited, London, (1992). 
Bourgoin J. and Lannoo M., Point Defects in Semiconductors II, Experimental Aspects, edited by M. Cardona, Springer Series, Vol. 35, Springer, New York ( 1983).

Bostelmann F., Bachelor thesis, Göttingen University, Germany (2011).

Bronner G. B. and Plummer J. D., Gettering of gold in silicon: A tool for understanding the properties of silicon interstitials, J. Appl. Phys. 61 (12), 5286 (1987).

Brotherton S. D., and Lowther J. E., Electron and hole capture at $\mathrm{Au}$ and $\mathrm{Pt}$ centers in silicon, Phys. Rev. Lett. 44, 606 (1980).

Brotherton S. D., Bradley P., Bicknell J., Electrical properties of platinum in silicon, J. Appl. Phys. 50, , 3396 (1979).

Brotherton S. D., Bradley P., Gill A., Iron and the iron-boron complex in silicon, J. Appl. Phys. 57, 1941(1985).

Brotherton S. D., Bradley P., Gill A., Weber E. R., Electrical observation of the Au-Fe complex in silicon, J. Appl. Phys. 55, 952 (1984).

Brotherton S. D., Parker G. J., Gill A., Photoionization cross section of electron irradiation induced levels in silicon, J. Appl. Phys. 54, 5112 (1983).

Buonassisi T., Istratov A. A., Heuer M., Marcus M. A., Jonczyk R., Isenberg J., Lai B., Cai Z., Heald S., Warta W., Schindler R., Willeke G., Weber E. R., Synchrotron-based investigations of the nature and impact of iron contamination in multicrystalline silicon solar cells, $J$. Appl. Phys. 97, 074901 (2005).

Castaldini A., Cavalcoli D., Cavallini A., Susi E., Hydrogen-induced boron passivation in Cz Si, Appl. Phys. A 75, 601 (2002).

Chen J., Yang D., Wang X., Que D., Kittler M., Aluminum gettering in photovoltaic silicon, Eur. Phys. J. Appl. Phys. 27, 119 (2004).

Collins C. B., and Carlson R. O., Properties of silicon doped with iron or copper, Phys. Rev. 108, 1409 (1957).

Collins C. B., Carlson R. O., Gallagher C. J., Properties of gold-doped silicon, Phys. Rev. 105, 1168 (1957).

Czaputa R., Transition metal impurities in silicon: New defect reactions, Appl. Phys. A 49, 431 (1989). 
del Cañizo C., and Luque A., A comprehensive model for the gettering of lifetime-killing impurities in silicon, J. Electrochem. Soc. 147, 2685 (2000).

Dubois S., Enjalbert N., Warchol F., Martinuzzi S., Is impurity gettering or passivation by hydrogen the improvement key of mc-Si solar cells during processing steps? Mater. Sci. Eng. B 159-160, 239 (2009).

Dubois S., Palais O., Pasquinelli M., Martinuzzi S., Jaussaud C., Rondel N., Influence of iron contamination on the performance of single crystalline silicon solar cells: Computed and experimental results, J. Appl. Phys. 100, 024510 (2006).

Dubois S., Palais O., Ribeyron P. J., Enjalbert N., Pasquinelli M., Martinuzzi S., Effect of intentional bulk contamination with iron on multicrystalline silicon solar cell properties, J. Appl. Phys. 102, 083525 (2007).

Estreicher S. K., Hastings J. L., Fedders P. A., Hydrogen-defect interactions in Si, Mater. Sci. Eng. B 58, 31 (1999).

Estreicher S. K., Hydrogen-related defects in crystalline semiconductors: a theorist's perspective, Mater. Sci. Eng. R 14, 319 (1995).

Estreicher S. K., Sanati M., Gonzalez Szwacki N., Iron in silicon: Interactions with radiation defects, carbon, and oxygen. Phys. Rev. B 77, 125214 (2008).

Falkenberg M. A., Abdelbarey D., Kveder V., Seibt M., Comparison of efficiency and kinetics of phosphorus-diffusion and aluminum gettering of metal impurities in silicon: a simulation study, Solid State Phenomena 156-158, 229 (2010).

Falster R., Pagani M., Gambaro D., Cornara M., Olmo M., Ferrero G., Pichler P., Jacob M., Vacancy-assisted oxygen precipitation phenomena in $\mathrm{Si}$, Solid State Phenomena 57-58, 129 (1997).

Falster R., Voronkov V. V., Quast F., On the properties of the intrinsic point defects in silicon: A perspective from crystal growth and wafer processing, Phys. Status Solidi B 222, 219 (2000).

Feichtinger H., Gschwandtner A., Waltl J., Interstitial iron and thermal defects in silicon, Phys. Status Solidi A 53, K71 (1979).

Feklisova O. V., and Yakimov E. B., An application of gold diffusion for defect investigation in silicon, Physica B 404, 4681 (2009a).

Feklisova O. V., and Yakimov E. B., Effect of dislocation trails on gold diffusion in Si, Phys. Status Solidi C 6, 1823 (2009b). 
Feklisova O. V., Parakhonsky A. L., Yakimov E. B., Weber J., Dissociation of iron-related centers in Si stimulated by hydrogen, Mater. Sci. Eng. B 71, 268 (2000).

Frank F. C., and Turnbull D., Mechanism of diffusion of copper in germanium, Phys. Rev. 104, 617 (1956).

Frank W., Gösele U., Mehrer H., Seeger A., Diffusion in crystalline solids, Academic, Orlando, FL, p. 64 (1984).

Frenkel J., On pre-breakdown phenomena in insulators and electronic semiconductors, Phys. Rev. 54, 647 (1938).

Ganichev S. D., Ziemann E., Prettl W., Yassievich I. N., Istratov A.A., Weber E.R., Distinction between the Poole-Frenkel and tunneling models of electric-field-stimulated carrier emission from deep levels in semiconductors. Phys. Rev. B 61, 10361 (2000).

Geerligs L. J., and Macdonald D., Dynamics of light-induced FeB pair dissociation in crystalline silicon. Appl. Phys. Lett. 85, 5227 (2004).

Gerson J. D., Cheng L. J., Corbett J. W., A quenched-in defect in borondoped silicon, J. Appl. Phys. 48, 4821 (1977).

Gilles D., Schröter W., Bergholz W., Impact of the electronic structure on the solubility and diffusion of $3 d$ transition elements in silicon. Phys. Rev. $B$ 41, 5770 (1990).

Goetzberger A. and Shockley W., Metal precipitates in silicon p-n junctions, J. Appl. Phys. 31, 1821 (1960).

Gonzalez Szwacki N., and Estreicher S.K., First-principles investigations of Fe-H interactions in silicon, Physica B 401-402, 171 (2007).

Gonzalez Szwacki N., Sanati M., Estreicher S. K., Two FeH pairs in n-type Si and their implications: A theoretical study, Phys. Rev. B 78, 113202 (2008).

Gösele U., Frank W., Seeger A., Mechanism and kinetics of the diffusion of gold in silicon, Appl. Phys. 23, 361 (1980).

Graff K., and Pieper H., The properties of iron in silicon, J. Electrochem. Soc. 128, 669 (1981).

Graff K., Metal Impurities in Silicon-Device Fabrication, Second edition. volume 24, Berlin, Springer (1999).

Graff K., Transition Metals in Silicon and their Gettering Behaviour, Mater. Sci. Eng. B4, 6369 (1989). 


\section{Chapter 6. References}

Green M. A., Emery K., Hishikawa Y., Warta W., Solar cell efficiency tables (version 37), Prog. Photovolt: Res. Appl.,19, 84 (2011).

Gunnlaugsson H. P., Fanciulli M., Dietrich M., Bharuth-Ram K., Sielemann R., Weyer G., the ISOLDE collaboration, charge state dependence of the diffusivity of interstitial $\mathrm{Fe}$ in silicon detected by Mössbauer spectroscopy, Appl. Phys. Lett. 80, 2657 (2002).

Hartiti B., Slaoui A., Muller J. C., Siffert P., Large diffusion length enhancement in silicon by rapid thermal codiffusion of phosphorus and aluminum, Appl. Phys. Lett. 63, 1249 (1993).

Hartke J. L., The three-dimensional Poole-Frenkel effect, J. Appl. Phys. 39, 4871 (1968).

Hatakeyama H., Suezawa M., Markevich V. P., Sumino K., Formation of hydrogen-oxygen-vacancy complexes in silicon, Mater. Sci. Forum 196-201, 939 (1995).

Hayamizu Y., Hamaguchi T., Ushio S., Abe T., Shimura F., Temperature dependence of minority-carrier lifetime in iron-diffused p-type silicon wafers, J. Appl. Phys. 69, 3077 (1991).

Heiser T., and Mesli A., Charge-state-dependent diffusion and carrieremission-limited drift of iron in silicon, Phys. Rev. Lett. 68, 978 (1992).

HiesImair H., Balasubramanian S., Istratov A. A., Weber E. R., Gettering simulator: physical basis and algorithm, Semicond. Sci. Technol. 16, 567 (2001).

HiesImair H., McHugo S., Weber E. R., Aluminum backside segregation gettering, Proceedings of the 25th IEEE Photovoltaic Specialists Conference. Washington D.C., 13-17 May, pp 441-444 (1996).

Irmscher K., Klose H., Maass K., Electric field enhanced electron emission from gold acceptor level and A-centre in silicon, Phys. Status Solidi A, 75, K25 (1983).

Istratov A. A., Buonassisi T., McDonald R. J., Smith A. R., Schindler R., Rand J. A., Kalejs J. P., Weber E. R., Metal content of multicrystalline silicon for solar cells and its impact on minority carrier diffusion length, J. Appl. Phys. 94, 6552 (2003b).

Istratov A. A., Buonassisi T., Pickett M. D., Heuer M., Weber E. R., Control of metal impurities in "dirty" multicrystalline silicon for solar cell, Mater. Sci. Eng B 134, 282 (2006).

Istratov A. A., Hieslmair H., Weber E. R, Iron and its complexes in silicon, Appl. Phys. A: Mater. Sci. Process. 69, 13 (1999). 
Istratov A. A., Hieslmair H., Weber E. R., Iron contamination in silicon technology, Appl. Phys. A: Mater. Sci. Process. 70, 489 (2000a).

Istratov A. A., HiesImair H., Weber E.R, Advanced gettering techniques in ULSI Technology, MRS Bulletin, p. 33 (2000b).

Istratov A. A., Huber W., Weber E. R., Modeling of competitive gettering of iron in silicon integrated circuit technology, J. Electrochem. Soc. 150, G244 (2003a).

Jacob M., Pichler P., Ryssel H., Falster R., Determination of vacancy concentrations in the bulk of silicon wafers by platinum diffusion experiments, J. Appl. Phys. 82, 182 (1997).

Jastrzebski L., Lagowski J., Henley W., Edelman P., In: Beam-Solid Interactions for Materials Synthesis and Characterization, ed. By D. C. Jacobson, D. E. Luzzi, T. F. Heinz, M. Iwaki, Mater. Res. Soc., Pittsburgh, p. 405 (1995).

Jeong J.-W., Rosenblum M. D., Kalejs J. P., Rohatgi A., Hydrogenation of defects in edge-defined film-fed grow aluminum-enhanced plasma enhanced chemical vapor deposited silicon nitride multicrystalline silicon, J. Appl. Phys. 87, 7551 (2000).

Jiang F., Stavola M., Rohatgi A., Kim D., Holt J., Atwater H., Kalejs J., Appl. Phys. Lett. 83, 931 (2003).

Jooss W., Hahn G., Fath P., Willeke G., Bucher E., Improvement of diffusion lengths in multicrystalline $\mathrm{Si}$ by $\mathrm{P}$-Al co-gettering during solar cell processing, Proceedings of the $2^{\text {nd }}$ World Conference on Photovoltaic Solar Energy Conversion, Vienna, Austria (1998).

Joshi S. M, Gösele U. M., Tan T. Y., Improvement of minority carrier diffusion length in Si by Al gettering, J. Appl. Phys. 77, 3858 (1995).

Joshi S. M, Gösele U. M., Tan T. Y., Extended high temperature Al gettering for improvement and homogenization of minority carrier diffusion lengths in multicrystalline Si, Sol. Energy Mater. Sol. Cells 70, 231 (2001).

Jost W., Weber J., Lemke H., Hydrogen-induced defects in cobalt-doped ntype silicon, Semicond. Sci. Technol. 11, 22 (1996).

Kaminski P., Kozlowski R., Jelenski A., Mchedlidze T., Suezawa M., Highresolution photoinduced transient spectroscopy of electrically active iron-related defects in electron irradiated high-resistivity silicon, Jpn. J. Appl. Phys. 42, 5415 (2003). 
Kang J. S. and Schröder D. K., Gettering in silicon, J. Appl. Phys. 65, 2974 (1989).

Karg D., Pensl G., Schulz M., Proceedings of third World Conference on Photovoltaic Energy Conversion, Osaka, May 12-16, Volume 2, p. 1112 (2003).

Kazmerski L. L., Solar photovoltaics R\&D at the tipping point: A 2005 technology overview. Journal of Electron Spectroscopy and Related Phenomena 150, 105 (2006).

Khalil R., Ph. D. thesis, Göttingen University, Germany (2004).

Khalil R., Kveder V., Schröter W., Seibt M., Electrical properties of clustered and precipitated iron in silicon, Solid State Phenomena 108-109, 109 (2005b).

Khorosheva M. A., Orlov V. I., Abrosimov N. V., Kveder V. V., Determination of the nonequilibrium concentration of vacancies in silicon crystals by measuring the concentration of nickel atoms at lattice sites, J. Exp. Theor. Phys. 110, 796 (2010).

Kimerling L. C ., Benton J. L., Rubin J. J., Defects and radiation effects in semiconductors, Inst. Phys. Conf. Ser. 59, p. 217, (1981).

Kimerling L. C., and Benton J. L., Oxygen-related donor states in silicon, Appl. Phys. Lett. 39, 410 (1981).

Kimerling L. C., Recombination enhanced defect reactions, Solid State Electron. 21, 1391 (1978).

Kimerling L.C., and Benton J. L., Electronically controlled reactions of interstitial iron in silicon, Physica B 116, 297 (1983).

Komarov B. A., Special features of radiation-defect annealing in silicon $p-n$ structures: The role of Fe impurity atoms, Semiconductors 38 (9), 1041 (2004).

Korol E. N., Ionization of impurity state by an electric field, Sov. Phys. Solid State 19, 1327 (1977).

Kouketsu M., and Isomae S., Hydrogen passivation of iron-related hole traps in silicon, J. Appl. Phys. 80, 1485 (1996).

Kouketsu M., Watanabe K., Isomae S., Hydrogen passivation of iron-related hole traps in silicon, Mater. Sci. Forum 196-201, 861 (1995).

Krain R., Herlufsen S., Schmidt J., Internal gettering of iron in multicrystalline silicon at low temperature, Appl. Phys. Lett. 93, 152108 (2008). 
Kveder V., Schröter W., Sattler A., Seibt M., Simulation of Al and phosphorus diffusion gettering in Si, Mater. Sci. Eng. B 71, 175 (2000).

Laades A., Lauer K., Blech M., Maier C., Alber D., Bähr M., Lawerenz A., Iron gettering in CZ silicon solar cells, $24^{\text {th }}$ European Photovoltaic Solar Energy Conference and Exhibition, 21-24 September 2009, Hamburg, Germany.

Lang D. V., Deep level transient spectroscopy: A new method to characterize traps in semiconductors, J. Appl. Phys. 45, 3023 (1974).

Ledebo L. A., and Wang Z. G., Evidence that the gold donor and acceptor in silicon are two levels of the same defect, Appl. Phys. Lett. 42, 680 (1983).

Lemke, H. Eigenschaften einiger Storstellenkomplexe von Zink in Silizium, Phys. Stat. Sol. (a) 72, 177 (1982).

Luque A., Moehlecke A., Lagos R., del Cañizo C., Segregation model for Si gettering by Al, Phys. Status Solidi A 155, 43 (1996).

Macdonald D., Cuevas A., Geerligs L. J., Measuring dopant concentrations in compensated p-type crystalline silicon via iron-acceptor pairing , Appl. Phys. Lett. 92, 202119 (2008).

Macdonald D., Cuevas A., Wong-Leung J., Capture cross-sections of the acceptor level of iron-boron pairs in p-type silicon by injection-level dependent lifetime measurements, J. Appl. Phys. 89, 7932 (2001).

Martinuzzi S., Henquinet N. G., Perichaud I., Mathieu G., Torregrossa F., Efficiency of cavity gettering in single and in multicrystalline silicon wafers, Mater. Sci. Eng. B 71, 229 (2000).

Martinuzzi S., Perichaud I., Simon J. J., External gettering by aluminumsilicon alloying observed from carrier recombination at dislocations in float zone silicon wafers, Appl. Phys. Lett. 70, 2744 (1997).

Martinuzzi S., Poitevin H., Zehaf M, Zurletto C., Improvement of electron diffusion lengths in polycrystalline silicon wafers by aluminum, Rev. Phys. Appl. 22, 645 (1987).

Martinuzzi S., Porre O., Perichaud I., Pasquinelli M., Aluminum gettering in silicon wafers, J. Phys. III France 5, 1337 (1995).

Massalski T. B., Murray J. L., Bennett L. H., Baker H., Binary Alloy Phase Diagrams, ASM International, Materials Park, Ohio, (1986).

Massalski T. B., Okamoto H., Subramanian P.R., Kacprzak L., Binary Alloy Phase Diagrams, ASM International, Materials Park, Ohio, USA (1990). 


\section{Chapter 6. References}

Mchedlidze T. and Suezawa M., New electron spin resonance spectra from iron-vacancy pair in silicon: I. Defect with two values for the spin, Physica B 308-310, 421 (2001).

Mchedlidze T., and Suezawa M., An iron-phosphorus pair in silicon, J. Phys. Condens. Matter 16, L79-L84 (2004).

Mchedlidze T., and Suezawa M., Properties of an iron-vacancy pair in silicon, Jpn. J. Appl. Phys. 41, 7288 (2002).

Mchedlidze T., Formation and properties of iron-phosphorus and ironphosphorus-hydrogen complexes in silicon, Solid State Phenomena 108-109, 379 (2005).

McHugo S. A., and HiesImair H., Gettering in silicon, Wiley Encyclopedia of Electrical and Electronics Engineering volume 8, ed. J. G. Webster (New York, Wiley) p. 388 (1999).

McHugo S. A., McDonald R. J., Smith A. R., Hurley D. L., Weber E.R., iron solubility in highly boron-doped silicon, Appl. Phys. Lett. 73, 1424 (1998).

Miller G. L., Lang D. V., Kimerling L. C., Capacitance transient spectroscopy, Ann. Rev. Mater. Sci, 7, 377 (1977).

Mooney P. M., Identification of defects in semiconductors, In: Semiconductors and Semi-metals, edited by M. Stavola Volume 51B, p. 93, Academic Press, (1999).

Muller S. H., Tuynman G. M., Sieverts E. G., Ammerlaan C. A. J., Electron paramagnetic resonance on iron-related centers in silicon, Phys. Rev. $B$ 25, 25 (1982).

Myers S. M., Seibt M., Schröter W., Mechanisms of transition-metal gettering in silicon, J. Appl. Phys. 88, 3795 (2000).

Nakamura M., Kato T., Oi N., A Study of gettering effect of metallic impurities in silicon, Jpn. J. Appl. Phys. 7, 512 (1968).

Nakashima H., Sadoh T., Tsurushima T., Electrical and thermal properties of structurally metastable iron-boron pairs in silicon, Phys. Rev. B 49, 16983 (1994).

Nassibian A. G., and Golja B., Comparison of $\mathrm{Ar}^{-}, \mathrm{O}^{-}$and $\mathrm{Cl}^{-}$ion implantdamage gettering of gold from silicon using metal oxide silicon techniques, J. Appl. Phys. 54, 6168 (1982). 
Ourmazd A., and Schröter W., Phosphorus gettering and intrinsic gettering of nickel in silicon, Appl. Phys. Lett. 45, 781 (1984).

Pankove J. I., Carlson D. E., Berkeyheiser J. E., Wance R. O., Neutralization of shallow acceptor levels in silicon by atomic hydrogen, Phys. Rev. Lett. 51, 2224 (1983).

Pankove J. I., Zanzucchi P. J., Magee C. W., Hydrogen localization near boron in silicon, Appl. Phys. Lett. 46, 421 (1985).

Pearton S. J., and Tavendale A. J., Electrical properties of deepmsilver and iron-related centers in silicon, J. Phys. C: Solid State Phys. 17, 6701 (1984).

Phang S. P., and Macdonald D., Direct comparison of boron, phosphorus and aluminum gettering of iron in crystalline silicon, J. Appl. Phys. 109, 073521 (2011).

Pichler P., Intrinsic point defects, impurities, and their diffusion in silicon, computational microelectronics. Spring, Wien (2004).

Pomerantz D., A cause and cure of stacking faults in silicon epitaxial layers, J. Appl. Phys. 38, 5020 (1967).

Pons D., Accurate determination of the free carrier capture kinetics of deep traps by space-charge methods, J. Appl. Phys. 55, 3644 (1984).

Porre O., Martinuzzi S., Pasquinelli M., Perichaud I., Gay N., Gettering effect of aluminum in mc-Si and c-Si wafers and in solar cells, Proceedings of the 25th IEEE Photovoltaic Specialists Conference. Washington D.C. 13-17 May (1996) 629-632.

Riedel F., Ph. D thesis, Göttingen University, (1994).

Rijks H. J., Bloem J., Gilin L. J., Heat treatment of silicon and the nature of thermally induced donors. J. Appl. Phys. 50, 1370 (1979).

Rivlin G., and Raynor G. V., Phase equilibria in iron ternary a critical evaluation of constitutions of aluminum-iron-silicon system, International Metals Reviews 26, 133 (1981).

Robbins H., and Schwartz B., Chemical etching of silicon, J. Electrochem. Soc. 106, 505 (1959).

Rohatgi A., Yelundur V., Jeong J.-W., Ebong A., Rosenblum M. D., Hanoka J. I., Fundamental understanding and implementation of Al-enhanced PECVD SiN $\mathrm{S}_{\mathrm{X}}$ hydrogenation in silicon ribbons, Sol. Energy Mater. Sol. Cells 74, 117 (2002). 
Sachse J.-U., Sveinbjörnsson E. O., Jost W., Weber J., Electrical properties of platinum-hydrogen complexes in silicon, Phys. Rev. B 55, 16176 (1997).

Sadoh T., Tsukamoto K., Baba A., Bai D., Kenjo A., Tsurushima T., Mori H., Nakashima H., Deep level of iron-hydrogen complex in silicon, J. Appl. Phys. 82, 3828 (1997).

Sah C. T., Sun J. Y.-C., Tzou J. J.-T., Deactivation of the boron acceptor in silicon by hydrogen, Appl. Phys. Lett. 42, 204 (1983).

Sana P., Rohatgi A., Kalejs J.P., Bell R.O., Gettering and hydrogen passivation of EFG multicrystalline silicon solar cells by Al diffusion and forming gas anneal, Appl. Phys. Lett. 64, 97 (1994).

Sanati M., Szwacki N. G., Estreicher S. K., Interstitial Fe in $\mathrm{Si}$ and its interactions with hydrogen and shallow dopants, Phys. Rev. B 76, 125204 (2007).

Sattler A., Ph. D. thesis, Göttingen University, Germany (2002).

Sattler A., Seibt M., Kveder V., Schröter W., Interaction of interstitially dissolved cobalt and oxygen-related centres in silicon, Solid State Phenomena 95-96, 553 (2004).

Schmidt J., and Cuevas A., Electronic properties of light-induced recombination centers in boron-doped Czochralski silicon, J. Appl. Phys. 86, 3175 (1999).

Schröder D. K., Semiconductor Material and Device Characterization- Third Edition. Hoboken, New Jersey: John Wiley \& Sons, Inc. (2006).

Schröter W., Döller A., Zozime A., Kveder V., Seibt M., Spiecker E., Phosphorus diffusion gettering of metallic impurities in silicon: mechanisms beyond segregation, Solid State Phenomena 95-96, 527 (2003).

Schröter W., Kronewitz J., Gnauert U., Riedel F., Seibt M., Band like and localized states at extended defects in silicon, Phys. Rev. B 52, 13726 (1995).

Schröter W., Seibt M., Gilles D., High temperature properties of 3d transition elements in silicon, In: Electronic Structure and Properties of Semiconductors, von Materials Science and Technology: A Comprehensive Treatment, R. W. Cahn, P. Haasen, E. J. Kramer, VCH, New York, , volume 4, p. 539 (1991).

Schröter W., Seibt M., Gilles D., High Temperature Properties of 3d Transition Elements in Silicon, In: Electronic Structure and Properties of 
Semiconductors von Handbook of Semiconductor Technology, K. A. Jackson and W. Schröter, VCH, New York, volume 1, p. 597 (2000).

Schubert E. F., Doping in III-V Semiconductors, Cambridge University Press, 1993.

Schubert W. K., and Gee J. M., Phosphorus and aluminum getteringinvestigation of synergistic effects in single crystal and multicrystalline silicon, Proceedings of the $25^{\text {th }}$ IEEE Photovoltaic Specialists Conference, Washington D.C. pp. 437-440 (1996).

Schwager P., Diploma thesis, Göttingen University, Germany (2011).

Seager C. H., Anderson R. A., Brice D. K., In situ measurements of hydrogen motion and bonding in silicon, J. Appl. Phys. 68, 3268 (1990).

Seager C. H., Anderson R. A., Panitz J. K. G., The diffusion of hydrogen in silicon and mechanisms for "unintentional" hydrogenation during ion beam processing, J. Mater. Res. 2, 96 (1987).

Seibt M., Döller A., Kveder V., Sattler A., Zozime A. Phosphorus diffusion gettering of platinum in silicon: Formation of near surface precipitates, Phys. Status Solidi B 222, 327 (2000).

Seibt M., Sattler A., Rudolf C., Voß O., Kveder V., Schröter W., Gettering in silicon photovoltaics: current state and future perspectives, Phys. Status Solidi A 203 (4), 696 (2006).

Sheperd W. H., and Turner J. A., Iron-boron pairing in silicon , J. Phys. Chem. Solids 23, 1697 (1962).

Shiraishi M., Sachse J.-U., Lemke H., Weber J., DLTS analysis of nickelhydrogen complex defects in silicon, Mater. Sci. Eng. B 58, 130 (1999).

Smigelskas A.D. and Kirkendall E.O., Zinc diffusion in alpha brass, Trans. AIME, 171, 130 (1947).

Sopori, B L., Silicon solar-cell processing for minimizing the influence of impurities and defects, J. Elect. Mater. 31, 972 (2002).

Sopori B. L., Deng X., Benner J. P., Rohatgi A., Sana P., Estreicher S. K., Park Y. K., Roberson M. A., Hydrogen in silicon: A discussion of diffusion and passivation mechanisms, Sol. Energy Mater. Sol. Cells 41-42, 159 (1996).

Steinert M., Acker J., Henßge A., Wetzig K., Experimental studies on the mechanism of wet chemical etching of silicon in HF/HNO3 mixtures. $J$. Electrochem. Soc. 152, C843 (2005). 


\section{Chapter 6. References}

Struthers D., Solubility and diffusivity of gold, iron, and copper in silicon, J. Appl. Phys. 27, 1560 (1956).

Sullivan J. P., Graham W. R., Tung R. T., Schrey F., Pitfalls in the measurement of metal/p-Si contacts: The effect of hydrogen passivation, Appl. Phys. Lett. 62, 2804 (1993).

Sundaresan R., Burk D. E., Fossum J. G., Potential improvement of polysilicon solar cells by grain boundary and intragrain diffusion of aluminum, J. Appl. Phys. 55, 1162 (1984).

Swanson R., in Proceedings of the 20th European PV Solar Energy Conference, Barcelona, 2004.

Sze S. M., Physics of semiconductor devices, John Wiley, (USA) 1981.

Szymański K., Baas J., Dobrzyński L., Satula D., Magnetic and Mössbauer investigation of $\mathrm{FeSi}_{2-\mathrm{x}} \mathrm{Al}_{\mathrm{x}}$, Physica B 225, 111 (1996).

Takahashi H., Suezawa M., Sumino K., Charge-state-dependent activation energy for diffusion of iron in silicon, Phys. Rev. B 46, 1882 (1992).

Takahashi T., and Suezawa M., ESR study of Fe-H complexes in Si, Physica B 273-274, 445 (1999).

Tan T.Y. and Li N., Precipitate dissolution and gettering under vacancy injection in silicon, Final Subcontract Report 21 March 2006-15 January 2008.

Tang C.K., Vines L., Svensson B.G., Monakhov E.V., Interaction between hydrogen and the Fe-B pair in boron-doped p-type silicon, Applied Physics Letters 99, 052106 (2011).

Tasch A. F., and Sah C.T, Recombination-generation and optical properties of gold acceptor in silicon, Phys. Rev. B1, 800 (1970).

Tavendale A. J., Williams A. A., Pearton S. J., In: Defects in Electronic Materials, edited by M. Stavola, S. J. Pearton, and G. Davies, MRS Symposia Proceedings No. 104, Materials Research Society, Pittsburgh, p. 285 (1988).

Thompson R. D., and Tu K.N., Low temperature gettering of $\mathrm{Cu}, \mathrm{Ag}$ and $\mathrm{Au}$ across a wafer of Si by Al, Appl. Phys. Lett. 41, 440 (1982).

Tice W. K., Tan T.Y., Precipitation of oxygen and intrinsic gettering in silicon, Mat. Res. Soc. Symp. Proc. 2, 367 (1981).

Trauwaert M.-A., Vanhellemont J., Maes H. E., Van Bavel A.-M., Langouche G., Clauws P., Low-temperature anneal of the divacancy in $p$-type 
silicon: A transformation from $\mathrm{V}_{2}$ to $\mathrm{V}_{x} \mathrm{O}_{y}$ complexes, Appl. Phys. Lett. 66, 3056 (1995).

Trushin M.O., Vyvenko O., Seifert W., Jia G., Kittler M., Iron-oxygen interaction in silicon: A combined XBIC/XRF-EBIC-DLTS study of precipitation and complex building, Physica B 404, 4645 (2009).

Utzig J., and Schröter W., Donor and acceptor behavior of gold in silicon, Appl. Phys. Lett. 45, 761(1984).

Verhoef L. A., Michiels P. P., Roorda S., Sinke W. C., Van Zolingen R. J. C., Gettering in polycrystalline silicon solar cells, Mater. Sci. Eng. B 7, 49 (1990a).

Verhoef L. A., Michiels P. P., Sinke W. C., Denisse C. M., Hendriks M. Van Zolingen R. J. C., Combined impurity gettering and defect passivation in polycrystalline silicon solar cells, Appl. Phys. Lett. 57, 2704 (1990b).

Vinod P. N., Porous silicon and aluminum co-gettering experiment in p-type multicrystalline silicon substrate, Science and Technology of Advanced Materials 8, 231 (2007).

Voronkov V. V., and Falster R., Intrinsic point defects and impurities in silicon crystal growth, J. Electrochem. Soc. 149, G167 (2002).

Walz D., Poly J. P., Kamarinos G., On the recombination behaviour of iron in moderately boron-doped p-type silicon, Appl. Phys. A 62, 345 (1996).

Watkins G. D., Properties of crystalline silicon, edited by R. Hull (INSPEC/ IEE, London, p. 643 (1999).

Weber E. R., Transition metals in silicon, Appl. Phys. A 30, 1 (1983).

Weber E. R., Understanding defects in semiconductors as key to advancing device technology, Physica B 340-342, 1 (2003).

Weber E., and Riotte H. G., Iron as a thermal defect in silicon. Appl. Phys. Lett. 33, 433 (1978).

Weber E., and Riotte H. G., The solution of iron in silicon, J. Appl. Phys. 51, 1484 (1980).

Weber J., Hydrogen in semiconductors: From basic physics to technology, Phys. Status Solidi C 5, 535 (2008).

Weber J., Knack S., Feklisova O. V., Yarykin N. A., Yakimov E. B., Hydrogen penetration into silicon during wet-chemical etching, Microelectronic Engineering 66, 320 (2003). 
Westbrook J. H., Moffatt's handbook of binary phase diagrams (Genium Publishing Co., New York (1997).

Woodbury H. H., and Ludwig G. W., Spin resonance of transition metals in silicon, Phys. Rev. 117, 102 (1960).

Wünstel K., and Wagner P., Interstitial iron and iron-acceptor pairs in silicon, Appl. Phys. A 27, 207 (1982).

Yakimov E. B., and Parakhonsky A. L., Hydrogen stimulated destruction of Fe-B pairs in p-Si, Solid State Phenomena 57-58, 383 (1997).

Yelundur V., Rohatgi A., Jeong J.-W., Gabor A. M., Hanoka J. I., Wallace R. L., Proceedings of the $28^{\text {th }}$ Photovoltaic Specialists Conference (IEEE, Anchorage) p. 91( 2000).

You Z., Gong M., Chen Y., Corbett J. W., Iron-vacancy-oxygen complex in silicon, J. Appl. Phys. 63, 324 (1988).

Zimmermann $\mathrm{H}_{\text {., }}$ and Ryssel $\mathrm{H}_{\text {., }}$ Direct determination of point-defect equilibrium concentrations, Phys. Rev. B44, 9064 (1991c).

Zimmermann $\mathrm{H}$., and Ryssel $\mathrm{H}$., Observation of inverse U-shaped profiles after platinum diffusion in silicon, Appl. Phys. Lett. 59, 1209 (1991a).

Zimmermann $\mathrm{H}$., and Ryssel $\mathrm{H}$., The modeling of platinum diffusion in silicon under non-equilibrium conditions, J. Electrochem. Soc. 139, 256 (1992).

Zimmermann H., and Ryssel H., Trivalent character of $\mathrm{Pt}$ in silicon, Appl. Phys. Lett., 58, 499 (1991b).

Zimmermann H., Vacancy distributions in silicon and methods for their accurate determination, defect and diffusion forum Volumes 153-155, pp 111-136 (1998).

Zohta Y., and Watanabe M. 0, On the determination of the spatial distribution of deep centers in semiconducting thin films from capacitance transient spectroscopy, J. Appl. Phvs. 53. 1809 (1982).

Zoth G., Diploma thesis, Göttingen University, 1980.

Zoth G., and Bergholz W., A fast preparation-free method to detect iron in silicon, J. Appl. Phys. 67, 6764 (1990). 


\title{
Aluminum gettering of iron in silicon as a problem of the ternary phase diagram
}

\author{
D. Abdelbarey, V. Kveder, ${ }^{\text {a) }}$ W. Schröter, and M. Seibt ${ }^{\text {b) }}$ \\ IV. Physikalisches Institut der Georg-August-Universität Göttingen, Friedrich-Hund-Platz 1, D-37077 \\ Göttingen, Germany
}

(Received 14 October 2008; accepted 21 January 2009; published online 11 February 2009)

\begin{abstract}
Deep level transient spectroscopy is used to study the segregation of Fe from crystalline Si to an $\mathrm{Al}: \mathrm{Si}$ liquid at its surface, which is the basic mechanism of aluminum gettering used in silicon photovoltaics. The measured segregation coefficient is smaller than estimates from the binary Fe:Si and $\mathrm{Al}: \mathrm{Fe}$ phase diagrams. This apparent discrepancy originates from the ternary character of the system where the solubility of $\mathrm{Fe}$ in $\mathrm{Si}$ in equilibrium with the Al-doped $\alpha$-FeSi ${ }_{2}$ has to be taken as a reference. Our data suggest that this solubility exceeds that in the binary Fe:Si system by two orders of magnitude. (C) 2009 American Institute of Physics. [DOI: 10.1063/1.3080666]
\end{abstract}

Low-cost multicrystalline Si materials for photovoltaic applications typically contain quite high concentrations of metal impurities such as $\mathrm{Cr}, \mathrm{Fe}, \mathrm{Ni}$, and $\mathrm{Cu}^{1,2}$ In order to achieve reasonable conversion efficiencies it is imperative to incorporate gettering techniques into the processing scheme of solar cells. Traditionally, phosphorus-diffusion gettering is most widely used since it is automatically included in emitter formation on $p$-type Si. Additional gettering action can be gained during back surface field formation from $\mathrm{Al}$ alloying above the eutectic temperature of the binary $\mathrm{Al}: \mathrm{Si}$ system $\left(577{ }^{\circ} \mathrm{C}\right){ }^{3}$ The underlying mechanism is simply the segregation of metal impurities in the liquid $\mathrm{Al}: \mathrm{Si}$ layer at the backside of a Si wafer due to its higher solubility there compared to $\mathrm{Si}^{4}$ If one estimates the segregation coefficient of a metal impurity $M$ as the ratio of metal solubilities extracted from the binary $\mathrm{Al}: M$ and $\mathrm{Si}: M$ phase diagrams, one obtains values of about $10^{7}$ for $\mathrm{Co}$ or $\mathrm{Fe}$ at $900{ }^{\circ} \mathrm{C}$. Available experimental data yield instead a considerably smaller value of $6 \times 10^{5}$ for Co (Ref. 5) and (1.5-3) $\times 10^{5}$ for Fe. ${ }^{6}$ Such discrepancies are unacceptable for predictive gettering simulations, ${ }^{7-11}$ which are frequently used in order to estimate and improve the gettering efficiency of solar cell processing schemes.

In this paper we have used deep level transient spectroscopy (DLTS) to measure the segregation coefficient of Fe in $\mathrm{Al}: \mathrm{Si}$ with respect to $\mathrm{Si}$ in the temperature range between 950 and $1100{ }^{\circ} \mathrm{C}$ where the $\mathrm{Fe}$ solubility in $\mathrm{Si}$ is defined with respect to $\alpha-\mathrm{FeSi}_{2}$ in the binary $\mathrm{Fe}: \mathrm{Si}$ and with respect to the $\mathrm{Al}$ containing $\alpha-\mathrm{FeSi}_{2}: \mathrm{Al}$ in the ternary $\mathrm{Al}: \mathrm{Fe}: \mathrm{Si}$ phase diagram. The obtained values between $4 \times 10^{4}$ and 2.5 $\times 10^{5}$ are reliably found for different temperature cycling conditions. The discrepancy from simple estimates is related to a larger solubility of $\mathrm{Fe}$ in $\mathrm{Si}$ in equilibrium with the ternary Al-doped $\alpha$ - $\mathrm{FeSi}_{2}$ : $\mathrm{Al}$ compared to its solubility in equilibrium with the binary $\alpha-\mathrm{FeSi}_{2}$.

The starting material was dislocation-free float-zone $p$-type Si (thickness: $520 \mu \mathrm{m},[\mathrm{B}]=3 \times 10^{15} \mathrm{~cm}^{-3}$ ). Highpurity $\mathrm{Fe}(99.999 \%)$ was evaporated prior to $\mathrm{Fe}$ in-diffusion

\footnotetext{
${ }^{a)}$ Permanent address: Institute of Solid State Physics, RAS, Chernogolovka 142432 Russia.

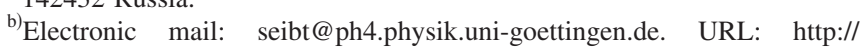
www.ph4.physik.uni-goettingen.de.
}

at $T_{\text {ind }}$ by furnace annealing in $\mathrm{Ar}$ atmosphere, which was terminated by quenching into silicone oil [cooling rate $\simeq 500 \mathrm{~K} / \mathrm{s}$ (Ref. 12)]. For subsequent $\mathrm{AlG}$ treatment, the residual $\mathrm{FeSi}_{2}$ layer was removed by mechanical polishing and subsequent chemical etching in $\mathrm{HF}: 7 \mathrm{HNO}_{3}$. After an $\mathrm{HF}$ dip, $\mathrm{Al}$ (purity 99.999\%) was evaporated to a thickness of 10 $\mathrm{nm}$. AlG was performed by annealing in $\mathrm{Ar}$ atmosphere and terminated by quenching in $10 \% \mathrm{NaOH}$ [cooling rate $\simeq 2000 \mathrm{~K} / \mathrm{s}$ (Ref. 12)]. Schottky diodes for DLTS measurements were formed by thermal evaporation of $\mathrm{Al}$ on the freshly etched sample in a depth of about $25 \mu \mathrm{m}$ below the original AlSi layer. Ohmic contacts were made by rubbing in an Al-Ga alloy into the back surface. All samples were kept in the dark for 2 days before DLTS measurements in order to complete the reaction of interstitial $\mathrm{Fe}_{i}$ with substitutional $\mathrm{B}_{s}$ to form $\mathrm{Fe}_{i} \mathrm{~B}_{s}$-pairs.

As expected, the only signal detected in DLTS spectra before and after $\mathrm{AlG}$ treatment is due to $\mathrm{Fe}_{i} \mathrm{~B}_{s}$-pairs. From spectra measured with several refilling pulse voltages the concentration of $\mathrm{Fe}_{i} \mathrm{~B}_{s_{3}}$-pairs was calculated taking into all necessary corrections. ${ }^{13} \mathrm{Fe}$ concentrations $[\mathrm{Fe}]_{\mathrm{Si} \text {,ind }}$ after $\mathrm{Fe}$ in-diffusion obtained in this way agreed with solubility data measured by radioactive techniques (neutron activation analysis, ${ }^{14}$ radiotracer ${ }^{15,16}$ ) within $30 \%$, proving that within the error margins of the different techniques, total $\mathrm{Fe}$ concentrations are measured in our approach. In particular, these results show that the applied cooling rates are sufficiently high to avoid Fe precipitation during cooling.

The most important parameter for AlG is the segregation coefficient $S$ given by ${ }^{17}$

$$
S=\frac{[\mathrm{Fe}]_{\mathrm{AlSi}, \text { gett }}}{[\mathrm{Fe}]_{\mathrm{Si}, \text { gett }}},
$$

where $[\mathrm{Fe}]_{\mathrm{Si}, \text { gett }}$ and $[\mathrm{Fe}]_{\mathrm{AlSi} \text {,gett }}$ denote $\mathrm{Fe}$ concentrations in $\mathrm{Si}$ and in the $\mathrm{Al}: \mathrm{Si}$ liquid after reaching equilibrium of the $\mathrm{Fe}$ distribution during $\mathrm{AlG}$ treatment, respectively, both given in atomic fractions. While $[\mathrm{Fe}]_{\mathrm{Si} \text {,gett }}$ is directly measured in our experiments, $[\mathrm{Fe}]_{\mathrm{AlSi} \text {,gett }}$ is calculated from the conservation of $\mathrm{Fe}$ atoms. According to previous experiments on $\mathrm{AlG}$ of $\mathrm{Co}$ in $\mathrm{Si}$ using radioactive tracers, this is a valid assumption since metal impurities can be reversibly redistributed between the $\mathrm{Si}$ and the $\mathrm{Al}: \mathrm{Si}$ gettering layer by temperature cycling. $5,11,18$ 


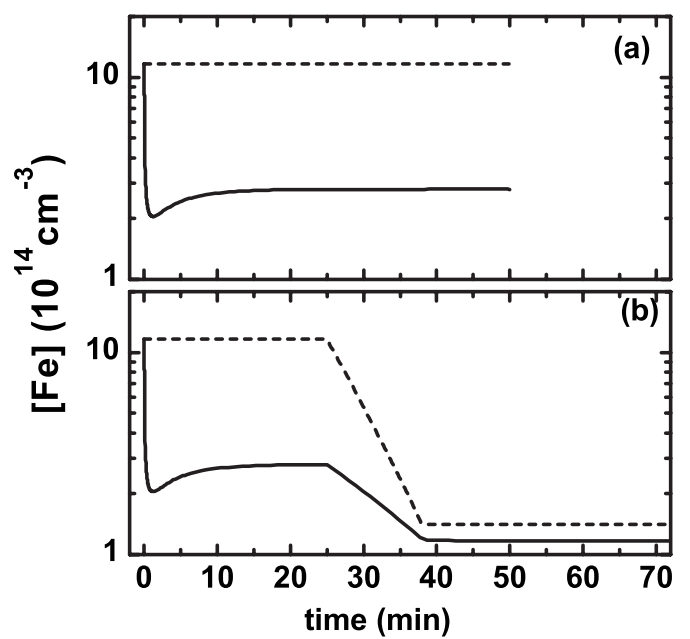

FIG. 1. Simulation of AlG of Fe using the experimentally determined segregation coefficient. Solid lines show the Fe concentration at a depth of $25 \mu \mathrm{m}$; dashed lines show the Fe solubility in equilibrium with $\alpha-\mathrm{FeSi}_{2}$ according to Ref. 14. (a) One-step gettering at $1050{ }^{\circ} \mathrm{C}$ for $50 \mathrm{~min}$. It should be noted that the final concentration has been reached within $2 \%$ after 15 min. (b) Two-step gettering consisting of $\mathrm{AlG}$ at $1050{ }^{\circ} \mathrm{C}$ for $25 \mathrm{~min}$ followed by ramping to $950{ }^{\circ} \mathrm{C}$ within $13 \mathrm{~min}$ and final $\mathrm{AlG}$ there for another 35 min. It should be noted that the $\mathrm{Fe}$ concentration remains below the $\mathrm{Fe}$ solubility in $\mathrm{Si}$ with respect to $\mathrm{FeSi}_{2}$ during the whole process.

For a reliable determination of the segregation coefficient of $\mathrm{Fe}$, certain prerequisites have to be fulfilled. First of all it is necessary to experimentally establish equilibrium between the solid solution of $\mathrm{Fe}$ in the $\mathrm{Si}$ sample and in the gettering layer. Furthermore, the segregation coefficient should only depend on temperature and in particular be independent of the path to equilibrium. In order to meet these requirements, simulations of $\mathrm{AlG}$ have been used to design and check experimental conditions.

Figure 1 summarizes simulations using the segregation coefficient obtained experimentally and presented in Fig. 2. In a first set of experiments $\mathrm{AlG}$ was performed at a gettering temperature $T_{\text {gett }}=T_{\text {ind }}$ for 50 min, subsequently referred to as one-step gettering. These conditions guarantee that Fe sili-

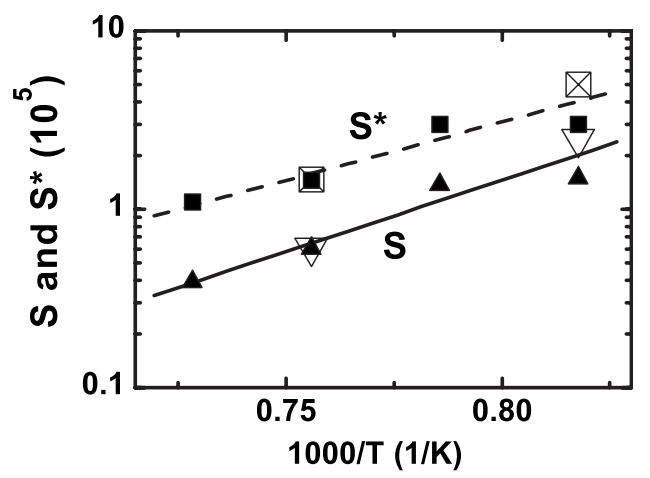

FIG. 2. Arrhenius plots of the segregation coefficient $S$ (triangles) and the apparent segregation coefficient $S^{*}$ (squares), which relates to directly measured quantities by $S^{*}=\left([\mathrm{Fe}]_{\mathrm{Si}, \text { ind }}-[\mathrm{Fe}]_{\mathrm{Si}, \text { gett }}\right) d_{\mathrm{Si}} /\left([\mathrm{Fe}]_{\mathrm{Si}, \text { gett }} d_{\mathrm{Al}}\right)$. Here $d_{\mathrm{Si}}$ and $d_{\mathrm{Al}}$ are the thicknesses of the Si sample and of the evaporated Al layer, respectively, and $[\mathrm{Fe}]_{\mathrm{Si} \text {,ind }}$ denotes the initial $\mathrm{Fe}$ concentration in the $\mathrm{Si}$ sample. The agreement of values obtained from one-step (open symbols) and two-step (closed symbols) AlG shows their independence of the path to equilibrium and of the $\mathrm{Fe}$ concentration in the investigated concentration range. Solid and dashed lines show least-square fits of the respective data, which yield $S=0.056 \exp \left(1.59 \mathrm{eV} / k_{B} T\right)$ and $S^{*}=1.87 \exp \left(1.29 \mathrm{eV} / k_{B} T\right)$, respectively. cide precipitates, which might form during heating, will immediately dissolve once $T_{\text {gett }}$ has been reached so that AlG kinetics are limited by the diffusion of $\mathrm{Fe}$ in $\mathrm{Si}^{5,11}$ Figure 1(a) shows the time dependence of the Fe concentration at a depth of $25 \mu \mathrm{m}$ (solid line). After a steep decrease from its initial value the final concentration is reached within $2 \%$ after 15 min of gettering, which is much shorter than the experimentally used gettering time of $50 \mathrm{~min}$, showing that equilibrium is established under such conditions.

In the second set of experiments a two-step scheme was used; the AlG initially starts from $T_{\text {gett }}=T_{\text {ind }}$ for $25 \mathrm{~min}$ followed by ramping to $T_{\text {gett }}<T_{\text {ind }}$ within $13 \mathrm{~min}$ and a final gettering there for another $35 \mathrm{~min}$. Figure 1(b) shows that ramping conditions and final $T_{\text {gett }}$ have been chosen such that Fe precipitation is prevented. The latter is shown by the fact that the Fe solubility [dashed line in Fig. 1(b)] stays above the $\mathrm{Fe}$ concentration throughout the two-step process.

Filled triangles in Fig. 2 show experimental values of $S$ obtained using the one-step gettering, which agree with those resulting from two-step AlG (open triangles). Hence, $S$ only depends on temperature.

The segregation coefficients obtained in this study are of the same order of magnitude as those for Co (Ref. 5) and that of Hieslmair et al. ${ }^{6}$ at $T_{\text {gett }}=950{ }^{\circ} \mathrm{C}$. Hence, the discrepancy between measured segregation coefficients and those estimated from binary phase diagrams is fully confirmed by our data in accordance with previously published values.

When seeking for possible explanations for this discrepancy, one first of all recognizes that thermodynamics of AlG should be described in terms of the ternary $\mathrm{Al}: \mathrm{Si}: M$ phase diagram instead of the two $\mathrm{Si}: M$ and Al: $M$ binary phase diagrams, where $M$ denotes the metal impurities, which is $\mathrm{Fe}$ in our case. At $1000{ }^{\circ} \mathrm{C}$ the solubility of Fe determined as its concentration in $\mathrm{Si}$ in equilibrium with $\alpha-\mathrm{FeSi}_{2}$ at its surface is $[\mathrm{Fe}]_{\mathrm{Si}}^{(\mathrm{eq})}=8 \times 10^{-7}$ at. $\% .^{14}$ From the ternary phase diagram $^{19}$ one obtains the concentration of $\mathrm{Fe}$ in liquid $\mathrm{Al}: \mathrm{Si}: \mathrm{Fe}$ in equilibrium with $\alpha$ - $\mathrm{FeSi}_{2}: \mathrm{Al}$ as $[\mathrm{Fe}]_{\mathrm{Al}: \mathrm{Si}: \mathrm{Fe}}^{(\mathrm{eq})}$ $\simeq 18$ at. \%, where $\alpha-\mathrm{FeSi}_{2}: \mathrm{Al}$ denotes a solid solution of $\mathrm{Al}$ in $\alpha$-FeSi $i_{2}$. This yields $S \simeq 2 \times 10^{7}$, which again exceeds the experimental value by a factor of about 100 . In our opinion the main reason for this discrepancy is that the value of $[\mathrm{Fe}]_{\mathrm{Si}}^{(\mathrm{eq})}=8 \times 10^{-7}$ at. $\%$ has been measured in equilibrium with undoped $\alpha$-FeSi $i_{2}$, while $[\mathrm{Fe}]_{\mathrm{Al}: \mathrm{Si}: \mathrm{Fe}}^{(\mathrm{eq})} \simeq 18$ at. \% refers to the equilibrium with $\mathrm{Al}$-doped $\alpha-\mathrm{FeSi}_{2}: \mathrm{Al}$.

The solubility of $\mathrm{Al}$ in $\alpha-\mathrm{FeSi}_{2}: \mathrm{Al}$ is up to 10 at. $\% .^{19}$ Even at small $\mathrm{Al}$ concentrations some properties such as the magnetic susceptibility and the stabilization of $\alpha-\mathrm{FeSi}_{2}: \mathrm{Al}$ against $\beta$ - $\mathrm{FeSi}_{2}: \mathrm{Al}$ at $700{ }^{\circ} \mathrm{C}$ have been found to significantly change with $\mathrm{Al}$ doping. ${ }^{20}$ The influence of $\mathrm{Al}$ on the chemical potential of $\mathrm{Fe}$ in $\alpha-\mathrm{FeSi}_{2}: \mathrm{Al}$, however, is an open problem. In order to account for the discrepancy between estimated and measured segregation coefficients, an increase in the chemical potential by $0.5 \mathrm{eV}$ is necessary, which at $1000{ }^{\circ} \mathrm{C}$ yields a $\mathrm{Fe}$ solubility in $\mathrm{Si}$ exceeding that in equilibrium with $\alpha-\mathrm{FeSi}_{2}$ by about two orders of magnitude.

The above interpretation implies that if undoped $\mathrm{Si}$ was brought into contact with solid $\alpha-\mathrm{FeSi}_{2}: \mathrm{Al}$ at high temperature, the Fe concentration in $\mathrm{Si}$ would exceed the solubility of $\mathrm{Fe}$ with respect to the binary $\alpha-\mathrm{FeSi}_{2}$. Hence, $\alpha-\mathrm{FeSi}_{2}$ precipitates should form in the Si bulk during $\mathrm{Fe}$ in-diffusion from an $\alpha-\mathrm{FeSi}_{2}: \mathrm{Al}$ source. Please note that a quasistation- 
ary metastability would arise due to the vast difference in Fe and $\mathrm{Al}$ diffusivity in $\mathrm{Si}$.

In conclusion, we have measured the segregation coefficient of $\mathrm{Fe}$ in $\mathrm{Al}: \mathrm{Si}: \mathrm{Fe}$ liquids with respect to undoped $\mathrm{Si}$ between 950 and $1100{ }^{\circ} \mathrm{C}$. The values are smaller by one to two orders of magnitude compared to values estimated from binary phase diagrams. For Fe, the most probable explanation is the effect of the $\mathrm{Al}$ content on its chemical potential in $\alpha-\mathrm{FeSi}_{2}: \mathrm{Al}$. Since quantitative data on this effect are not available, experimentally measured values of segregation coefficients are required if predictive simulations of Al gettering shall yield reliable results.

This work was financially supported by the German Federal Ministry for the Environment, Nature Conservation and Nuclear Safety and all the industry partners within the research cluster SolarFocus (Grant No. 0327650 B). The content of this publication is the responsibility of the authors. One of us (D.A.) gratefully acknowledges a scholarship of the Egyptian government.

${ }^{1}$ A. A. Istratov, T. Buonassisi, R. J. McDonald, A. R. Smith, R. Schindler, J. A. Rand, J. P. Kalejs, and E. R. Weber, Appl. Phys. Lett. 94, 6552 (2003).

${ }^{2}$ T. Buonassisi, A. A. Istratov, M. D. Pickett, M. Heuer, J. P. Kalejs, G. Hahn, M. A. Marcus, B. Lai, Z. Cai, S. M. Heald, T. F. Ciszek, R. F. Clark, D. W. Cunningham, A. M. Gabor, R. Jonczyk, S. Narayanan, E. Sauar, and E. R. Weber, Prog. Photovoltaics 14, 513 (2006).
${ }^{3}$ L. Verhoef, P. Michiels, S. Roorda, and W. Sinke, Mater. Sci. Eng., B 7, 49 (1990).

${ }^{4}$ M. Apel, I. Hanke, R. Schindler, and W. Schröter, J. Appl. Phys. 76, 4432 (1994).

${ }^{5}$ A. Sattler, Ph. D. thesis, Göttingen University, 2003.

${ }^{6} \mathrm{H}$. Hieslmair, S. McHugo, and E. R. Weber, Proceedings of the 25th IEEE Photovoltaic Specialist Conference, Washington, D.C., 13-17 May 1996 (unpublished).

${ }^{7}$ P. Plekhanov, R. Gafiteanu, U. Gösele, and T. Y. Tan, J. Appl. Phys. 86, 2453 (1999).

${ }^{8}$ V. Kveder, W. Schröter, A. Sattler, and M. Seibt, Mater. Sci. Eng., B 71, 175 (2000).

${ }^{9}$ C. del Cañizo and A. Luque, J. Electrochem. Soc. 147, 2685 (2000).

${ }^{10}$ H. Hieslmair, S. Balasubramanian, A. Istratov, and E. R. Weber, Semicond. Sci. Technol. 16, 567 (2001).

${ }^{11}$ M. Seibt, A. Sattler, C. Rudolf, O. Voß, V. Kveder, and W. Schröter, Phys. Status Solidi A 203, 696 (2006).

${ }^{12}$ A. A. Istratov, H. Hedemann, M. Seibt, O. F. Vyvenko, W. Schröter, T. Heiser, C. Flink, H. Hieslmair, and E. R. Weber, J. Electrochem. Soc. 145, 3889 (1998).

${ }^{13}$ A. Mircea and A. Mitonneau, Appl. Phys. Lett. 8, 15 (1975).

${ }^{14}$ E. R. Weber, Appl. Phys. A 30, 1 (1983).

${ }^{15}$ C. B. Collins, R. O. Carlson, and C. J. Gallagher, Phys. Rev. 105, 1168 (1957)

${ }^{16}$ D. Struthers, J. Appl. Phys. 27, 1560 (1956).

${ }^{17}$ S. M. Myers, M. Seibt, and W. Schröter, J. Appl. Phys. 88, 3795 (2000)

${ }^{18}$ A. Sattler, M. Seibt, V. Kveder, and W. Schröter, Solid State Phenom. 95-96, 553 (2004).

${ }^{19}$ G. Rivlin and G. V. Raynor, Int. Met. Rev. 26, 133 (1981).

${ }^{20}$ K. Szymański, J. Baas, L. Dobrzyński, and D. Satula, Physica B 225, 111 (1996). 


\title{
Light-induced point defect reactions of residual iron in crystalline silicon after aluminum gettering
}

\author{
D. Abdelbarey, V. Kveder, W. Schröter, and M. Seibt ${ }^{\text {a) }}$ \\ IV. Physikalisches Institut der Georg-August-Universität Göttingen, Friedrich-Hund-Platz 1, D-37077 \\ Göttingen, Germany
}

(Received 25 June 2010; accepted 7 July 2010; published online 25 August 2010)

\begin{abstract}
Deep level transient spectroscopy is used to study light-induced reactions of residual iron impurities after aluminum gettering $(\mathrm{AlG})$ in crystalline silicon. White-light illumination at room temperature leads to the formation of a defect which is associated with a donor level at $0.33 \mathrm{eV}$ above the valence band. This defect is stable up to about $175^{\circ} \mathrm{C}$ where it dissociates reversibly in case of small iron concentrations and irreversibly for high iron concentrations. Since marker experiments using gold and platinum diffusion show a high vacancy concentration after AlG a tentative identification of the new defect as the metastable iron-vacancy pair is proposed. () 2010 American Institute of Physics. [doi:10.1063/1.3474658]
\end{abstract}

\section{INTRODUCTION}

Iron is one of the most frequently studied metal impurities in crystalline silicon due to its detrimental effects on the material quality and the plethora of device failures associated with various iron-related species. ${ }^{1}$ Most prominent examples of iron-related complexes are pairs with shallow acceptors like $\mathrm{B}, \mathrm{Al}, \mathrm{Ga}$, and In in p-type silicon materials. ${ }^{2}$ Recently, research activities in the silicon photovoltaics area have renewed the interest in defect reactions of iron in B-doped crystalline silicon. ${ }^{3}$ Further developments of injectiondependent lifetime measurement techniques are now routinely used to measure concentrations of interstitial iron $\left(\mathrm{Fe}_{i}\right)$ and photoluminescence mapping is utilized to image $\mathrm{Fe}_{i}$ distributions in silicon wafers. ${ }^{4,5}$ Various pairs with other point defects have been reported depending on the defect population of the material under investigation, as is exemplified by $\mathrm{FeAu}$ pairs after $\mathrm{Au}-\mathrm{Fe}$ codiffusion silicon ${ }^{6}$ or $\mathrm{FeH}$ complexes if $\mathrm{H}$ is introduced into the silicon by chemical etching. ${ }^{7}$

Due to detrimental effects of transition metal impurities, like iron, on solar cells efficiency some gettering steps are routinely included into silicon solar cells manufacturing. Standard solar cell processing include two potential gettering steps, i.e., the emitter diffusion (phosphorus-diffusion gettering, PDG) and the backsurface field formation (aluminum gettering, AlG) although the gettering capabilities are not fully exploited in present-day solar cell processing schemes. Both techniques base on an increased solubility of metal impurities in a thin surface-near gettering layer, i.e., in the highly P-doped region for PDG and in the Al-Si melt for AlG. An additional long-range beneficial effect of AlG in connection with subsequent $\mathrm{H}$ passivation has been attributed to the injection of vacancies (V) (Refs. 8-11) which enhances $\mathrm{H}$ diffusion ${ }^{9}$ and promotes dissociation of molecular hydrogen. ${ }^{12}$ Such synergetic effects have been concluded to contribute to material improvement after $\mathrm{AlG}$ in various studies. ${ }^{13-16}$ From the behavior of intrinsic point defects dur-

${ }^{a)}$ Electronic mail: seibt@ph4.physik.uni-goettingen.de. ing silicon crystal growth ${ }^{17}$ it can be concluded that vacancies survive in complexes like $\mathrm{V} 0, \mathrm{VO}_{2}, \mathrm{~V}_{2}$, and $\mathrm{VH}_{n}$ after AlG.

The reaction of vacancies with a typical minority carrier life-time controlling impurity like $\mathrm{Fe}_{i}$ or $\mathrm{FeB}$ pair in Si has been studied by electron paramagnetic resonance (EPR) and theoretical modeling. ${ }^{18-20}$ For these experiments $1-3 \mathrm{MeV}$ electron irradiation has been used to generate vacancies, which survive in a great variety of complexes, among these-if the specimen contained $\mathrm{Fe}_{i}$ or $(\mathrm{FeB})$ before irradiation- $\left(\mathrm{Fe}_{i} \mathrm{~V}\right)$ and $\left(\mathrm{Fe}_{i} \mathrm{~V}_{2}\right)$-pairs and possibly $\mathrm{Fe}_{s}$. Their atomic structure, spin states, binding, and formation energies have been determined experimentally or theoretically but their levels within the silicon band gap could not be studied experimentally because of the large variety of irradiationinduced defects.

In this paper we report a detailed deep level transient spectroscopy (DLTS) study of point defect reactions in iron containing float-zone silicon after AlG. In iron contaminated samples before and after AlG iron can be found exclusively in pairs with boron ( $\mathrm{FeB}$ pairs) as is expected in agreement with previous data. ${ }^{21,22}$ However, after AlG a white-light illumination leads to the formation of an iron-related defect associated with a deep state at $\mathrm{E}_{V}+0.33 \mathrm{eV}$ and subsequently referred to as the $\mathrm{FeD}$ defect. It is a donor as evidenced by the absence of the Poole-Frenkel effect which is expected in case of an acceptor level. In addition, a small DLTS line associated with the emission characteristics of the divacancy $\left(\mathrm{V}_{2}\right)$ appears.

The iron-related $\mathrm{FeD}$ defect is stable at room temperature and can be destroyed during annealing at about $175{ }^{\circ} \mathrm{C}$ leaving the $\mathrm{V}_{2}$-defects unaffected in accord with literature data. ${ }^{23}$ Hence, our results provide evidence that AlG drastically changes the point defect population of crystalline silicon.

In an additional set of experiments, indiffusion of Pt or $\mathrm{Au}$ into silicon after AlG has been used to monitor vacancy concentrations. They consistently show strongly enhanced concentrations of substitutional Pt and Au indicating vacancy 
concentrations as high as $10^{15} \mathrm{~cm}^{-3}$ after AlG. Although not a direct proof these results strongly suggest that the $\mathrm{FeD}$ defect is some vacancy-related Fe complex, possibly the metastable $\mathrm{Fe}_{i} \mathrm{~V}$ defect, as is discussed in detail in this paper.

\section{EXPERIMENTAL}

The experiments were carried out on float-zone silicon wafers (520 $\mu \mathrm{m}$ thickness) of p-type (boron doping $\mathrm{N}_{\mathrm{B}}=3$ $\left.\times 10^{15} \mathrm{~cm}^{-3}\right)$. The iron indiffusion procedure and subsequent $\mathrm{AlG}$ has been described in detail previously. ${ }^{21}$ Briefly, samples were intentionally contaminated with iron by vacuum evaporation of high purity Fe layer onto sample surface and subsequent annealing in argon atmosphere at a chosen temperature $T_{\text {ind }}$ (between 950 and $1100{ }^{\circ} \mathrm{C}$ ) for a time sufficient to guarantee uniform distribution of $\mathrm{Fe}$ throughout the sample. After Fe indiffusion, the samples were quenched into silicone oil (cooling rate $\approx 500 \mathrm{~K} / \mathrm{s}$ ) to freeze in the iron distribution and to prevent iron precipitation during cooling.

A surface layer of about $10 \mu \mathrm{m}$ thickness together with the residual $\mathrm{FeSi}_{2}$ layer was removed from the samples surfaces by mechanical polishing with subsequent chemical etching in $\mathrm{HF}: 7 \mathrm{HNO}_{3}$.

The AlG experiments were performed in the following way: after removing silicon oxide from the sample surfaces by a HF dip, a layer of aluminum (10 nm thick, purity: $99.999 \%$ ) was thermally evaporated onto one sample surface in a vacuum better than $10^{-6}$ mbar. Immediately after $\mathrm{Al}$ evaporation, the sample was placed into a hot furnace and annealed at a chosen temperature $T_{\text {gett }}$ equal to $T_{\text {ind }}$ for 50 min in argon gas flow. Thereafter, samples were quenched in $10 \% \mathrm{NaOH}: \mathrm{H}_{2} \mathrm{O}$ solution (cooling rate $\approx 2000 \mathrm{~K} / \mathrm{s}$ ) to prevent iron precipitation.

A layer of about 10-20 $\mu \mathrm{m}$ thickness together with the $\mathrm{Al}: \mathrm{Si}$ :Fe alloy formed during annealing was removed from the sample surface by mechanical polishing. DLTS was used to measure the deep level defects in our samples. For this purpose, Schottky diodes with a diameter of $1 \mathrm{~mm}$ for DLTS measurements were prepared by thermal evaporation of $\mathrm{Al}$, while Ohmic contacts were made by rubbing an $\mathrm{Al}-\mathrm{Ga}$ alloy into back surface of samples. In order to reduce the possible effects of hydrogen injection during wet etching which can result in passivation of boron atoms, FeB-pair decomposition, and formation of different hydrogen related defects with iron in the depletion region under the Schottky contact, ${ }^{24}$ we used very short (10-20 s) etching in $\mathrm{HF}: 7 \mathrm{HNO}_{3}$ followed by $20 \mathrm{~s}$ rinsing in $\mathrm{HF}: 10 \mathrm{H}_{2} \mathrm{O}$ before the evaporation of AlSchottky contacts.

To investigate the influence of light on defect reactions and transformations we expose samples to white-light produced by a halogen tungsten lamp for durations between 15 and $45 \mathrm{~min}$. We used a glass filter to eliminate the infrared components of light below $0.5-0.7 \mathrm{eV}$. Behind the filter the light intensity was about $50 \mathrm{~mW} / \mathrm{cm}^{2}$ which is close to the intensity of the sun light in the spectral range from 0.7 to 2.5 $\mathrm{eV}$. According to our estimations based on results by Geerligs and MacDonald, ${ }^{3}$ this light treatment was enough to guarantee dissociation of more than $95 \%$ of FeB pairs to a depth corresponding approximately to the minority carrier

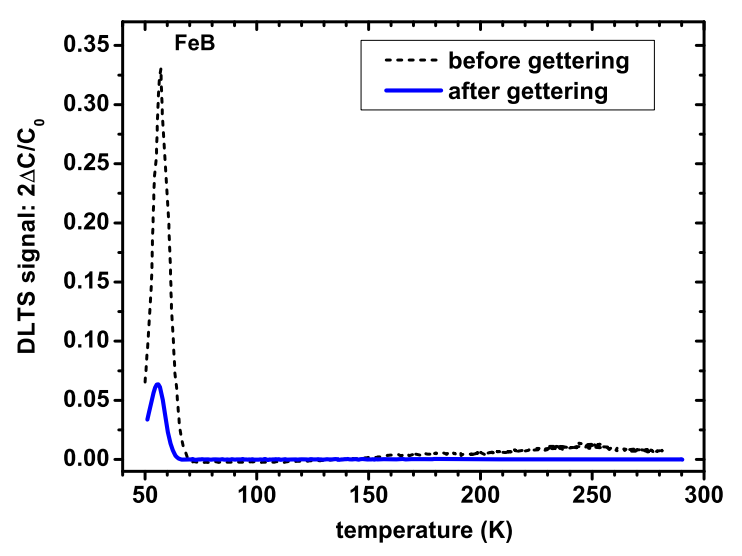

FIG. 1. (Color online) DLTS spectra of iron in silicon after indiffusion at $1050{ }^{\circ} \mathrm{C}$ (dashed line) and after subsequent $\mathrm{AlG}$ at $1050{ }^{\circ} \mathrm{C}$ (solid line); both high temperature treatments have been terminated by rapid quenching. Both spectra show iron as FeB pairs as the dominant signal. It is clearly seen that $\mathrm{AlG}$ reduces the iron concentration in accord with previously published data (Ref. 21).

diffusion length, i.e much deeper than the depth of our DLTS measurements even for concentrations of iron as high as 2 $\times 10^{14} \mathrm{~cm}^{-3}$.

To estimate the initial vacancy concentration $[V]_{\text {init }}$ in our samples we performed gold indiffusion for $2 \mathrm{~h}$ at $850{ }^{\circ} \mathrm{C}$ or platinum indiffusion at $730{ }^{\circ} \mathrm{C}$ for $30 \mathrm{~min}$ into the same $\mathrm{Si}$ wafer we used for iron experiments but without the initial iron indiffusion. We performed these experiments before and after AlG. The latter was performed for $50 \mathrm{~min}$ at $1100{ }^{\circ} \mathrm{C}$ using $\mathrm{Al}$ layer thicknesses of 10 and $400 \mathrm{~nm}$. The layer of $30 \mu \mathrm{m}$ together with Al:Si alloy was removed after AlG and Au was subsequently evaporated on this freshly etched surface. After $\mathrm{Au}$ indiffusion a surface layer with a thickness ranging from 20 to $150 \mu \mathrm{m}$ was removed by mechanical polishing and DLTS spectra were measured. Similar experiments have been carried out using Pt indiffusion at $730{ }^{\circ} \mathrm{C}$ for 30 min using the same preparation procedure as for the $\mathrm{Au}$ indiffusion.

DLTS spectra have been recorded using a Boonton B72 capacitance meter operating at $1 \mathrm{MHz}$. All spectra shown in this paper have been measured at $5 \mathrm{~V}$ bias voltage, $4 \mathrm{~V}$ pulse voltage, $261 \mathrm{~Hz}$ pulse repitition frequency, and a pulse length of $100 \mu \mathrm{s}$.

\section{RESULTS}

Figure 1 shows, as an example, typical DLTS spectra measured in one of our samples before and after AlG at $T_{\text {gett }}=T_{\text {ind }}=1050{ }^{\circ} \mathrm{C}$. In both spectra $(\mathrm{FeB})$ pairs with a donor energy level at about $\mathrm{E}_{V}+0.1 \mathrm{eV}$ are dominant in the spectra, while the signal from the $\mathrm{Fe}_{i}$ donor (at $\mathrm{E}_{V}$ $+0.39 \mathrm{eV})$ as well as the signals from any other possible electrically active species are nearly negligible. From such kind of measurements the segregation coefficient for $\mathrm{AlG}$ can be calculated depending on gettering temperature as was done in our previous paper. ${ }^{21}$

It is well established that if the concentration of interstitial iron is much smaller than the boron concentration $\left(\left[\mathrm{Fe}_{i}\right] \ll \mathrm{N}_{\mathrm{B}}\right)$ in p-type silicon, $\mathrm{Fe}_{i}$ atoms become trapped by substitutional boron forming a complex $\mathrm{Fe}_{i}^{(+)} \mathrm{B}_{s}^{(-)}$essentially 


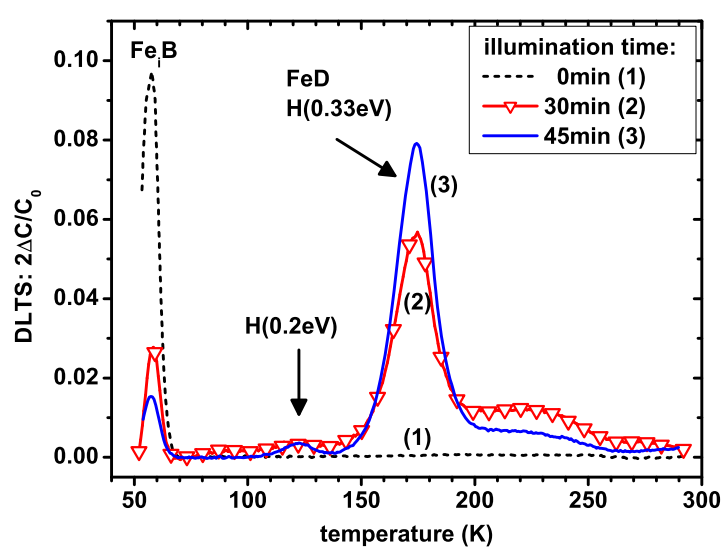

FIG. 2. (Color online) DLTS spectra showing the effect of cold-light illumination on residual iron after $\mathrm{AlG}$ at $1100{ }^{\circ} \mathrm{C}$. Initially, iron is found in form of $\mathrm{Fe}_{i} \mathrm{~B}$ pairs [(1), dashed line]. Room temperature illumination using white-light $\left(50 \mathrm{~mW} / \mathrm{cm}^{2}\right)$ for $30 \mathrm{~min}[(2)$, solid line and triangles] leads to a decrease in the FeB-line and a simultaneous increase in the line labeled "FeD" at $\mathrm{E}_{V}+0.33 \mathrm{eV}$. After $45 \mathrm{~min}$ of illumination [(3), solid line] nearly all iron is found in the FeD line, in addition to a small DLTS signal corresponding to a defect at $\mathrm{E}_{V}+0.2 \mathrm{eV}$.

bound by Coulomb interaction. For the concentrations of iron and boron in our samples, complete pairing of $\mathrm{Fe}_{i}$ is expected at room temperature. The characteristic time constant of this first order reaction is estimated according to Ref. 25 for the boron doping in our samples and for room temperature as $2.5 \mathrm{~h}$. Typically, more than seven hours elapsed between annealing or illumination and the DLTS measurements so that we can expect to mainly observe the DLTS signal of $\mathrm{FeB}$ pairs with an activation enthalpy of about $\mathrm{E}_{V}$ $+0.1 \mathrm{eV}$.

\section{A. Light-induced reactions of Iron}

\section{Formation of FeD}

Figure 2 shows the DLTS spectra for the sample doped with iron and then subjected to $\mathrm{AlG}\left(T_{\text {gett }}=T_{\text {ind }}=1100^{\circ} \mathrm{C}\right)$. Spectrum (1) was measured within a few hours after $\mathrm{AlG}$, while spectra (2) and (3) within a few hours after additional white-light illumination of this sample for $30 \mathrm{~min}$ and 45 min, respectively. One can see that the white-light illumination results in appearance of a new DLTS peak at about 174 $\mathrm{K}$, labeled as "FeD." Furthermore, the increase in the FeD concentration correlates well with a decrease in the concentration of FeB pairs. It should be explicitly mentioned here that the same illumination of any of our samples after iron indiffusion and without AlG does not result in the appearance of the FeD line in DLTS spectra. Please note, that an additional small DLTS signal appears $[\mathrm{H}(0.2)$ in Fig. 2] which corresponds to a defect with an energy level at $\mathrm{E}_{V}$ $+0.2 \mathrm{eV}$ and an apparent capture cross-section of $\sigma_{p}$ $\times \exp \left(S / k_{B}\right)=\sigma_{p}^{*}=3 \times 10^{-15} \mathrm{~cm}^{2}$, where $S$ is the ionization entropy of the defect.

The activation energy for FeD defects, obtained from analysis of DLTS spectra measured at different frequencies, is $0.33 \mathrm{eV}$ implying the energy level of FeD defects at $\mathrm{E}_{V}$ $+0.33 \mathrm{eV}$. The apparent capture cross-section calculated from pre-exponential factor of the thermal emission rate is $\sigma_{p}^{*}=3 \times 10^{-14} \mathrm{~cm}^{2}$.

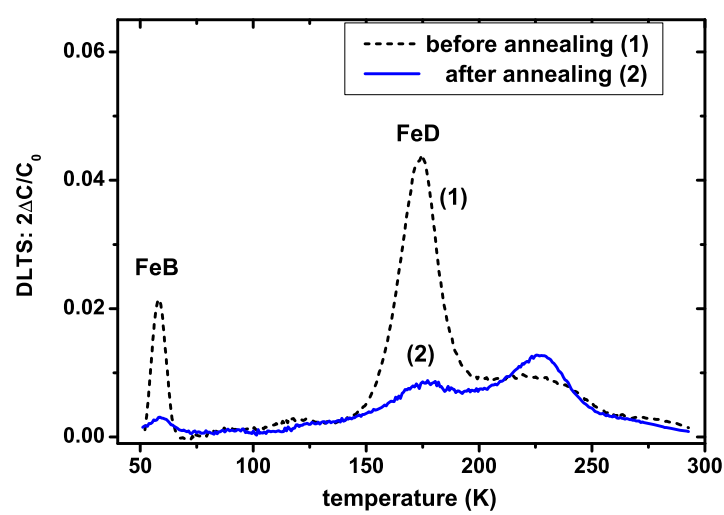

FIG. 3. (Color online) Effect of thermal annealing at $175^{\circ} \mathrm{C}$ for $35 \mathrm{~min}$ for the case of high iron concentration $\left([\mathrm{Fe}] \simeq 3.5 \times 10^{14} \mathrm{~cm}^{-3}\right)$. The inital DLTS spectrum (dashed line) measured after white-light illumination shows the FeD defect as the dominant species with some iron still as FeB pairs. After annealing (solid line) both lines have almost disappeared indicating that iron has mainly precipitated.

In order to get a hint on the donor or acceptor character of this level, we have measured the hole emission rate of $\mathrm{FeD}$ defects at two different average electric fields in the depletion region of the Schottky contact: $\mathcal{E}_{1}=3.9$ $\times 10^{4} \mathrm{~V} / \mathrm{cm}\left(U_{b}=5 \mathrm{~V}, U_{p}=5 \mathrm{~V}\right) \quad$ and $\quad \mathcal{E}_{2}=2.0$ $\times 10^{4} \mathrm{~V} / \mathrm{cm}\left(U_{b}=5 \mathrm{~V}, U_{p}=1.5 \mathrm{~V}\right)$. For $T=175 \mathrm{~K}$ the emission rate was $613 \mathrm{~s}^{-1}$ at $\mathcal{E}_{1}$ and $603 \mathrm{~s}^{-1}$ at $\mathcal{E}_{2}$, that is the same within experimental accuracy implying the FeD defect to be a donor. For an acceptor level one expects an increase in emission rate by about factor 1.35 with increase in electric field from $\mathcal{E}_{2}$ to $\mathcal{E}_{1}$ due to the Poole-Frenkel effect. ${ }^{26}$

\section{Dissociation of FeD}

In order to estimate the thermal stability of FeD defect we made annealing experiments. Figure 3 shows the results for one of our samples, where the Fe indiffusion with subsequent AlG were made at $T_{\text {gett }}=T_{\text {ind }}=1100{ }^{\circ} \mathrm{C}$. The sample was first illuminated to generate FeD defects. The initial concentration of iron before illumination was of about 3.5 $\times 10^{14} \mathrm{~cm}^{-3}$. Spectrum (1) was measured before annealing and spectrum (2) after annealing at $175^{\circ} \mathrm{C}$ for $35 \mathrm{~min}$. Annealing at $175^{\circ} \mathrm{C}$ for 35 min results in a dramatic reduction in concentrations of both FeB and FeD defects. The reduction in FeB concentration is not surprising and can be easily understood assuming thermal dissociation of $\mathrm{FeB}$ pairs and a subsequent precipitation of $\mathrm{Fe}_{i}$ in accord with previous investigations. $^{27}$

Two reaction paths, however, can account for the decrease in the FeD concentration, i.e.,

1 dissociation of $\mathrm{FeD}$ producing $\mathrm{Fe}_{i}$ and its subsequent precipitation, or

2 the transformation from a metastable defect (FeD) into a more stable configuration which cannot be detected by DLTS in p-type silicon.

It is clear that these paths cannot be distinguished on the basis of experimental data presented above. Reaction path (2) should be independent on the total iron concentration while a reaction along path (1) can be reduced or even suppressed by a reduction in the iron concentration. Hence, 


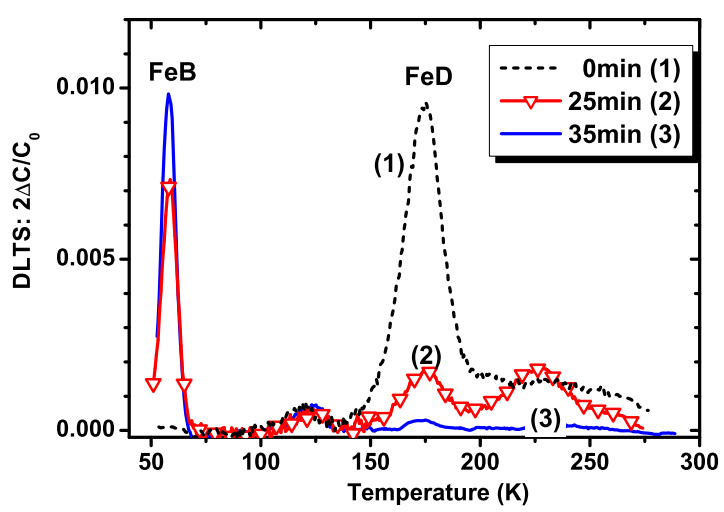

FIG. 4. (Color online) Effect of thermal annealing at $175{ }^{\circ} \mathrm{C}$ for the case of small iron concentration $\left([\mathrm{Fe}] \simeq 4 \times 10^{13} \mathrm{~cm}^{-3}\right)$. The inital DLTS spectrum [(1), dashed line] measured after white-light illumination shows the FeD defect as the dominant species with some iron still as FeB pairs. After annealing at $175{ }^{\circ} \mathrm{C}$ for $25 \mathrm{~min}$ [(2), triangles and solid line] and $35 \mathrm{~min}$ [(3), solid line] the FeD signal has decreased which is accompanied by a respective increase in the FeB signal. Hence, the thermal dissociation reaction is reversible for small iron concentrations.

these experiments have been repeated with samples containing only about $10 \%$ iron after AlG. Figure 4 shows the results of annealing experiments with a sample which was iron diffused and gettered at $1000{ }^{\circ} \mathrm{C}\left(T_{\text {gett }}=T_{\text {ind }}=1000{ }^{\circ} \mathrm{C}\right)$ resulting in an iron concentration after AlG of about 4 $\times 10^{13} \mathrm{~cm}^{-3}$, i.e., about one order of magnitude below the data presented in Fig. 3. Under these conditions the decrease in the $\mathrm{FeD}$ concentration is accompanied by an increase in the FeB concentration implying a reversible reaction. Hence, we can conclude that annealing at $175{ }^{\circ} \mathrm{C}$ dissociates the $\mathrm{FeD}$ defect producing mobile $\mathrm{Fe}_{i}$ which then precipitates or forms $\mathrm{FeB}$ pairs during room temperature storage for large and small iron concentrations, respectively.

\section{B. Marker experiments using Au and Pt diffusion}

Since the light-induced formation of the $\mathrm{FeD}$ line was exclusively observed in samples subjected to an AlG treatment, this procedure has to change the defect spectrum of silicon wafers. In addition, these changes are far-reaching since DLTS has been measured up to $100 \mu \mathrm{m}$ below the surface opposite to the $\mathrm{Al}$ layer used for gettering, i.e., at least at a distance of $200 \mu \mathrm{m}$ away from the gettering layer. This excludes a possible direct effect of $\mathrm{Al}$ atoms themselves since the $\mathrm{Al}$ diffusion coefficient in $\mathrm{Si}$ is small and $\mathrm{Al}$ cannot diffuse into $\mathrm{Si}$ during $\mathrm{AlG}$ annealing more than a few microns. ${ }^{28}$

A long-range effect of AlG in addition to the pure gettering effect has been observed in multicrystalline silicon for photovoltaics as a synergetic action of $\mathrm{AlG}$ and hydrogen passivation from a $\mathrm{SiN}_{x}$ layer produced by plasma-enhanced chemical-vapor deposition. ${ }^{8,15}$ It has been attributed to the production of vacancies during $\mathrm{AlG}$ resulting from the formation of liquid AlSi above the eutectic temperature of $577^{\circ} \mathrm{C}$, an interpretation that has not been supported by later platinum diffusion experiments performed on different silicon materials. ${ }^{29}$ This method was proposed by Zimmermann and Ryssel $^{30}$ and further developed by Jacob et al. ${ }^{31}$ and is able to quantify the initial vacancy concentration $[\mathrm{V}]_{0}$ present in silicon samples at the onset of platinum or gold diffusion.

In order to estimate vacancy concentrations after $\mathrm{AlG}$ in our samples we performed gold and platinum indiffusion as marker experiments. Our preliminary experiments include two different $\mathrm{Al}$ layer thicknesses of $10 \mathrm{~nm}$ - used also for the experiments described above- and of $400 \mathrm{~nm}$. In the latter case, the effect is huge, $[V]_{0} \simeq(2-3) \times 10^{15} \mathrm{~cm}^{-3}$, while for the thin Al layer of $10 \mathrm{~nm}$ it is smaller but still significant between $4 \times 10^{13}$ and $10^{14} \mathrm{~cm}^{-3}$.

\section{DISCUSSION}

\section{A. General conclusions}

The results described above first of all show that point defect reactions of iron in boron-doped float-zone silicon after AlG are fundamentally different from the well-known pairing of its interstitial species with substitutional boron. Hence, it can be concluded that AlG substantially changes the defect spectrum of the material. Preliminary marker experiments further show a considerably higher vacancy concentration after AlG indicating that vacancy-related defects are responsible for the observed light-induced reaction of interstitial iron.

According to Ref. 3 the intensity of the white-light illumination used in our experiments is sufficient to almost completely dissociate $\mathrm{FeB}$ pairs in a few minutes within the depth of about one electron diffusion length. Therefore, a reasonable conclusion is that $\mathrm{FeD}$ defects appear due to the reaction of an unknown species with $\mathrm{Fe}_{i}$ atoms rather than a reaction with existing $\mathrm{FeB}$ pairs. In addition to the dissociation of FeB pairs, white-light illumination may also lead to a radiation enhanced defect reaction (REDR) (Ref. 32) by (i) lowering a possible reaction barrier of the FeD reaction, (ii) enhancing the diffusion of the constituents, or (iii) by optically stimulating the release of the possibly vacancy-related component from other defect vacancy complexes present after AlG and quenching.

Indeed, the fact that the light dissociates some of the V-complexes existing in our samples after $\mathrm{AlG}$ was directly observed in our experiments since the illumination not only produces $\mathrm{FeD}$ complexes but also results in the appearance of a DLTS line H(0.2) which is clearly seen in Figs. 2 and 4. It has an activation energy for hole emission of $0.20 \mathrm{eV}$ and its emission characteristics are the same as those observed in Refs. 22 and 33 for the donor level of the divacancy $\left(\mathrm{V}_{2}\right)$ as is shown by a direct comparison of hole emission rates in Fig. 5. In addition, comparing the time constant for FeB pairing (150 $\mathrm{min}$ in our samples) with the time necessary to form $\mathrm{FeD}$ defects under illumination (typically $30-45 \mathrm{~min}$ at room temperature) provides evidence of a REDR if one bears in mind that $\mathrm{FeD}$ defects do not form during room temperature storage in the dark.

\section{B. Nature of the FeD defect}

Before entering a detailed discussion of vacancy-related candidates for the FeD defect we briefly want to consider a possible reaction of interstitial iron with hydrogen which 


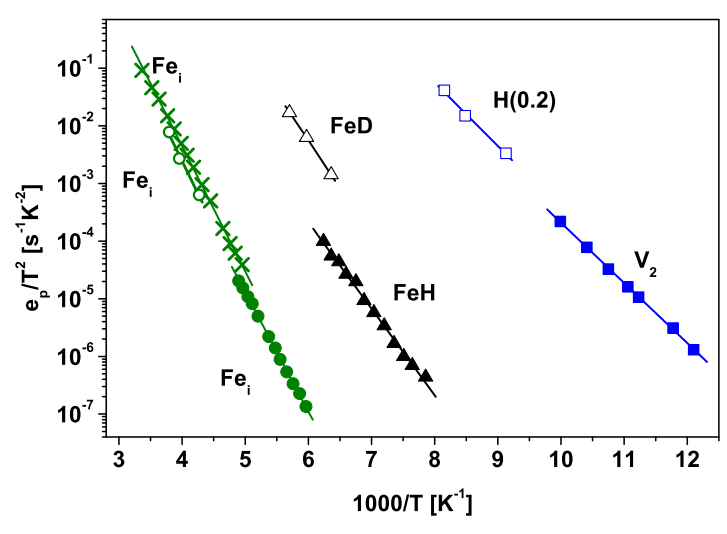

FIG. 5. (Color online) Thermal hole emission rates $e_{p}$ of DLTS lines measured in this work (open symbols) compared to literature data. Our data for $\mathrm{H}(0.2)$ (open squares) are in agreement with emission rates reported by Brotherton et al. (Ref. 22) (filled squares), whereas those of FeD (open triangles) differ significantly from data reported for $\mathrm{FeH}$ by Sadoh et al. (Ref. 7) (filled triangles). The comparison of data for the $\mathrm{Fe}_{i}$ donor shows the coincidence of our data (open circles) with those of Sadoh et al. (Ref. 7) (filled circles) and those of Wünstel and Wagner (Ref. 11) (crosses) which corroborates the conclusion that FeD cannot be identified with $\mathrm{FeH}$ reported in Ref. 7.

typically is introduced during Schottky contact preparation via chemical etching. In fact, Sadoh et $a .^{7}$ have reported a deep level attributed to an iron-hydrogen complex $\left(\mathrm{Fe}_{i} \mathrm{H}\right)$. The authors observed a deep level at $\mathrm{E}_{V}+0.31 \mathrm{eV}$ which is produced by chemical etching of n-type float-zone silicon containing interstitial iron. Thermal annealing at $175{ }^{\circ} \mathrm{C}$ removed the defect indicating that $\mathrm{FeD}$ could be identified with $\mathrm{FeH}$. Thermal emission rates of the FeD defect, however, exceed those of the $\mathrm{Fe}_{i} \mathrm{H}$ complex reported by Sadoh et al. by at least a factor of 20 which is an experimentally significant difference. In order to exclude discrepancies in the determination of the sample temperature between our experimental setup and that of Sadoh and co-workers, we have included data measured for $\mathrm{Fe}_{i}$ which agree within typical error margins (compare Fig. 5). It has to be concluded that FeD cannot be identified with this FeH complex.

Focusing the discussion of the possible nature of the FeD defect on iron complexes related to intrinsic point defects, oxygen and carbon, let us refer to the comprehensive theoretical treatment of Estreicher et al. ${ }^{18}$ as a starting point. The authors show that stable complexes of iron and preexisting vacancy-related defects typically contain the substitutional iron species, i.e., $\mathrm{Fe}_{s}, \mathrm{Fe}_{s} \mathrm{~V}, \mathrm{Fe}_{s} \mathrm{O}_{i}$, or $\mathrm{Fe}_{s} \mathrm{~B}_{s}$ with the exception of the $(\mathrm{VFeV})$ complex of iron and the divacancy where the iron atom sits about halfway between the two vacancies. In addition, $\mathrm{Fe}_{i}$ can be trapped in metastable configurations such as $\mathrm{Fe}_{i} \mathrm{~V}$ and $\mathrm{Fe}_{i} \mathrm{~V}_{2}$ which are energetically separated by an energy barrier from the respective stable configurations $\mathrm{Fe}_{s}$ and $(\mathrm{VFeV})$, respectively.

The iron-related complexes $\mathrm{Fe}_{s} \mathrm{O}$ and $\mathrm{Fe}_{i} \mathrm{~V}_{2}$ can be ruled on the basis of their deep levels which are a donor level at $\mathrm{E}_{C}-0.36 \mathrm{eV}$ (Ref. 18) and a acceptor level at $\mathrm{E}_{V}+0.50 \mathrm{eV},{ }^{19}$ respectively, rather than a donor level at $\mathrm{E}_{V}$ $+0.33 \mathrm{eV}$ as observed here for the FeD defect. In addition, $\mathrm{Fe}_{i} \mathrm{~V}_{2}$ complexes are stable up to $400{ }^{\circ} \mathrm{C}$ (Refs. 19 and 34) in contradiction to our data.
An intriguing candidate for the $\mathrm{FeD}$ defect is the metastable $\mathrm{Fe}_{i} \mathrm{~V}$ pair. This defect was experimentally found by EPR in iron contaminated silicon after high energy electron irradiation and denoted as the NL19 center. ${ }^{20}$ The NL19 EPR center has a trigonal symmetry and contains one $\mathrm{Fe}_{i}^{(+)}$atom with spin $3 / 2$. It anneals out at $160{ }^{\circ} \mathrm{C}$ in a good agreement with our experimental results for $\mathrm{FeD}$.

According to our knowledge the $\mathrm{Fe}_{i} \mathrm{~V}$ complex was never investigated by DLTS and the exact position of its energy level is not known. However, it was recently investigated theoretically by Estreicher et al. ${ }^{18}$ showing that the $\mathrm{Fe}_{i} \mathrm{~V}$ pair should have a donor level at $\mathrm{E}_{V}+0.35 \mathrm{eV}$ in a good agreement with our data for FeD. These calculations also show, however, that the $\mathrm{Fe}_{i} \mathrm{~V}$ pair should also introduce an acceptor level into the silicon band gap at $\mathrm{E}_{C}-0.71 \mathrm{eV}$. A corresponding DLTS signal has not been observed which questions the hypothesis of the $\mathrm{Fe}_{i} \mathrm{~V}$ complex as being the FeD defect. One should, however, bear in mind that the DLTS signal of a possible acceptor level close to midgap might be strongly reduced due to electron emission into the conduction band.

The dissociation kinetics-complete dissociation at $175{ }^{\circ} \mathrm{C}$ within $40 \mathrm{~min}$-implies a binding energy of the $\mathrm{FeD}$ defect of $1.5-1.6 \mathrm{eV}$ in accord with theory. ${ }^{18}$ The product of $\mathrm{FeD}$ dissociation is interstitial iron as can be concluded from the observed increase in the FeB concentration after annealing of a sample with a low iron concentration. As is seen in Fig. 4 such free $\mathrm{Fe}_{i}$ reacts with boron acceptors to again form $\mathrm{FeB}$ pairs after cooling. Considering again the $\mathrm{Fe}_{i} \mathrm{~V}$ complex the most obvious reaction path would be the direct dissociation reaction (I) $\mathrm{Fe}_{i} \mathrm{~V} \Rightarrow \mathrm{Fe}_{i}+\mathrm{V}$ producing $\mathrm{Fe}_{i}$ and isolated vacancies that could readily form complexes at $175^{\circ} \mathrm{C}$. The competing forward reaction (II) $\mathrm{Fe}_{i} \mathrm{~V} \Rightarrow \mathrm{Fe}_{s}$ producing substitutional iron should, however, prevail according to the binding energies and barriers provided by theory. ${ }^{18}$ The latter might be a subject of debate since in the calculations $\mathrm{Fe}_{i}$ has been moved only along special paths and at certain velocities into the vacancy of the $\mathrm{Fe}_{i} \mathrm{~V}$ complex. In addition, one may think of an alternative dissociation path involving the diffusion of the $\mathrm{Fe}_{i} \mathrm{~V}$ defect as a whole and its reaction with e.g., an $\mathrm{O}_{2}$ complex to form stable $\mathrm{VO}_{2}$ and $\mathrm{Fe}_{i}$. This scenario is in complete accord with our experiments and theoretical data ${ }^{18}$ although information about the migration of $\mathrm{Fe}_{i} \mathrm{~V}$ complexes is not available so far.

\section{SUMMARY AND CONCLUSION}

We have observed a light-induced reaction of residual iron in silicon after $\mathrm{AlG}$ leading to the formation of a new $\mathrm{Fe}$ species denoted as FeD. The defect is associated with a donor level at $\mathrm{E}_{V}+0.33 \mathrm{eV}$ and dissociates during annealing at $175^{\circ} \mathrm{C}$. This dissociation reaction is reversible or irreversible at low and high iron concentrations, respectively. Owing to the enhanced vacancy concentration observed after AlG, we have described a tentative scenario of light-induced FeD formation and thermal dissociation involving the reaction of $\mathrm{Fe}_{i}$ and $\mathrm{V}$ to the metastable $\mathrm{Fe}_{i} \mathrm{~V}$ pair described theoretically by Estreicher et al. ${ }^{18}$ In order to be consistent with these calculations we have proposed that $\mathrm{Fe}_{i} \mathrm{~V}$ is a mobile complex 
which is a hypothesis that needs to be verified or disproved by further experiments or theoretical investigations.

Vacancy injection as a result of AlG treatment has been proposed previously $^{8-10}$ as being beneficial for subsequent hydrogen passivation treatments. The results presented here provide direct evidence for such a vacancy injection which can be concluded from gold and platinum marker experiments and the light-induced formation of $\mathrm{V}_{2}$. Previous marker experiments ${ }^{29}$ have lead to the conclusion that no substantial vacancy injection occurs during AlG which apparently contradicts our observations. However, processing conditions as well as silicon materials used in this work and in Ref. 29 are considerably different which might lead to different results. The underlying mechanism of vacancy injection during AlG is not known so far and needs further investigations.

\section{ACKNOWLEDGMENTS}

We are especially indebted B. Schlieper-Ludewig for excellent technical support. This work was financially supported by the German Federal Ministry for the Environment, Nature Conservation, and Nuclear Safety and all the industry partners within the research cluster SolarFocus (Grant No. $0327650 \mathrm{~B}$ ). The content of this publication is the responsibility of the authors. One of us (D.A.) gratefully acknowledges a scholarship provided by Physics Department, Faculty of Science, Menoufia University, Egypt.

\footnotetext{
${ }^{1}$ A. A. Istratov, H. Hieslmair, and E. R. Weber, Appl. Phys. A: Mater. Sci. Process. 70, 489 (2000).

${ }^{2}$ A. A. Istratov, H. Hieslmair, and E. R. Weber, Appl. Phys. A: Mater. Sci. Process. 69, 13 (1999).

${ }^{3}$ L. J. Geerligs and D. Macdonald, Appl. Phys. Lett. 85, 5227 (2004).

${ }^{4}$ R. Krain, S. Herlufsen, and J. Schmidt, Appl. Phys. Lett. 93, 152108 (2008).

${ }^{5}$ D. Macdonald, A. Cuevas, and L. J. Geerligs, Appl. Phys. Lett. 92, 202119 (2008).

${ }^{6}$ S. D. Brotherton, P. Bradley, A. Gill, and E. R. Weber, J. Appl. Phys. 55, 952 (1984).

${ }^{7}$ T. Sadoh, K. Tsukamoto, A. Baba, D. Bai, A. Kenjo, T. Tsurushima, H. Mori, and H. Nakashima, J. Appl. Phys. 82, 3828 (1997).

${ }^{8}$ A. Rohatgi, V. Yelundur, J.-W. Jeong, A. Ebong, M. D. Rosenblum, and J. I. Hanoka, Sol. Energy Mater. Sol. Cells 74, 117 (2002).
}

${ }^{9}$ B. L. Sopori, X. Deng, J. P. Benner, A. Rohatgi, P. Sana, S. K. Estreicher, Y. K. Park, and M. A. Roberson, Sol. Energy Mater. Sol. Cells 41-42, 159 (1996).

${ }^{10}$ L. A. Verhoef, P.-P. Michiels, W. C. Sinke, C. M. M. Denisse, M. Hendriks, and R. J. C. van Zolingen, Appl. Phys. Lett. 57, 2704 (1990).

${ }^{11}$ K. Wünstel and P. Wagner, Appl. Phys. A: Mater. Sci. Process. 27, 207 (1982).

${ }^{12}$ S. K. Estreicher, J. L. Hastings, and P. A. Fedders, Mater. Sci. Eng., B 58, 31 (1999).

${ }^{13}$ S. Dubois, O. Palais, M. Pasquinelli, S. Martinuzzi, C. Jaussaud, and N. Rondel, J. Appl. Phys. 100, 024510 (2006).

${ }^{14}$ S. Dubois, O. Palais, P. J. Ribeyron, N. Enjalbert, M. Pasquinelli, and S. Martinuzzi, J. Appl. Phys. 102, 083525 (2007).

${ }^{15}$ J.-W. Jeong, M. D. Rosenblum, J. P. Kalejs, and A. Rohatgi, J. Appl. Phys. 87, $7551(2000)$.

${ }^{16}$ V. Yelundur, A. Rohatgi, J.-W. Jeong, A. M. Gabor, J. I. Hanoka, and R. L. Wallace, Proceedings of the 28th Photovoltaic Specialists Conference (IEEE, Anchorage, 2000), p. 91.

${ }^{17}$ R. Falster, V. V. Voronkov, and F. Quast. Phys. Status Solidi B 222, 219 (2000).

${ }^{18}$ S. K. Estreicher, M. Sanati, and N. Gonzalez Szwacki, Phys. Rev. B 77, 125214 (2008).

${ }^{19}$ T. Mchedlidze and M. Suezawa, Jpn. J. Appl. Phys., Part 1 41, 7288 (2002).

${ }^{20}$ S. H. Muller, G. M. Tuynman, E. G. Sieverts, and C. A. J. Ammerlaan, Phys. Rev. B 25, 25 (1982).

${ }^{21}$ D. Abdelbarey, V. Kveder, W. Schröter, and M. Seibt, Appl. Phys. Lett. 94, 061912 (2009).

${ }^{22}$ S. D. Brotherton, G. J. Parker, and A. Gill, J. Appl. Phys. 54, 5112 (1983).

${ }^{23}$ H. Hatakeyama, M. Suezawa, V. P. Markevich, and K. Sumino, Mater. Sci. Forum 196-201, 939 (1995).

${ }^{24}$ O. Feklisova, A. L. Parakhonsky, E. B. Yakimov, and J. Weber, Mater. Sci. Eng., B 71, 268 (2000).

${ }^{25}$ G. Zoth and W. Bergholz, J. Appl. Phys. 67, 6764 (1990).

${ }^{26}$ L. C. Kimerling and J. L. Benton, Appl. Phys. Lett. 39, 410 (1981).

${ }^{27}$ R. Khalil, V. Kveder, W. Schröter, and M. Seibt, Phys. Status Solidi C 6, 1802 (2005).

${ }^{28}$ D. de Cogan and Y. M. Haddara, Properties of Crystalline Silicon,R. Hull (ed.), (The Institute of Electrical Engineering, London, 1999), p. 599.

${ }^{29}$ D. Karg, G. Pensl, and M. Schulz, Proceedings of third World Conference on Photovoltaic Energy Conversion, Osaka, May 12-16 2003, Vol. 2, pp. 1112 .

${ }^{30}$ H. Zimmermann and H. Ryssel, Appl. Phys. Lett. 59, 1209 (1991).

${ }^{31}$ M. Jacob, P. Pichler, H. Ryssel, and R. Falster, J. Appl. Phys. 82, 182 (1997).

${ }^{32}$ L. C. Kimerling, Solid-State Electron. 21, 1391 (1978).

${ }^{33}$ M.-A. Trauwaert, J. Vanhellemont, H. E. Maes, A.-M. Van Bavel, G. Langouche, and P. Clauws, Appl. Phys. Lett. 66, 3056 (1995).

${ }^{34}$ B. A. Komarov, Semiconductors 38, 1041 (2004). 


\section{List of Publications}

Abdelbarey D., Kveder V., Schröter W., Seibt M., Aluminum gettering of iron in silicon as a problem of the ternary phase diagram. Appl. Phys. Lett. 94, 061912 (2009).

Abdelbarey D., Kveder V., Schröter W., Seibt M., Light-induced point defect reactions of residual iron in crystalline silicon after aluminum gettering, $\mathrm{J}$. Appl. Phys. 108, 043519 (2010).

Abdelbarey D., Kveder V., Schröter W., Seibt M., Platinum and gold diffusion monitor vacancy profiles induced into silicon wafers by aluminum alloying, to be published.

Falkenberg M. A., Abdelbarey D., Kveder V., Seibt M., Comparison of efficiency and kinetics of phosphorus-diffusion and aluminum gettering of metal impurities in silicon: a simulation study, Solid State Phenomena 156-158, 229 (2010).

Seibt M., Abdelbarey D., Kveder V., Rudolf C., Saring P., Stolze L., Voß O., Structure, chemistry and electrical properties of extended defects in crystalline silicon for photovoltaics, Phys. Status Solidi C 6, 1847 (2009).

Seibt M., Abdelbarey D., Kveder V., Rudolf C., Saring P., Stolze L., Voß O., Interaction of metal impurities with extended defects in crystalline silicon and its implications for gettering techniques used in photovoltaics, Mater. Sci. Eng. B 159-160, 264 (2009).

Seibt M., Saring P., Hahne P., Stolze L., Falkenberg M. A., Rudolf C., Abdelbarey D., Schuhmann H., Transmission electron microscopy investigations of metalimpurity-related defects in crystalline silicon, Solid State Phenomena 178-179, 275, (2011).

Tankovsky N., Baerner K and AbdelBarey D., Oscillating bubble as a sensor of low frequency electro-acoustic signals in electrolytes, J. Phys.: Condens. Matter 18, 7605 (2006). 


\section{Acknowledgement}

This thesis contains the main work performed during my $\mathrm{Ph}$. D scholarship at the IV Physikalische Institut, Göttingen Universität in Germany. All the work presented herein was initiated and conducted between January 2007 and October 2010 , thus this thesis represents the culmination of four years of background studies, troubleshooting, and experimental work and interpretation. Hopefully, some of these efforts can contribute to increasing the understanding and exploitation of photovoltaics.

I would like to express my indebted gratitude to my supervisor Prof. Michael Seibt for giving me a great chance and opportunity to work with him. He has always been extremely generous with his time, knowledge and advice and allowed me great freedom in my research. Due to my illness, there have been quite a few rough times throughout my study, and I will always remember his persistence and patient during those times. Without his guidance, this thesis would not have been possible.

I also wish to extend my sincere appreciation to Prof. Dr. M. Seibt and Prof. Dr. H. Hofsäß, for their kindness of taking the responsibility of being referee and coreferee for my thesis.

An extra special thanks also goes to Prof. Dr. W. Schröter and Prof. Dr. V. Kveder for the useful discussions about the evaluation and interpretation of the experimental data, and also their critical comments on manuscripts. They gave a remarkable contribution to reach the aims of this study. With their support, I showed up at international conferences and contributed papers in the respected scientific journals.

Many people have been involved in my work over the last three semesters and they all deserve recognition and gratitude for their contributions among them Prof. Dr. Angela Rizzi, Prof. Dr. Rainer Ulbrich, Dr. Jörg Malindretos , Antje Spliethoff-Laiser, Dr. K. Ahlborn, they kept me going and provided support through the difficult times which made my stay comfortable here. The gifts they have given me can never be repaid.

I would like to thank all of my group members for assistance and a very good work atmosphere. Special thanks are intended for P. Schwager and V. Radisch for helping in the TEM and FIB investigations. I am very much thankful to B. SchlieperLudewig for her incessant help in the laboratory.

I am very grateful to Andreas Juretzko, Thomas Lehmann, and Rasit kösker, in the mechanics and electronic workshop, for their instant and prompt response to solve my problems. 
My deepest thanks go to my family; there are no words to express my gratitude to my husband for his unconditional love, and invaluable support. For my children who suffered a lot during the work of this thesis, I want you to know that you were always in my heart. Finally, I would like to thank and highly appreciate the Egyptian Government for financing my study program.

Göttingen, 2011

Doaa Abdelbarey 